\section{TATRA \\ MOUNTaiNs \\ Mathematical Publications}

DOI: $10.2478 / \mathrm{tmmp}-2014-0028$

Tatra Mt. Math. Publ. 61 (2014), 1-85

\title{
MATHEMATICS AND ENGINEERING INNOVATION INSPIRED BY NATURE
}

\author{
RASTISLAV TELGÁRSKY ${ }^{\dagger}$
}

\begin{abstract}
A bstract. Observation of nature and design of experiments inspires new mathematical investigations often resulting in new computer algorithms and constructions of new devices. This paper attempts to collect many cases where mathematics is inspired by the nature, and leads to direct applications in engineering.

Short Contents: Introduction; My Approach; Numbers and Measures; Geometry and Shapes; Motion and Time; Energy and Forces; Life on Earth; Eyes and Imaging; Processes; Cooperation and Conflicts; Conclusions; References; Figure Credits (188 images in 112 figures).
\end{abstract}

\section{Contents}

1. Introduction

2. My Approach

3. Numbers and Measures

3.1. Counting of Objects

3.2. Special Numbers

3.3. Magnitudes and Distances

3.4. Mathematical Constants

3.5. Granularity of Space and Time

3.6. Fractions, Proportions and Equations 8

$\begin{array}{ll}\text { 3.7. Algorithms Inspired by Nature } & 10\end{array}$

4. Geometry and Shapes 16

$\begin{array}{ll}4.1 . \text { Line Segments } & 16\end{array}$

4.2. Circles and Vesica Piscis 16

4.3. Golden Ratio, Fibonacci Numbers and Spirals 18

$\begin{array}{lll}4.4 . & \text { Polygons and Polyhedrons } & 21\end{array}$

\begin{tabular}{lll}
\hline 4.5. & Other Shapes in Nature & 23
\end{tabular}

(C) 2014 Mathematical Institute, Slovak Academy of Sciences.

2010 Mathematics Subject Classification: 00A30, 00A35, 00A71, 00A09, 00A99.

Keywords: mathematics and nature, modelling, basic concept of mathematics engineering.

$\dagger$ December 22, 2014. The paper was finished with the assistance of Professor Telgársky's son Marek. 
4.6. Symmetry in Nature 26

$\begin{array}{ll}\text { 5. Motion and Time } & 28\end{array}$

$\begin{array}{ll}\text { 5.1. Motion Types } & 28\end{array}$

5.2. Motion of Matter 31

5.3. Motion of Living Organisms 32

5.4. Sounds and Vibrations in Nature 34

5.5. Periodic Motion and Waves 34

5.6. Theory of Everything and Big Bang 34

5.7. Time Measures 35

5.8. Time Devices 36

5.9. Time Discrepancies 37

6. Energy and Forces 38

6.1. Energy Sources in Nature 38

6.2. Forces of Nature 38

6.3. Electricity 40

6.4. Magnetism 44

6.5. Weather Patterns $\quad 45$

\begin{tabular}{ll}
\hline 7. & Life on Earth \\
\hline
\end{tabular}

7.1. Life Forms and Organisms 47

7.2. Structures in Nature 48

7.3. Changes and Evolution $\quad 52$

7.4. Life Cycles and Reproduction 53

$\begin{array}{lll}7.5 . & \text { Heredity and DNA } & 53\end{array}$

7.6. Population Dynamics 54

$8 . \quad$ Eyes and Imaging 56

8.1. Eves 56

$\begin{array}{lll}8.2 . & \text { Optics } & 60\end{array}$

8.3. Imaging 62

8.4. Camouflage 66

$\begin{array}{lll}\text { 8.5. Spectra and Fourier Transform } & 67\end{array}$

$\begin{array}{lll}9.2 \text { Processes } & 69\end{array}$

9.1. Events in Nature 69

$\begin{array}{ll}9.2 .2 \text { Causality } & 70\end{array}$

\begin{tabular}{lll}
\hline 9.3. & Randomness and Chaos & 72
\end{tabular}

9.4. Statistical Decisions 73

10. Cooperation and Conflicts 74

$\begin{array}{ll}\text { 10.1. Coexistence } & 74\end{array}$

$\begin{array}{lll}\text { 10.2. Communication } & 74\end{array}$

10.3. Conflicts. Control and Domination 74 


\section{Introduction}

The effort of mathematicians in 21st century can be divided into mathematics applied in engineering and sciences, and into abstract mathematics, which has no immediate connection to any application. The contemporary technology allows to reach deeper under the sea, far away into the cosmic space, break subatomic particles in high energy colliders, observe the growth of life from single cells to mature organisms, develop digital images from various electromagnetic bandwidths, manipulate bacteria into producing new drugs in pharmaceutical factories, and also to study and change genetic structure of viruses, bacteria, plants and animals. This is only possible with the processing power of computers, sensors, and data storage. Mathematics is always the essential part of these enterprises, because each research grows from a descriptive phase to a functional phase, which includes quantitative attributes and their causal relationships.

There are hundreds of books about the topics of this paper. Here are just few I have selected as complementary to this paper: Adam [1], Barrow [2], Coles [6], Henderson [8], Livio [11, Pickover [17], [18, Schneider [19], Siegfried [20], Taylor [21], and Tegmark [22].

\section{My Approach}

Numbers are everywhere, just look around! Fractions are everywhere, just compare the numbers! Geometry and shapes are everywhere in the world around us, just see it! Sounds and noises are almost everywhere! Motion is almost everywhere, too. And, motion is usually a sign of life. Some people say that whole nature, and cosmos as whole, is simply an analog computer. Max Tegmark 22. says that Nature is full of math!, so math exists in reality, not just in the human mind.

But we need to ask the question: what belongs to the nature itself and what is man-made, fully or partially? Mathematics is somewhat like whiskey which is not found in the nature, but is distilled from fermented nature's products. Another important question: what is the true statement about the nature? Mostly, 
we only approximate the truth; for example, all decimal digits of $\pi$ are not known, but we consider $\pi$ as known. Similarly, we talk about Fourier Transform, but we apply only Finite Fourier Transform. We talk about continuity of real numbers, but all computers and algorithms use only finitely many numbers, and each of those has only finite precision. Language and logic are important tools in formatting the scientific knowledge. And the last question: is the truth simple enough to be useful (i.e., applied), but too complicated to fully understand it?

The mathematical concepts are created by the observation of nature, measurement of nature, and the experimentation with the nature. These three human activities are either non-destructive or destructive. For example, no living organism can withstand the radiation of Scanning Electron Microscope. Engineering cannot do anything without mathematics! It is very true that important mathematics is invented in engineering processes, because the necessity is the mother of invention.

It is not without interest that the concepts of infinity, combinatorics and probability were developed by Jain mathematicians about $300 \mathrm{BC}$. The studies included combinations and permutations of objects or events. Jains were inspired by religion, but they influenced later studies in prediction of possible outcomes - the analysis of games of chance, and establishment of what game rules would make a fair game (Mankiewicz [12, p. 154). Jain thinkers developed the postulates that there can be as many as seven modes of prediction in a given case. This introduces an element of uncertainty in the predictions and therefore introduces the concept of probability. The Jain text is called Syadavada or, The doctrine of may be (www.engr.mun.ca/ asharan/bihar/jainism.html). However, the beginning probability theory in Europe owes its development to games of chance and gambling. The attempt to describe natural phenomena/processes - thermodynamics and quantum mechanics - came much later. My primary interest is in natural phenomena which lead through mathematical modeling to engineering applications.

\section{Numbers and Measures}

\subsection{Counting of Objects}

The simplest counting is the counting of individual objects. Then, we count objects, which are members of groups or assemblies. If things are not changing too fast, we can identify and count the parts of structures. However, fluids are counted using measuring cups with preset volumes or marks. We can also count events, whether synchronous or asynchronous. The asynchronous events are typically recognized as finite sequences of events. Similarly, we count actions and outcomes. The Geiger-Müller counter measures the levels of radioactivity 


\section{MATHEMATICS AND ENGINEERING INNOVATION INSPIRED BY NATURE}

(ionizing radiation) by counting alpha particles, beta particles and gamma rays (Wikipedia: Geiger counter).

\subsection{Special Numbers}

Some numbers are very special, because they are related to nature, culture, tradition or religion. The Pythagorean triangle with sides $3,4,5$ has area 6 . Human body has 1 heart, 2 lungs, $2+2=4$ limbs, $10+10=20$ fingers and $16+16$ $=32$ teeth. Tetragrammaton has 4 letters: $Y H W H$. The basic musical scales are: 5-note pentatonic, 7-note diatonic, 12-note chromatic, and 24-note quarter-tone. Persian music uses a different scale than those (Wikipedia: Persian scale). The carpenter's saying is: Measure 7 times before you cut. However, other versions require to measure only 2 times. Number 7 is very common: 7 days of week, 7 deadly sins, and 7 major stars in the Orion Star Cluster. A very old saying is: Possession is 9 points of the law. Tithing is the relinquishing $10 \%$ of one's income for the group. Minian is a quorum of 10 people (necessary to be present) for the Jewish prayer service. The Jewish, Christian and several other religious traditions have 10 Commandments. There are 10 spiritual graces in Christian tradition. According to Cabala, G-d has 10 Attributes - Eser Sefirot. These attributes are formated into structures (graphs) describing their relationship and importance.

Mathematical thinking is often inseparable from philosophical and religious thinking as we can see in all history, from ancient writings till today. We focus on three examples of special numbers or words, which are organized into 2D arrays (matrices).

There are 64 transformations (hexagrams) of I Ching (Figure 1) organized into a $8 \times 8$ matrix. In some practices, six numbers are generated randomly, then turned into a hexagram, which is then interpreted.

According to Jewish Cabala, there are 72 Names of G-d, Shem HaMephorash (Figure 2), organized into a $9 \times 8$ matrix.

The Islamic tradition conveys 99 Names of Allah, Asma Allah al-Husma (Figure 3), which are organized into a $10 \times 10$ matrix.

This is only a very tiny sample of special numbers.

\subsection{Magnitudes and Distances}

We can measure distance, length, width, depth, diameter, angle, area, volume, weight, duration, speed, etc. The sizes of objects can be tiny, small, large, and huge. We use the scientific notation to cover the extremely wide range of sizes. The large size have mountains, clouds, seas, etc. The objects with sizes comparable to human body are houses, rooms, animals, vegetables, fruits, etc. The traces of cosmic ray particles can be seen in a home-made cloud chamber, called the Wilson chamber. For the atomic particles such as photon, electron, 


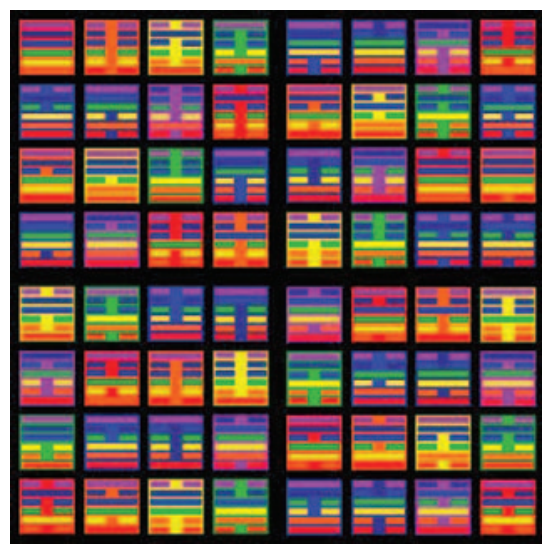

(A) Chakra of Hexagrams

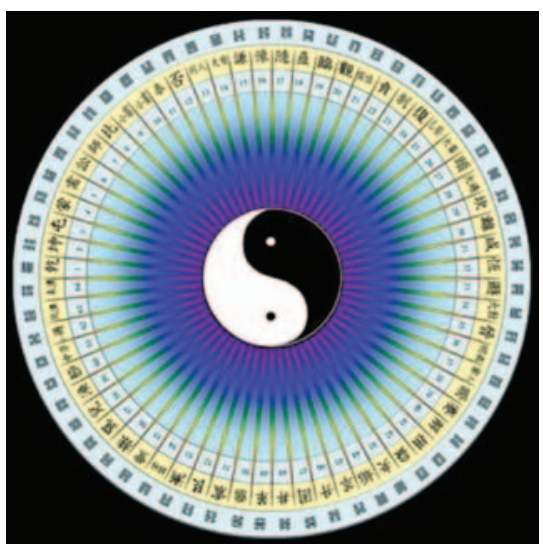

(в) Circular Chart

Figure 1. I Ching Hexagrams.

\begin{tabular}{|c|c|c|c|c|c|c|c|}
\hline כָּד & גָכָָָָ & 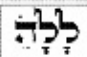 & פמוּה & 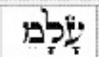 & סָיטלי & "כָ" & 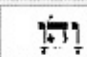 \\
\hline הקקט & דריר & מִבדה & ?t? & דृ & לָזָָ & אָָלָדָ & !ִ \\
\hline רָד & מִכָדיה & wh & 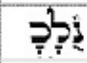 & פהדק? & לָרוֹ & קָּקָ & 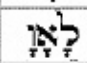 \\
\hline 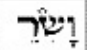 & קָָָָ & זָוָכ & ?h & שִָָָׁדָר & गָד? & דָדָ & נָדָדתה \\
\hline tịn & רהיל & דוֹעָעָם & אָּู & מִּנִּר & כָוָּק & חד & 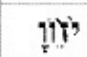 \\
\hline פִיריה & 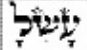 & זעוֹריר & סָאָדָ & "דָ" & רฺָָָּ & מִידָ & הרה \\
\hline בעז & מהדה & נָּ & 㷊 & 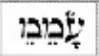 & הֶזועש & I & זָخ \\
\hline מנוזודי & דע & לדיה & 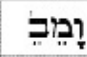 & מֵּזָּר & ה'רוזו & "ִיר? & בֵֵממִ \\
\hline בָוִָּ & דירי & "כבמִ & ראָדּ. & דוֹרוּד & 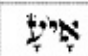 & מנָּק & דְבמב \\
\hline
\end{tabular}

Figure 2. 72 Names of G-d - Shem HaMephorash.

proton, neutron, etc, which are very small, there are sophisticated detection methods, and similarly for the subatomic particles such as leptons and fermions (Figure 4).

Recently a lot of attention is paid to atomic-scale electronic circuits. Nanotechnology is a technology dealing with objects in nanometer scale $\left(10^{-9} \mathrm{~m}\right)$. Yanson et al. 27] reported the construction of a wire made as a chain of single atoms of gold. They verified that this nanowire conducts the electricity. Clearly, there is no thinner wire made of gold than this one. Why gold? Iron or copper atoms would quickly oxidize and lose conductivity. A lot of new promising devices is made via carbon nanotubes (CNT). 


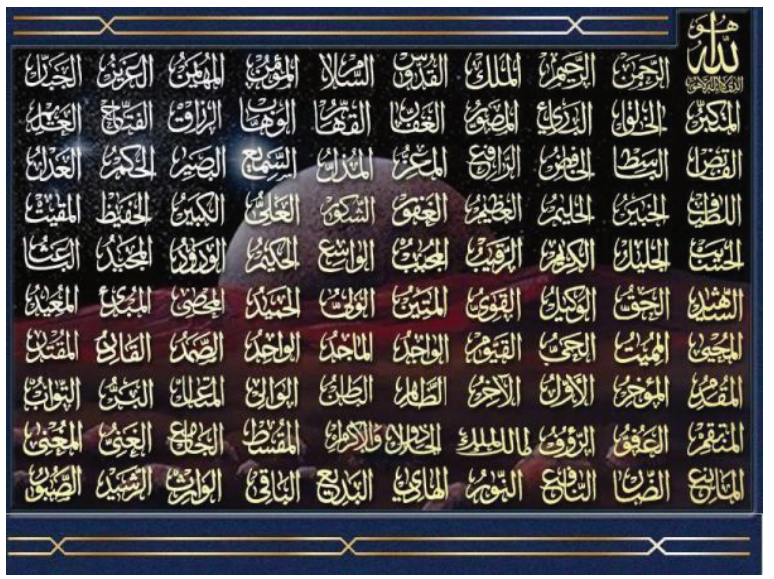

Figure 3. 99 Names of Allah - Asma Allah al-Husma.

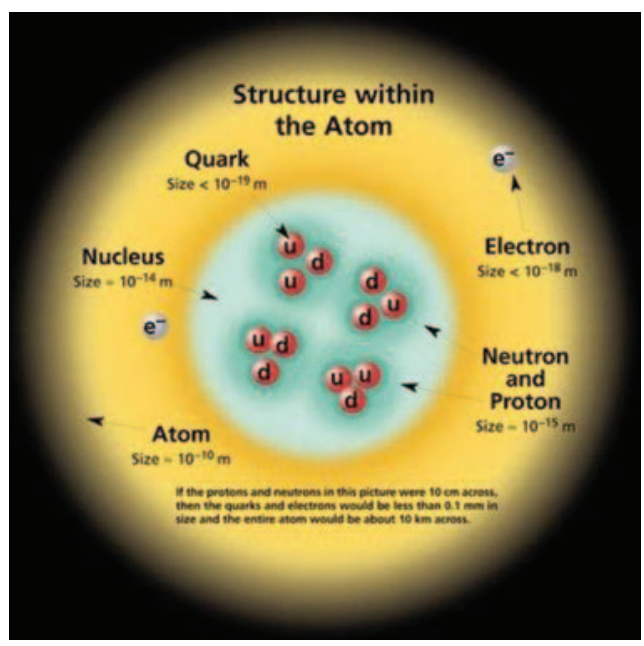

Figure 4. Structure within the atom.

Hunter et al. [9] established that photon is a circular ellipsoid with length $\lambda$ and diameter $\lambda / \pi$, where $\lambda$ is the wavelength.

The source of our knowledge is observation and measurement. If in a measurement we collect $n$ samples in the time interval $[0, T]$, then we get the sampling rate $n / T$. The continuous observation is a useful illusion made by a fast sampling rate. 


\subsection{Mathematical Constants}

The number, which is a mathematical constant, must be fully described somewhere, so that it will occupy a physical space (Jozef Gruska in [4]). The most important constants are zero and a finite number of integers. Finite, because not all integers can be written or recorded somewhere.

$\pi=$ circumference of a circle / diameter of the circle

$e=$ base of natural logarithms

The number $e$ does not occur in the nature directly; it is derived using the notion of limit. Both $\pi$ and $e$ are represented in mathematical applications by a sufficient number of decimal or binary digits. There are many other constants with amazing properties occurring in mathematical considerations (Wikipedia: Mathematical constant).

\subsection{Granularity of Space and Time}

Photon is the smallest atomic particle; there is no half-photon. In the quantum jump, an electron disappears from one orbit of an atom, and appears at another orbit without intermediate points. So, according to our current knowledge, the time, the space, the matter, the energy, etc. have granularity: they are not infinitely divisible. On the other hand, infinitely large and infinitely small (infinitesimal) quantities belong to useful mathematical techniques, even if they do not correspond to properties of the physical reality. The consideration of mathematics without infinity (Telgarsky [23]) is oriented toward algorithms and applications of mathematics.

We mention here only 4 physical constants (Wikipedia: Planck units).

The speed of light in vacuum $\mathrm{c}=299,792,458 \mathrm{~m} / \mathrm{s}$.

The Planck mass $M_{P}=2.17651 \times 10^{-8} \mathrm{~kg}$.

The Planck length $L_{P}=1.616199 \times 10^{-35} \mathrm{~m}$.

The Planck time $T_{P}=5.39106 \times 10^{-44} \mathrm{~s}$.

$L_{P}=T_{P} \times c$.

1 meter $=c \times(3.3$ nanoseconds $)$.

\subsection{Fractions, Proportions and Equations}

Fractions and proportions require the knowledge of two numbers (two measurements), where one (the denominator) becomes the reference for the other (the numerator). $3 / 6$ contains more information than 0.5 , because in $3 / 6$ we know that 3 is compared to 6 . Moreover, 0.5 is the relative size of 3 when comparing to 6 . So, a proportion is fully represented by three numbers. This becomes a necessity when the numerator and/or denominator are numbers with a large number of digits. If $m \leq n$ and $m>0$, then $m / n$ can be interpreted as a percentage or a probability. The equation states that two quantities (usually) obtained in a different way are the same (equal). 
The knowledge, that the ratio of the circumference of a circle to its diameter is constant was known to ancient builders of the Great Pyramid of Giza, c.25892566 BC (Wikipedia: $\mathrm{Pi}$ ). The value of this constant $\pi$ has been estimated using fractions, continuous fractions, infinite sums, infinite products, etc.

Archimedes developed a technique which enabled him to prove that sphere has $2 / 3$ the volume and $2 / 3$ of the surface area of its circumscribing cylinder including its bases. A sphere and its circumscribing cylinder were placed on the tomb of Archimedes at his request (Figure 5A). Using the same technique Archimedes derived that the ratio of the volume of circular cylinder to the volume of the cone inscribed in the cylinder is 3 , but this fact was known earlier.

To find out whether a crown was made of pure gold, Archimedes discovered the principle (Figure 5B): Any floating object displaces its own weight of fluid (Wikipedia: Archimedes' Principle).

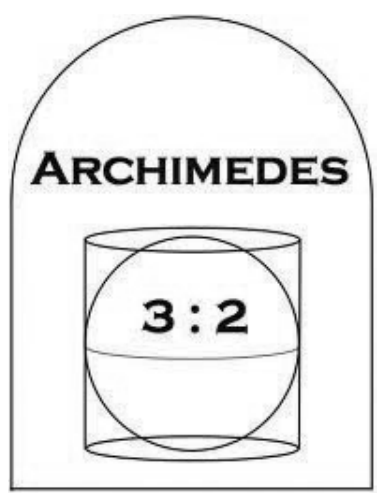

(A) Ratio of volumes

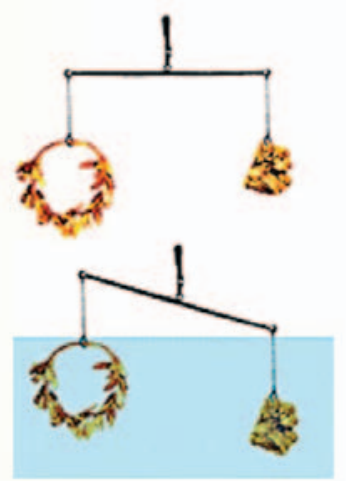

(в) Water balance

Figure 5. Archimedes' investigations.

Examining botanical trees, Leonardo da Vinci noted that the total cross section of branches is conserved across branching nodes (Figure 6). A number
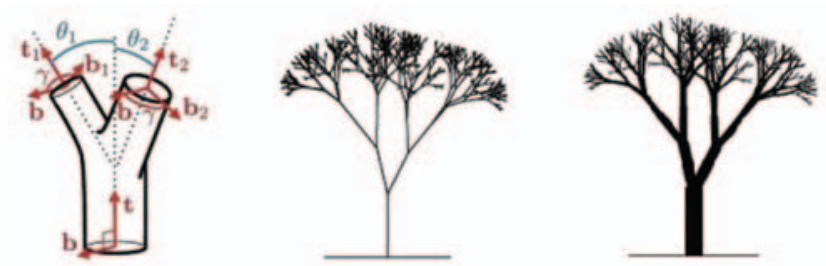

Figure 6. Leonardo da Vinci Tree Rule. 


\section{RASTISLAV TELGÁRSKY}

of people tried to figure out why this conservation principle holds. The best results indicate that a tree, or similar constructions based on this principle, are the most resilient against the winds.

The Euler's characteristic, or, the Euler-Poincaré characteristic, is an integer associated with any polyhedron, and defined as $\chi=$ Vertices - Edges + Faces (Wikipedia: Euler characteristic). Euler proved that for convex polyhedra $\chi=2$ (Figure 7).

\begin{tabular}{|c|c|c|c|c|c|}
\hline Name & Image & $\begin{array}{c}\text { Vertices } \\
V\end{array}$ & $\begin{array}{c}\text { Edges } \\
E\end{array}$ & $\begin{array}{c}\text { Faces } \\
F\end{array}$ & $\begin{array}{l}\text { Euler chatacteristic: } \\
\qquad V-E+F\end{array}$ \\
\hline Tetrahedion & & 4 & 6 & 4 & 2 \\
\hline Hexahedran of cube & & 8 & 12 & 6 & 2 \\
\hline Octatiedion & & 6 & 12 & 8 & 2 \\
\hline Dodecahedron & & 20 & 30 & 12 & 2 \\
\hline Icosahedron & & 12 & 30 & 20 & 2 \\
\hline
\end{tabular}

Figure 7. Euler characteristics of convex polyhedra.

\subsection{Algorithms Inspired by Nature}

Each neuron is a specialized cell (Figure 8). Thus, one-cell organisms do not have neurons. A neuron is connected by synapses to sensors and/or to muscles,

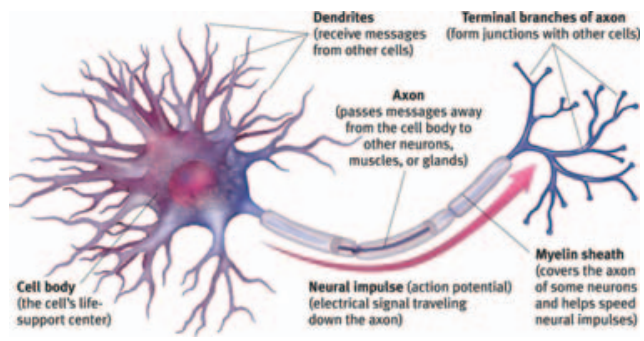

Figure 8. Motor neuron.

and also to other neurons (Wikipedia: Synapse). So, the neurons form a network, which controls the internal processes and reacts on external stimuli or situations (Figure 9). 


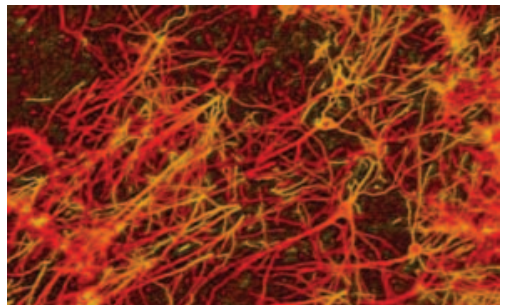

(A) Neurons in brain

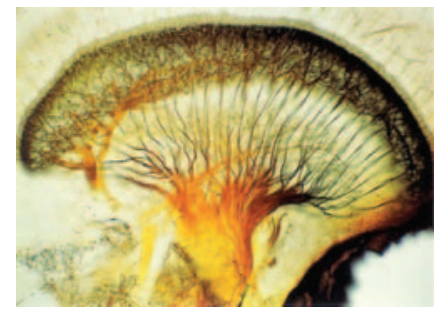

(в) Optics neurons in blowfly

Figure 9. Neural networks in brain and eye.

The signal processing in neurons is based on accumulation and thresholding of signals (impulses). A study of simple neural nets in nature led to their imitation in computer software. These software models, written in C, Matlab or in another convenient language, are called Artificial Neural Networks (ANN). The standard template for an artificial neural network consist of the input layer, the hidden layer, and the output layer (Figure [10). To set the optimal coeffi-

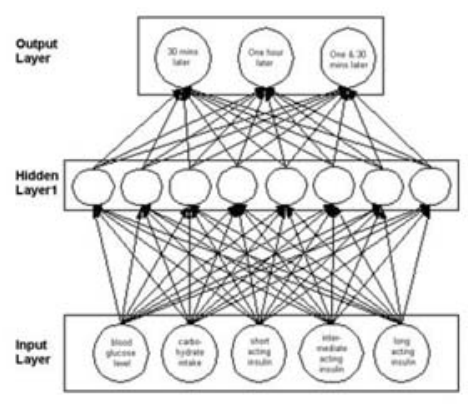

(A) Diabetes care

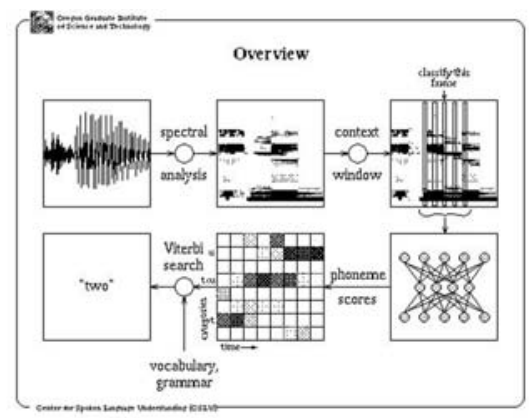

(B) Speech recognition

Figure 10. Applications of Artificial Neural Networks.

cients in an ANN, the typical network must be trained in order to perform right decisions. For example, to distinguish between images of apples and pears, the training should reveal what is in the image, but after sufficient learning the classification may go without learning. Artificial neural networks are used to match or recognize fingerprints, faces, sounds, phonemes, speech, irises, etc. Artificial neural networks are also used in combination with fuzzy sets. A number of interesting papers appeared on network representation in relation to the Kolmogorov Superposition Theorem. 


\section{RASTISLAV TELGÁRSKY}

The Snake Algorithms are image processing techniques for contour finding or matching by running a "snake" along the border between two regions (Figure 11A). A snake in digital image processing is a curved train of small regions (say, pixels), which stays connected, but its curved shape is allowed to change. Since the algorithm is quite robust, it is used in processing of microscope images to identify cell boundaries in histology images (Figure 11B ). A fast snake algorithm is also used for simultaneous tracking of multiple objects by identifying the objects contours.

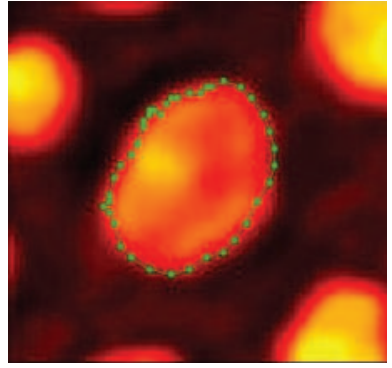

(A) Snake algorithm 1

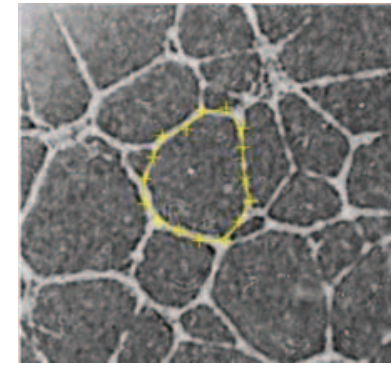

(в) Snake algorithm 2

Figure 11. Snake algorithms for contour matching.

The Ant Colony Optimization (ACO) algorithm is a probabilistic technique for solving computational problems which can be reduced to finding good paths through graphs (Figure 12A). Similarly to exceptions occurring in computer algorithms, an ant colony may get into a death spiral (circular mill), where ants spiral around until their complete exhaustion (Figure [12B).

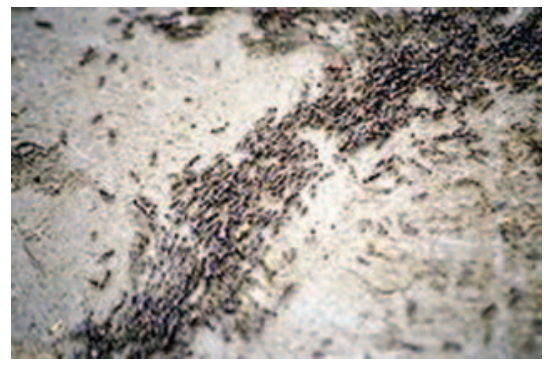

(A) Ant colony

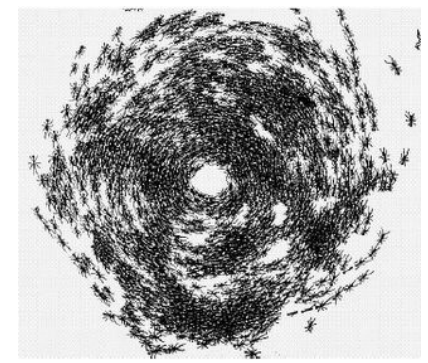

(B) Death spiral

Figure 12. Ant Colony Optimization Algorithm.

The swarm algorithms are derived from the observation of swarms of bees (Figure 13A), flocks of birds (Figure [13B), schools of fish (Figure 13C), etc. 
In contrast to the behavior of these animals when they are single, the behavior of the group is different: it shows the swarm intelligence (Wikipedia: Swarm behaviour).

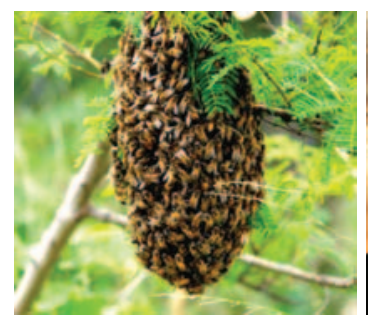

(A) Bee swarm

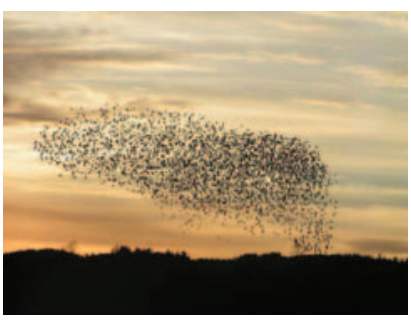

(в) Flocking birds

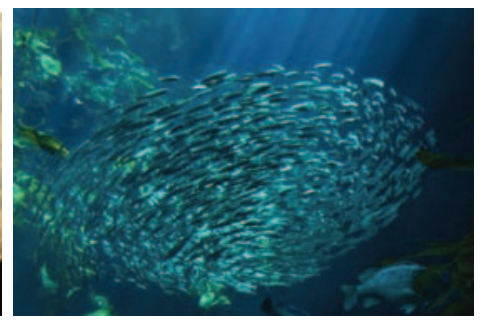

(c) School of fish

Figure 13. Swarm behavior.

The snow avalanches, mudslides and landslides are characterized by a cascade behavior: a small motion triggers a larger motion, this one even larger, and in effect we get a very large effect. Obviously, the conditions of snow (Figure 14A) or mud (Figure 14B $\mathrm{B}$ ) must be ready for an amplification by the escalating triggers.

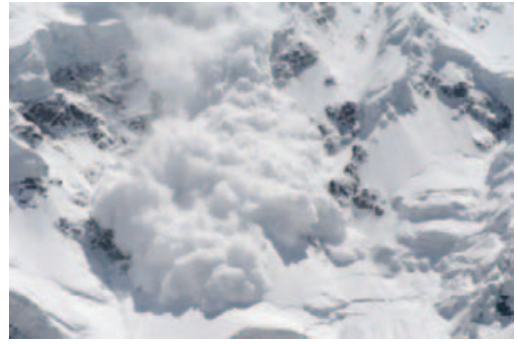

(A) Snow avalanche

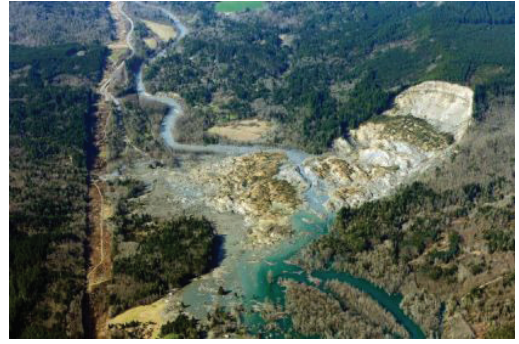

(B) Massive mudslide

Figure 14. Snow avalanches and mudslides.

The avalanche electronic devices are based on the same principle of having very small triggers gradually ending with large effects. These devices are able to detect a single photon (!) of a light flash, or a single alpha particle indicating the presence of a radioactive material. The photomultiplier electron tube is in Figure 15A and the digital avalanche photodiode is in Figure 15B. The scheme of avalanches in the Geiger-Müller tube is in Figure 16A, and those in single-photon avalanche diode are in Figure 16B. 


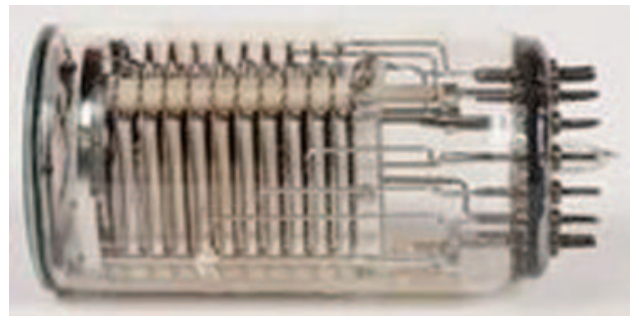

(A) Photomultiplier tube

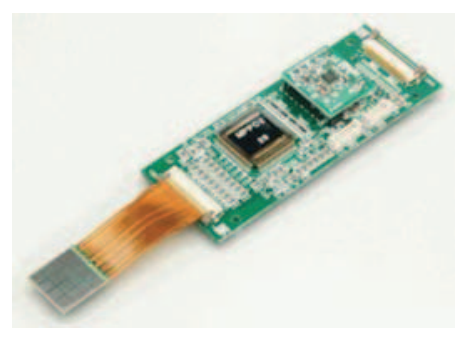

(в) Avalanche photodiode

Figure 15. Avalanche Electronic Devices.

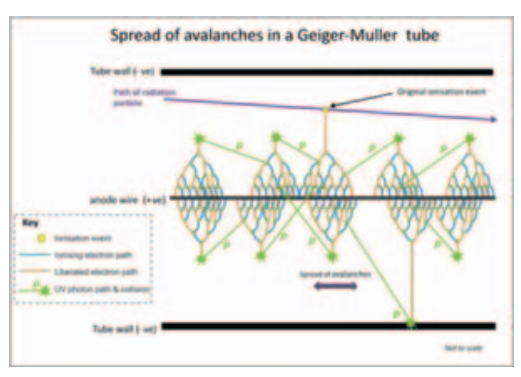

(A) Geiger-Müller tube

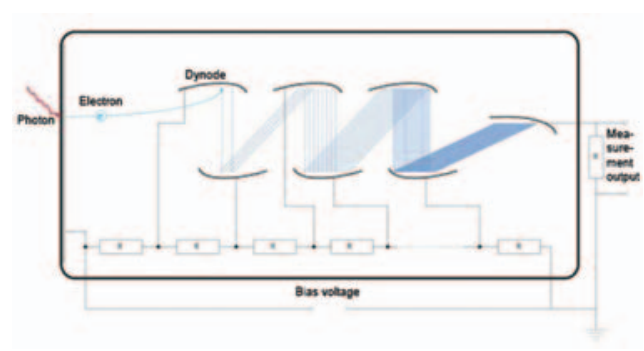

(в) Photomultiplier Diode

Figure 16. Schemes of Avalanche Devices.

The avalanches in financial markets are reactions to specific conditions when companies are running business at a high risk level but pretending that they are still in safety belts. Figure 17A shows the surprising share price increase in 2005-2007, and then the fall the share price during 2008. The raise and fall of share price is shown for Lehman Brothers. It is similar for Bear Stearns, Merrill Lynch, Morgan Stanley, Goldman Sachs, AIG, Washington Mutual, Fannie Mae, and Freddie Mac. Figure 17B shows the similar behavior of the Dow Jones Industrial Average in 2003-2008. After the unexpected increase of the average comes the fall at the end of 2008.

Viruses may have positive or negative roles in animal or plant bodies (Wikipedia: Virus). A virus must get inside a live cell to use it as a genetic building material and as a workshop to create many copies of itself. If a virus is not destroyed, then it is patiently waiting just for this opportunity. All viruses replicate by the parasitic behavior, but only some of them destroy the host cells. Figure 18 contains the pictures of Human Immunodeficiency virus (HIV) and Ebola virus. AIDS (Acquired Immunodeficiency Syndrome) is the final stage of HIV disease, which causes severe damage to the immune system. Viruses have 


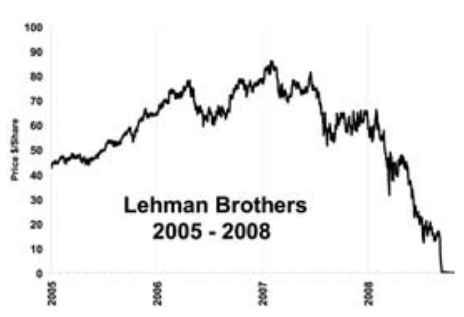

(A) Lehman Bros in 2005-2008

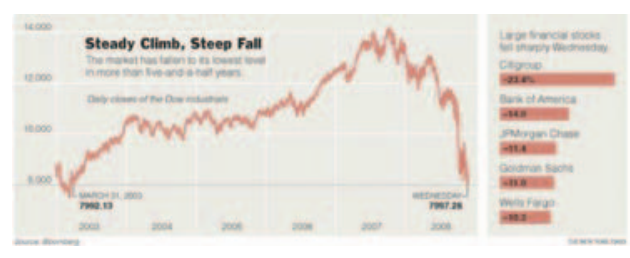

(в) Dow Jones in 2003-2008

Figure 17. Avalanches in Financial Markets.

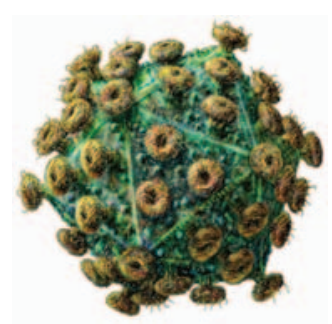

(A) HIV

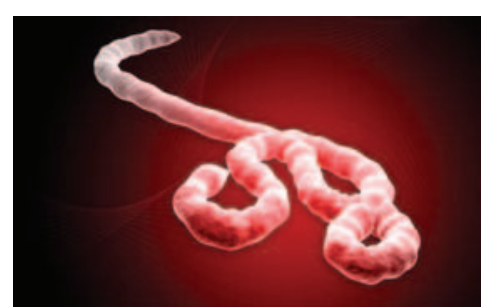

(B) Ebola virus

Figure 18. Viruses.

no metabolism. Their size is $17-300 \mathrm{~nm}$, thus they are too small for standard optical microscopes. The interest of mathematicians in viruses is in their geometric shapes, structures, and algorithms of their replication and mutation.

The DNA virus behavior of creating epidemics and destruction have been imitated by people, individuals or groups, who created malicious codes for computers (Wikipedia: List of computer viruses; Timeline of computer viruses and worms). The computer virus is a software program, which can be invisibly attached to a program downloaded from the Internet, or quietly copied from or to a USB flash drive connected to a computer. A computer virus can destroy the operating system or data files such as documents, spreadsheets, music, movies, etc. The advanced computer virus called Stuxnet was designed to cause a malfunction and destruction of centrifuges for the enrichment of uranium. It fulfilled the expectations, although the destruction was only partial (Wikipedia: Stuxnet).

Next algorithms inspired by the nature are the genetic algorithms (GA), which imitate the process of natural selection. They are characterized by a heuristic approach, and can solve some optimization and search problems. Genetic algorithms belong to the larger class of the evolutionary algorithms (EA), which 
generate solutions to optimization problems using techniques inspired by natural evolution including inheritance, mutation, selection, and crossover.

Cellular automata (Wikipedia: Cellular automaton) have been early attempts to model the behavior of living organisms. Artificial life (Wikipedia: Artificial life) imitates traditional biology by trying to recreate some aspects of biological phenomena by using software, hardware or biochemistry. Synthetic biology (Wikipedia: Synthetic biology; see also: Wikipedia: OpenWorm) is even more ambitious as an interdisciplinary science trying to combine disciplines such as biotechnology, evolutionary biology, molecular biology, systems biology and biophysics.

\section{Geometry and Shapes}

\subsection{Line Segments}

The line segments are not rare in nature. We observe the rays of sunlight on clouds. The trunks of trees (Figure 19]A) and stems of plants (Figure 19B) grow straight up, unless they had obstacles or have been damaged. The horizon over a sea or a large lake appears as a horizontal line, but in some circumstances, we can detect the Earth curvature. The trajectories of free falls of heavy objects are linear if the air resistance is negligible.

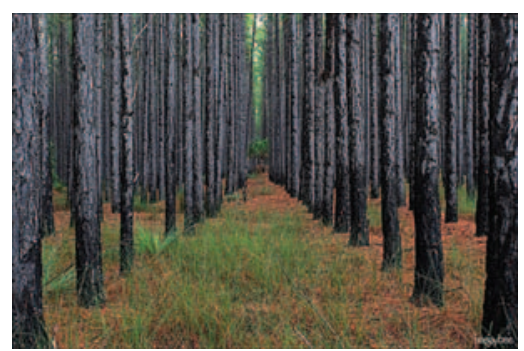

(A) Trunks of trees

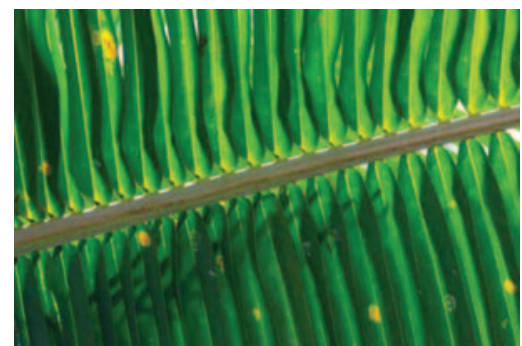

(в) Palm tree fronds

Figure 19. Linear patterns in palm leaves and trunks of trees.

\subsection{Circles and Vesica Piscis}

Circles occur in shapes of flowers, tree stumps (Figure 20A), and are caused by splash of water drop in a pool or lake. With the cumulative photography we can create a picture of the night sky, where the stars are moving around the Northern Star (Pole Star) in concentric circles (Figure [20B). The circles also occur as life cycles (reproductive cycles) of plants, beetles, butterflies, etc. The mammals 


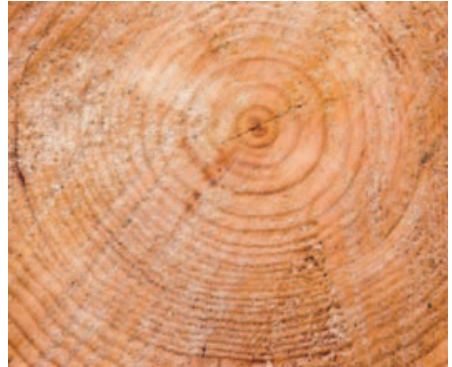

(A) Tree stump

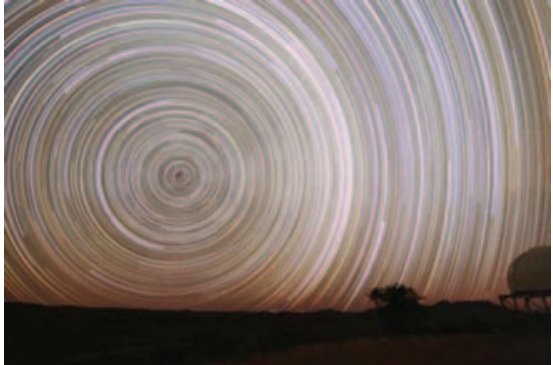

(в) Star trails

Figure 20. Circles.

have the circulatory blood system, where the heart is the intersection of multiple circles.

Vesica Piscis is the intersection of two circles (Figure 211A). It appears as the interference pattern of two intersecting circles on a water surface (Figure 21B). The vibrating string has the shape of Vesica Piscis (Figure 22). The stomata

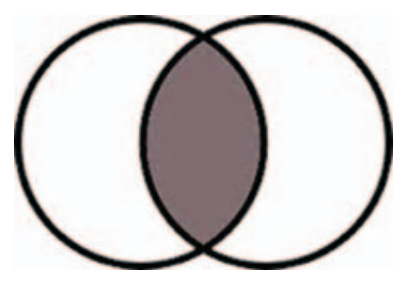

(A) Two circles

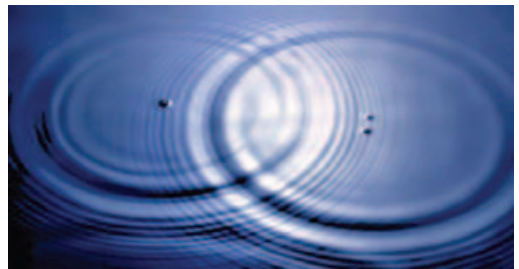

(в) Ripples on water

Figure 21. Vesica Piscis.

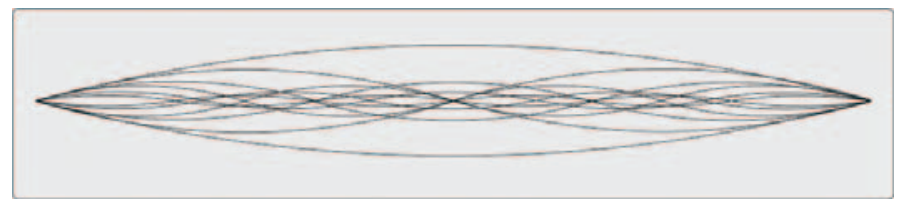

Figure 22. Vesica Piscis in vibrating string and harmonics.

have the shapes of Vesica Piscis (Figure 23). The function of stomata, located at surfaces of leaves, is to allow oxygen, carbon dioxide and water to move in and out of a leaf. 


\section{RASTISLAV TELGÁRSKY}

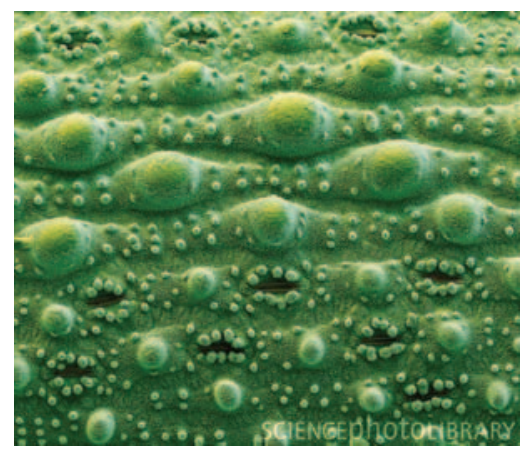

Figure 23. Stomata (pores) and oil glands.

\subsection{Golden Ratio, Fibonacci Numbers and Spirals}

The Golden Ratio is also called Golden Mean, Golden Section and Divine Proportion. The golden ratio $\Phi=1.6180339 \ldots$ has been extensively studied in mathematical literature, and applied in fine art and architecture. $\Phi$ is the positive root, $(1+\sqrt{5}) / 2$, of the quadratic equation $x /(1+x)=1 / x$, derived from the division of the interval of length $1+x$, so that the ratio of the smaller part of the unit length 1 to the larger part $x$ is the same as the ratio of larger part $x$ to the total length $1+x$.

Golden ratio is also the limit of ratios $\phi(n+1) / \phi(n)$, where $\phi(n)$ is the $n$th Fibonacci number defined recursively: $\phi(1)=\phi(2)=1$, and $\phi(n+2)=$ $\phi(n+1)+\phi(n)$. (The notation $\Phi$ is from Fidias, and $\phi$ from Fibonacci.) The ratios $\phi(n+1) / \phi(n)$ are reasonable rational approximation of $\Phi$, which itself is an irrational (algebraic) number.

Golden Spiral is a logarithmic spiral whose growth factor is $\Phi$ (Wikipedia: Golden spiral). An approximate Golden Spiral is constructed by drawing arcs in squares of the subdivisions of golden rectangles (Figure 24A A). The subdivisions of every golden rectangle consist of a square and a smaller golden rectangle. When lengths of the sides of subdivisions are Fibonacci numbers, the resulting spiral is called the Fibonacci spiral. The Golden Spirals are formed in nature by hurricanes. The satellite image of the hurricane Sandy resembles the shape of Golden Spiral (Figure 24B).

Of the 1600 species of wild bees native to Australia, about 14 species are stingless and harmless to humans. Some of these stingless species make hives in the shape of the Archimedean spiral (Figure25A). The stingless bees making spiral bee hives are also found in India.

The shells of ammonites grow as logarithmic spirals (Figure 25B), as well as many mollusks. 


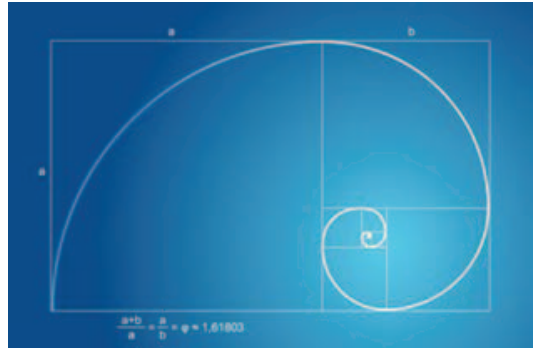

(A) Golden Ratio Spiral

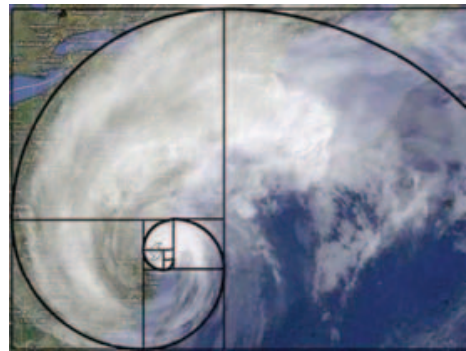

(в) Hurricane Sandy

Figure 24. Golden Ratio Spiral and Hurricane Spiral.

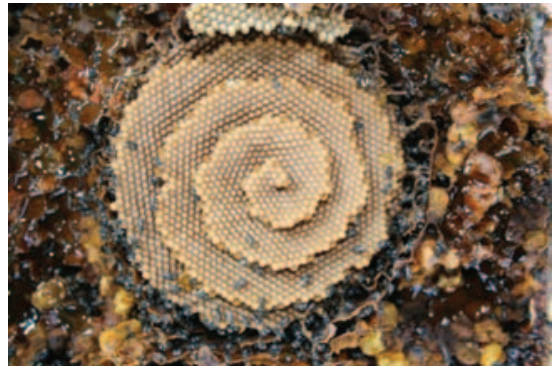

(A) Spiral honey comb

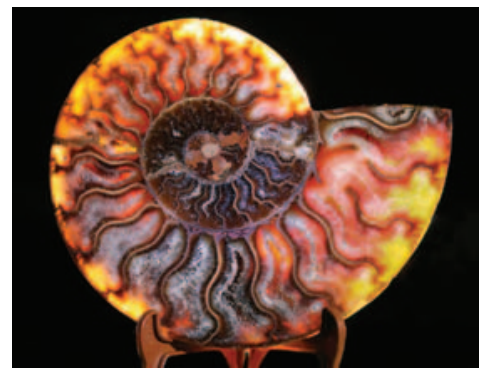

(в) Ammonite spiral shell

Figure 25. Honey combs and Ammonite Spirals.

Golden angle is 137.508 degrees $=360 /(1+\Phi)$ degrees $=2 \pi /(1+\Phi)$ radians. Golden triangle is determined by three angles: $36 \times 72 \times 72$ degrees. Golden rectangle has dimensions $1 \times \Phi$ units. Every triangle in the pentagram is a golden triangle.

Spirals are generated by increasing or decreasing sequences of numbers, and vice versa. The arithmetic sequence $1,2,3,4,5, \ldots$ creates the Archimedean spiral, which is uniformly growing. The Fibonacci sequence $1,1,2,3,5,8, \ldots$ creates the Fibonacci spiral, which is rapidly growing. The logarithmic spirals are described by the equation $r=a e^{b \theta}$ in polar coordinates.

Spirals are abundant in nature: whirlpool, Nautilus shell, red cabbage, cochlea in the ear (human, cow, guinea pig, mouse, rat, etc.), hurricanes and galaxies, just to name few. Corn kernels seem to form straight rows called orthostichies, but actually, the kernels spiral around and around the cob (eye). 


\section{RASTISLAV TELGÁRSKY}

Next, there are double spirals in sunflowers, chamomiles, pine cones, pineapples, raspberries, and many other plants. The numbers of spirals in both directions are the consecutive Fibonacci numbers. The sunflower in Figure 26 has 34 clockwise and 21 counterclockwise spirals. The chamomile flower in Figure 27]A

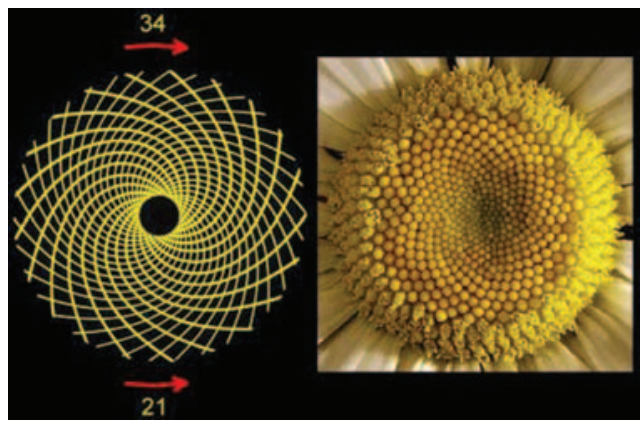

FiguRE 26. Sunflower with annotation of spirals.

has 21 clockwise and 13 counterclockwise spirals. The pine cone in Figure 27B has 13 clockwise and 8 counterclockwise spirals.

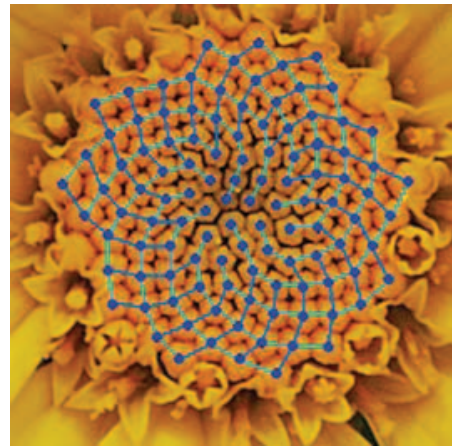

(A) Yellow chamomile

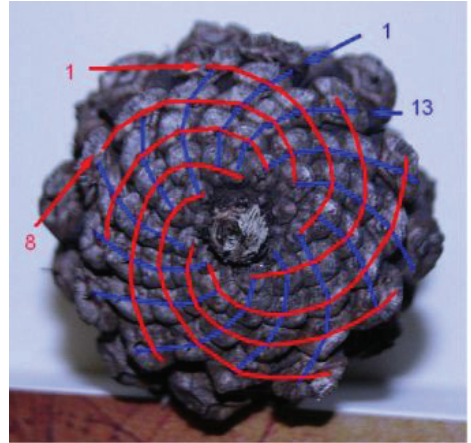

(B) Pine cone

Figure 27. Chamomile and pine cone with annotated spirals.

The Fibonacci numbers are seen in many flowers. For example, Dianthus (Figure 28A) has 5 petals. Passiflora (Figure 28B) has five features (top to down): Style (3), Anther (5), Corona (55), Sepals (5) and Petals (5).

The Fibonacci sequence is a derivate of Pascal Triangle (Figure 29), but Pascal Triangle is not directly observed in the nature.

The Golden Ratio appears in human body measurements (Figure 30), and 


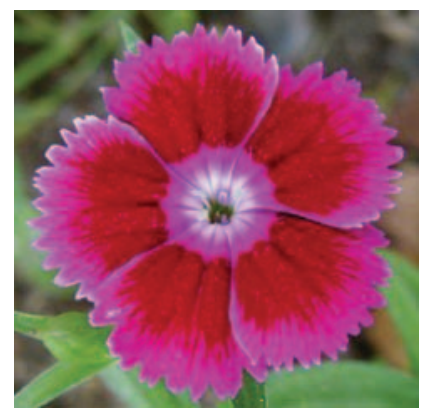

(A) Purple Dianthus

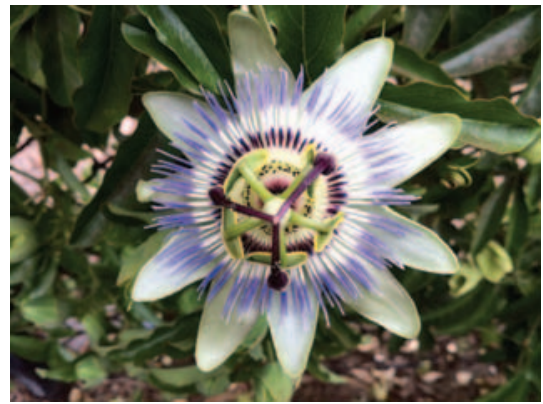

(в) Passion Fruit Flower

Figure 28. Dianthus and Passion Fruit Flower.

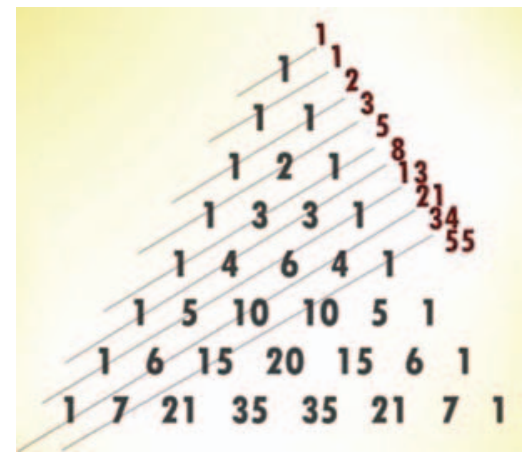

Figure 29. Pascal Triangle and Fibonacci Sequence.

it is also found in the palm of hand with measurements between bone joints (Figure 31A), and in human arm (Figure 31B). However, not every human body has the leading proportions close to the Golden Ratio. On the other hand, the Golden Ratio is one of the criteria for a beauty of human body, both male and female; it is used in blueprints for cosmetic surgeries.

Phyllotaxis (the leaf arrangement) achieves the minimum overlap of leaves (and the maximum exposure to the Sun) at 137.5 or 222.5 degrees (Figure 32). Architect Saleh Masoumi proposed skyscrapers, called Phyllotactic Towers, which use the golden angles like the plants to provide the maximum sunlight for the apartment units.

\subsection{Polygons and Polyhedrons}

Triangles, squares, rectangles, pentagons and hexagons are found in bacteria, microorganisms, and crystals. Graphite can create hexagonal sheets called 


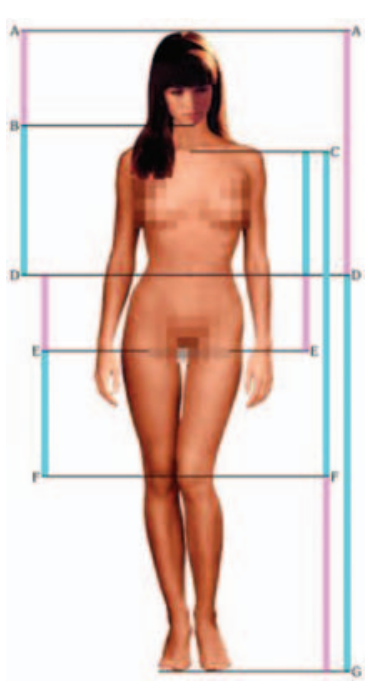

(A) Perfect Woman

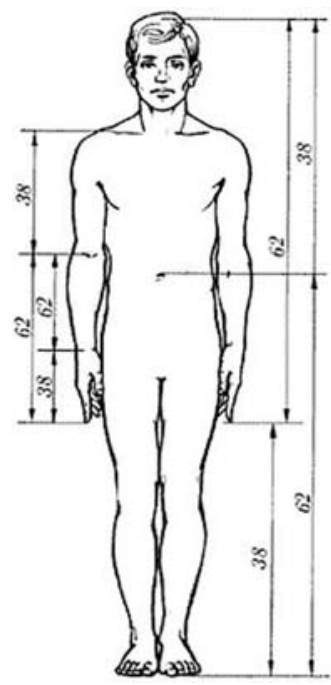

(в) Perfect Man

Figure 30. Golden Ratio in Human Bodies.

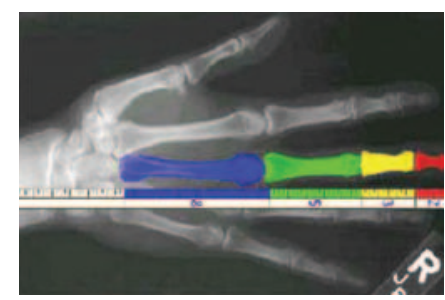

(A) Human palm

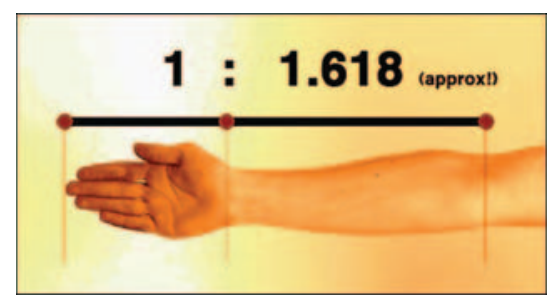

(в) Human arm

Figure 31. Golden Ratio in Human Hand Measurements.

graphenes. Honeycombs in beehives have hexagonal structures. Diamonds have tetrahedral architecture. The salt crystals are cubes (with some exceptions). Some viruses have form of the octahedron. The dodecahedron is found among microscopic radiolaria. The buckyball consists of 60 carbon atoms, 5 around each corner of a dodecahedron. The buckyballs are created in small quantities at the places where a lightning strikes a tree (an organic material with carbon contents). 


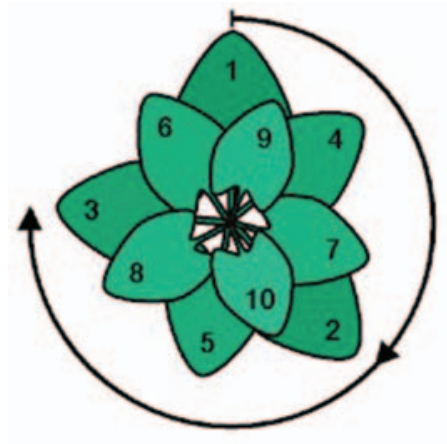

(A) Phyllotaxis scheme

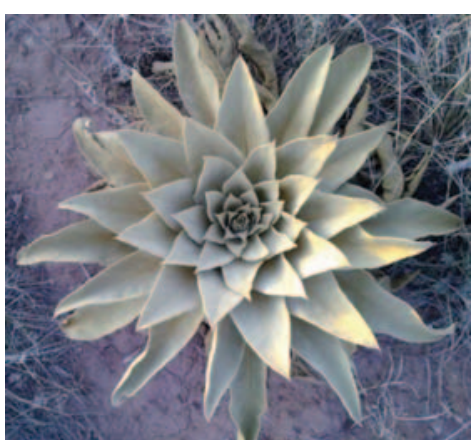

(в) Phyllotaxis plant

Figure 32. Golden ratio phyllotaxis.

\subsection{Other Shapes in Nature}

The shape of Earth is not a sphere, not even an ellipsoid, but a particular spherical harmonics, called geoid. The geoid shape of Earth is used for precise geographic calculations. The geographic coordinates are latitude, longitude and elevation. The grid is made by meridians and parallels. Another coordinate system in use is the UTM system (Wikipedia: Universal Transverse Mercator coordinate system). The shape of a chicken egg is also a spherical harmonics, but the shapes and sizes are not the same for different eggs.

The mountains have various shapes depending on their origin: volcanic, lifted from the sea bed, etc. They may look like cones, paraboloids, hemispheres, 2D Gaussian distribution, etc. The Chocolate Hills in Bohol Province, Philippines, have many visitors due to their interesting shapes (Figure 33).

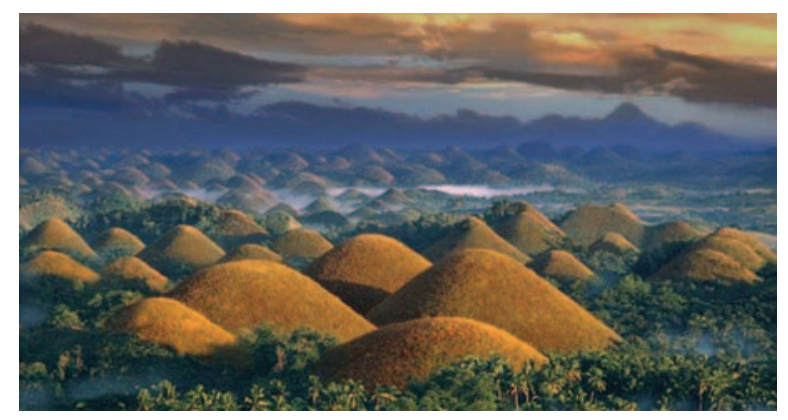

Figure 33. Chocolate Hills, Bohol Province, Philippines.

There are two main kinds of valleys: the U-shaped valleys, also called the glacier valleys (Figure 34A), and the V-shaped valleys (Figure 34B). 


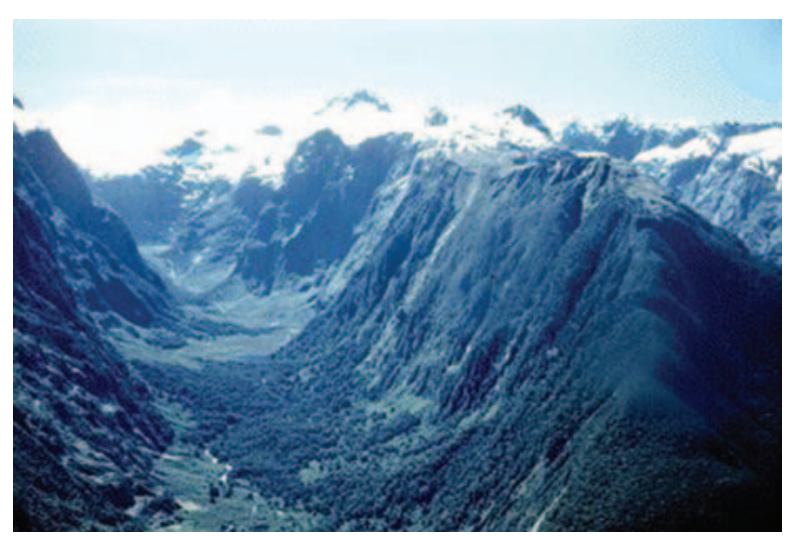

(A) U-shaped Valley

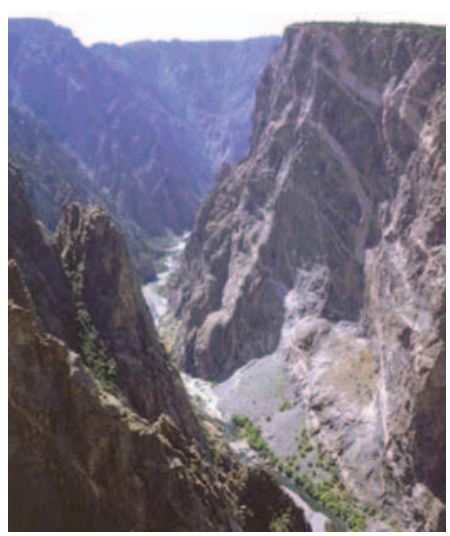

(в) V-shaped Valley

Figure 34. U-shaped and V-shaped Valleys.

The natural river beds are mostly curved and create meanders. Figure 35A shows the meanders of Rio Cauto at Guamo Embarcadero, Cuba. Where the rivers flow into the sea, they form river deltas. Figure $35 \mathrm{~B}$ shows the delta of the river Lena in Russia taken by Landsat in 2000. The image is a false-color composite image made by using shortwave infrared, infrared, and red wavelengths.

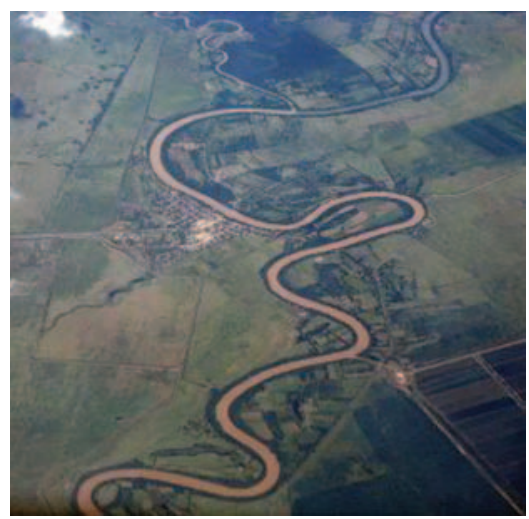

(A) Meanders of Rio Cauto

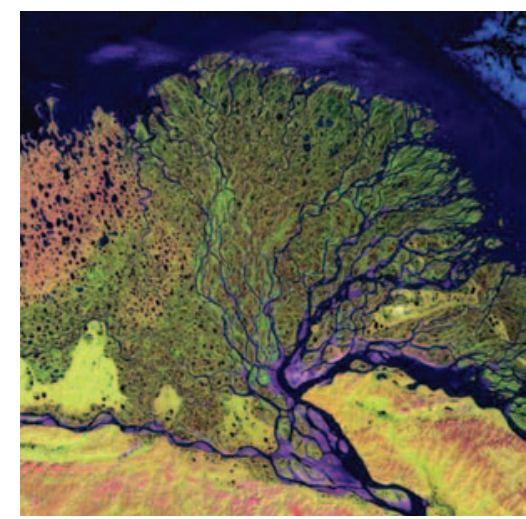

(в) Lena river delta

Figure 35. River meanders and delta.

The large areas of the Earth in aerial or satellite photographs are usually described as 2D fractals. Figure [36A shows the drainage patterns of Yemen, 
where once was flowing water. Figure $36 \mathrm{~B}$ shows the mountain ranges of Tibet when cloudless skies allowed a clear view in mid-December 2008.

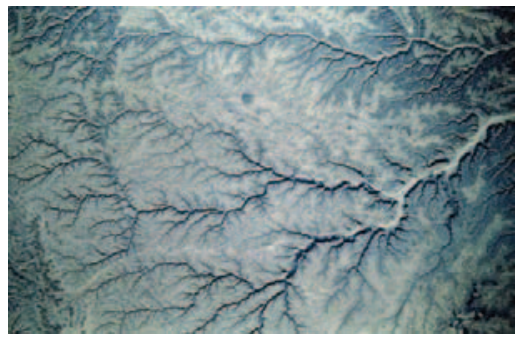

(A) Yemen: drainage pattern

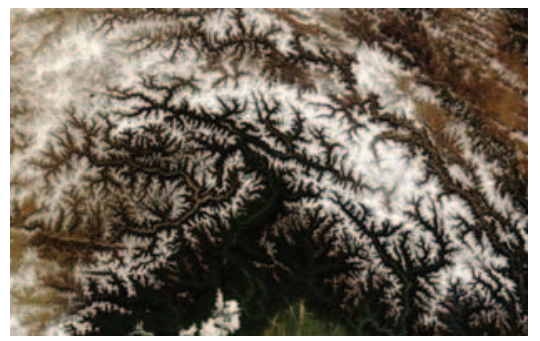

(в) Tibet: mountain ranges

FiguRE 36. Drainage and mountain ranges as fractals.

Some 2D and 3D fractals are growing in nature as plants and vegetables, for example, ferns (Figure 37]A), cauliflower, romanesco broccoli (Figure 37B), etc.

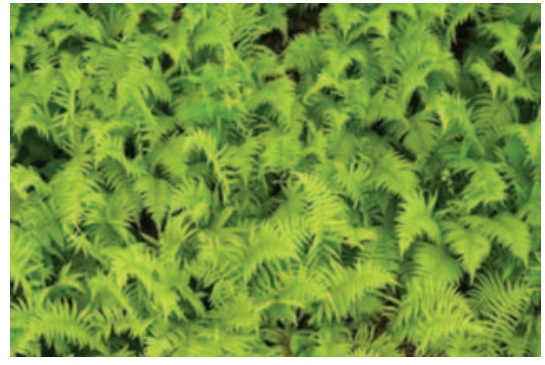

(A) Forest Ferns

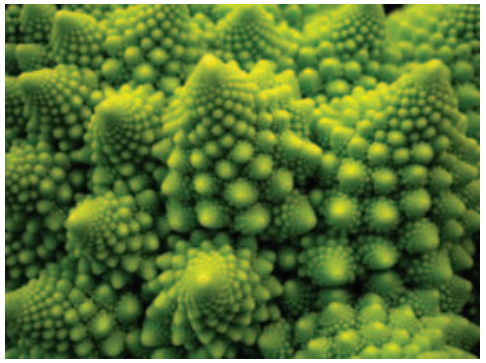

(в) Romanesco Broccoli

Figure 37. Fractals growing in nature.

The modeling of nature via fractal sets was preceded by topological studies of curves and continua in Euclidean spaces (Figure 38).

The topological fractals inspired the construction of fractal antennas (Figure 39) for smart phones, for sending and receiving multiple frequencies (reception, transmission, GPS, etc.). Some fractal antennas have been patented, but there have been claims that the same effect can be achieved with much simpler shapes. Smart phone antennas must receive signals of sufficient strength independently on the rotation relative to the communication towers.

The difference between mathematical fractals and fractals in nature is that mathematical fractals have infinite depth and details, and therefore they do not exist in nature. It is important to understand that fractals in nature have only 


\section{RASTISLAV TELGÁRSKY}

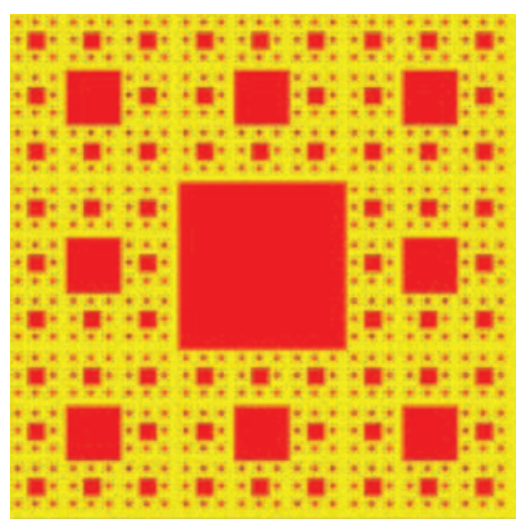

(A) Sierpiński Carpet

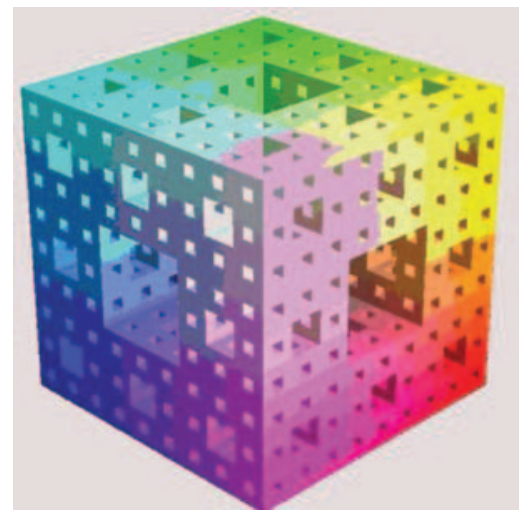

(в) Menger Sponge

Figure 38. Topological fractals in 2D and 3D spaces.

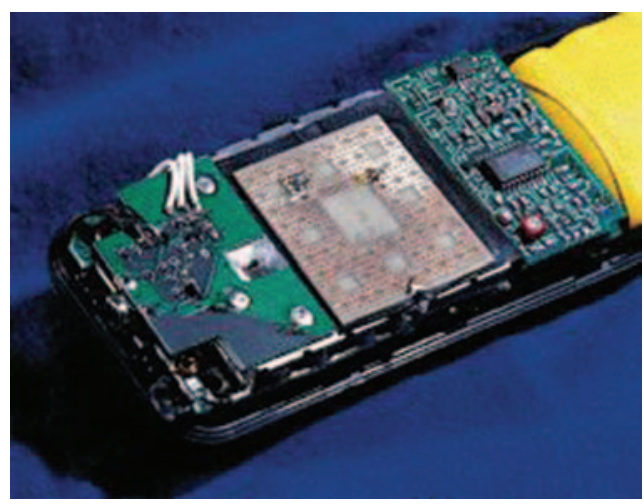

Figure 39. Cellphone with a Sierpiński Carpet antenna.

few iterations, and after those the structure is not recursive and is of a different kind. The elementary particles, which are building blocks of the matter, are not known to have fractal structures.

\subsection{Symmetry in Nature}

Living organisms and crystals have symmetries which inspire the mathematical studies of groups of symmetry. A symmetry must have a fixed point, or a fixed line, or a fixed plane, or a hyperplane in an n-dimensional phase space, where $n>3$. The most common symmetries are the axial and the radial symmetry. The axial symmetry is seen in animal faces and bodies. The radial symmetry 
is found in a slice of carrot, a green pepper top, a slice of onion, and in many flowers and fruits.

The crystalline snowflakes have six fold symmetry (Figure 40). Wilson Bentley

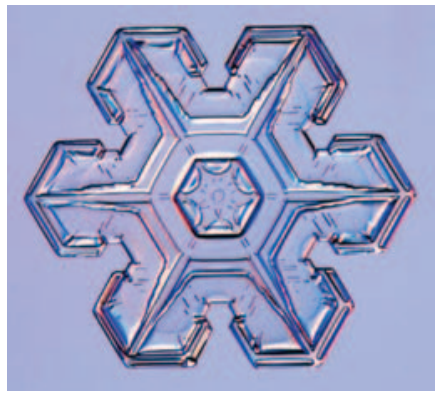

(A) Snowflake 1

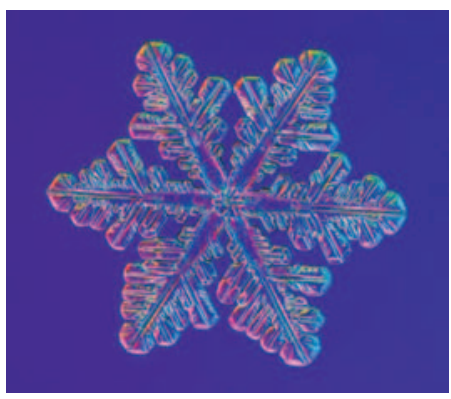

(B) Snowflake 2

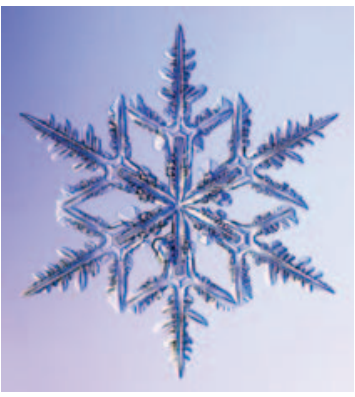

(c) Snowflake 3

Figure 40. Three samples of snowflakes.

photographed over 5000 snowflakes in the 1930. He found no two alike. What is going on? About one molecule out of every 5000 naturally occurring water molecules will contain an atom of deuterium in place of one of the hydrogens, and about one in 500 will contain an atom of ${ }^{18} \mathrm{O}$ instead of the more common ${ }^{16} \mathrm{O}$. A typical small snow crystal might contain $10^{18}$ water molecules, and about $10^{15}$ of these molecules will be different from the rest. These unusual molecules will be randomly scattered throughout the snow crystal, giving it a unique design. The probability that two snow crystals would have exactly the same layout of these water molecules is extremely small (www.its.caltech.edu/ atomic/snowcrystals/alike/alike.htm).

There are many varieties of crystals found in minerals. For example, the crystals of salt $\mathrm{NaCl}$ are almost exclusively cubes.

Various n-fold symmetries are found in many plants, flowers and fruits (Figure 41). Grapefruits have a variable number of slices, but mostly 12 .

There is a huge variety of symmetric shapes among Diatoms (Figure 42), which belong to phytoplankton community. These are microscopic organisms that live in watery environments, both salty and fresh. There is a huge variety of shapes and symmetries in bacteria and viruses.

Finally, there are patterns invariant to translations, similar to symmetries, called strip patterns. There are 7 kinds of strip patterns (Frieze group) and some of them can be seen in snake skins. 


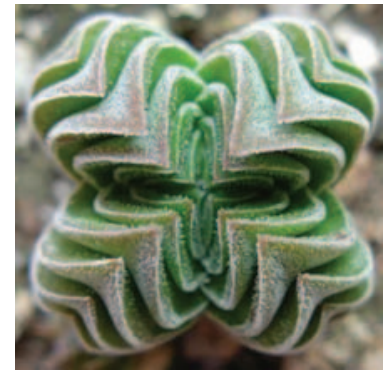

(A) Crassula

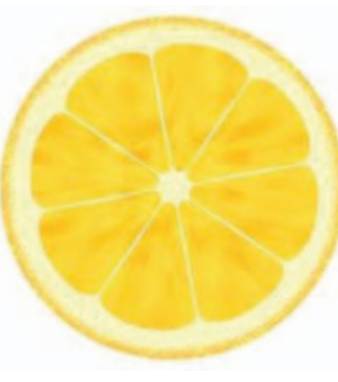

(в) Lemon slice

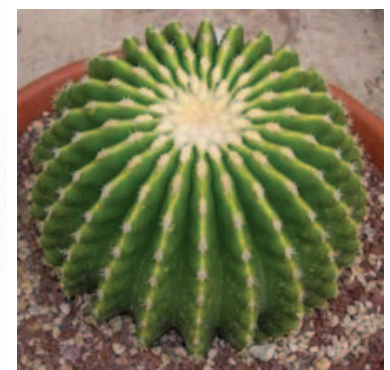

(c) Echinocactus

Figure 41. 4-, 8-, and 24-fold symmetries.

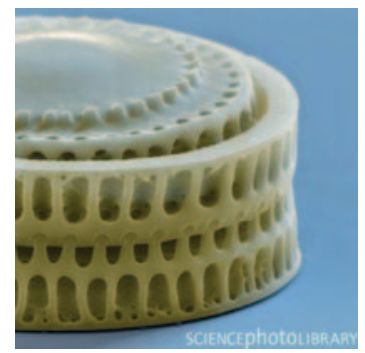

(A) Diatom 1

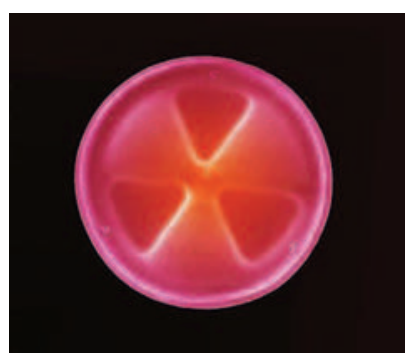

(B) Diatom 2

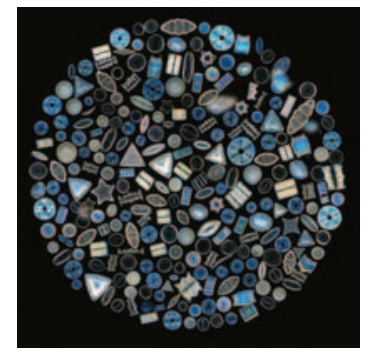

(c) Diatoms

Figure 42. Diatoms.

\section{Motion and Time}

\subsection{Motion Types}

We see that the common celestial bodies are always in motion: the Earth, the Sun, the Moon, the planets Mars and Venus, etc. In the macroscopic world, the most trajectories are curved lines. In a free fall of a heavy object, the trajectory is a straight line. If a rock is thrown in a non-vertical direction, the motion proceeds in a ballistic curve. The non-linear resistance of the air as a function of the velocity is the reason why the projectile motion is a ballistic curve and not a parabola. A linear motion, whether straight or curved, is performed by muscles as we see in the stroboscopic photography (Figure 43).

The industry, especially the robotics, needs artificial muscles, because they can provide a fast linear motion (traction). The artificial muscles are built on various principles: pneumatic, hydraulic, electric, piezoelectric, thermal, etc. 


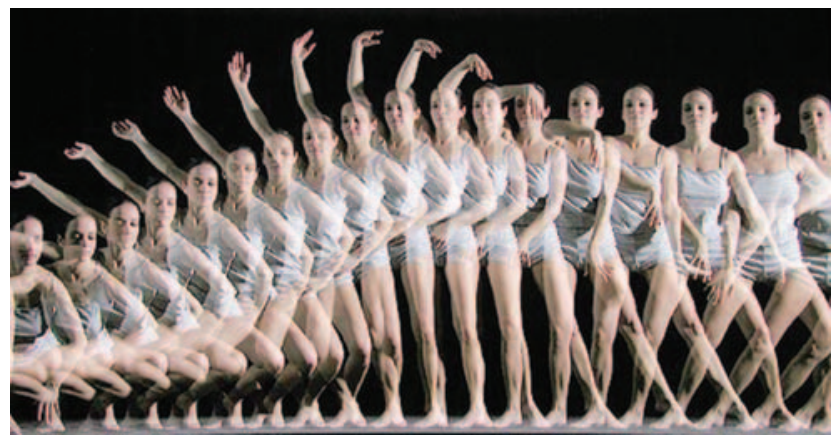

Figure 43. Stroboscopic motion photography.

There is a relatively new material for artificial muscles called Superelastic Carbon Nanotube Aerogel (2009). Furthermore, linear motors are used for fast trains, where a strong magnetic field provides both the levitation and forward motion.

A woodpecker drums a tree as fast as 22 beats a second, creating decelerations of up to $1200 \mathrm{~g}$, where $\mathrm{g}$ is the gravitational constant. While drumming, it keeps its beak perpendicular to the tree. The woodpecker's beak is extremely strong and does not bend or fracture. There is little room between the skull and the brain for cerebrospinal fluid, thus reducing the transmission of vibrations. The bone's porous structure stops low frequency vibrations from reaching the bird's brain.

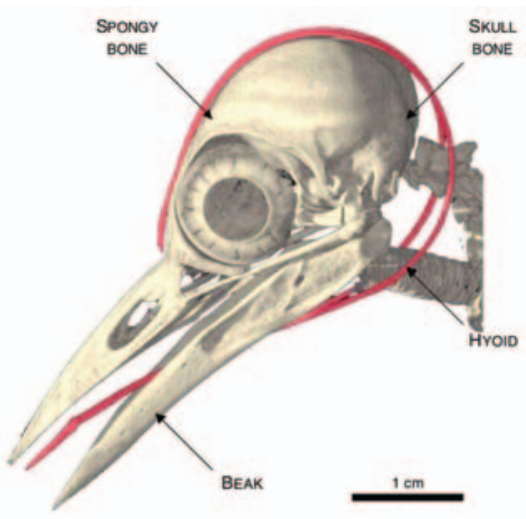

(A) Woodpecker skull

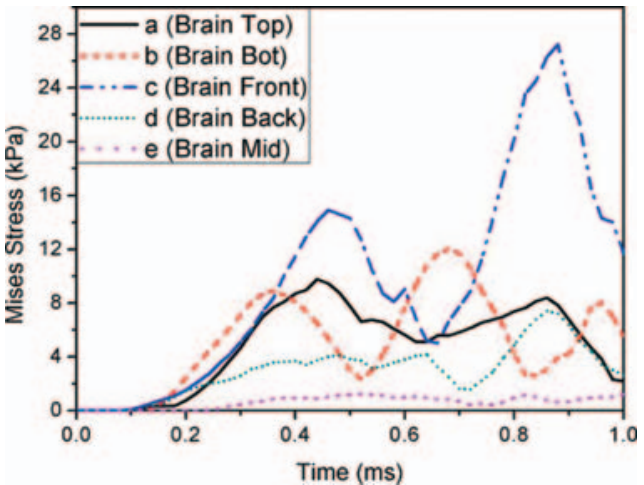

(в) Stress propagation

Figure 44. Woodpecker's skull and mechanical stress propagation.

The woodpecker's head inspired the construction of shock absorbers for protecting sensitive electronics. To test their system, Yoon and Park [28] placed it 
inside a bullet and used an airgun to fire it at an aluminum wall. They found that their system protected the electronics ensconced within it against shocks of up to $60,000 \mathrm{~g}$, while today's flight recorders are designed to withstand shocks of $1000 \mathrm{~g}$.

In microscopic living world we find mostly linear or nearly linear motion, but also a circular motion. For example, flagellum of a bacteria performs a circular spiral motion, which is also a periodic motion. The flagellum of many bacteria does not turn in its base, but it is firmly attached to the base. This fixed attachment also has the flagellum of the male spermatozoon (Figure 45), where the middle part contains mitochondria as the energy storage. The life span of a spermatozoon is short, and its energy spending is intense. Some bacteria, however,

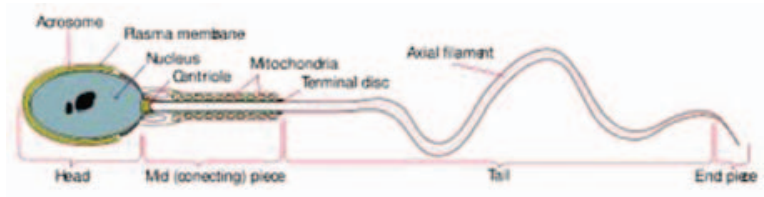

Figure 45. Human spermatozoon.

have stator and rotor to rotate the flagellum (Figure 46). Some bacteria even have several flagella, and each one has the flagellan motor.

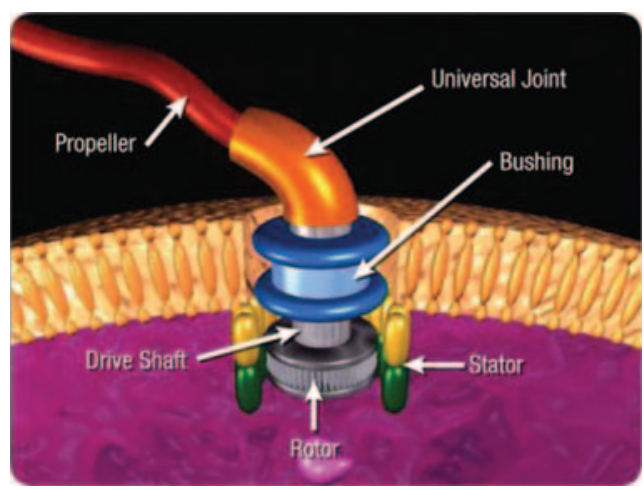

Figure 46. Bacterial motor for flagellum rotation.

In parallel the studies of bacterial motion in biology we can see the development of micro-electro-mechanical systems (MEMS) (Wikipedia: Microelectromechanical systems). Some components of MEMS devices are MEMS sensors including accelerometers, gyroscopes, digital compasses, inertial modules, pressure sensors, humidity sensors, microphones, etc. 
At the molecular and atomic level, the motion is linear, periodic or random, or a combination of those types. The cosmic rays have linear trajectories, as well as the alpha particles. The electrons appear to circle around the atom's core, but their locations and speeds have probability distributions rather than measurable values. The random motions are either random vibrations (Figure 47) or random walks (Figure 48); both are related to thermal energy, heat and temperature. The random vibrations and random walks of molecules should stop at the temperature of 0 degrees of Kelvin.

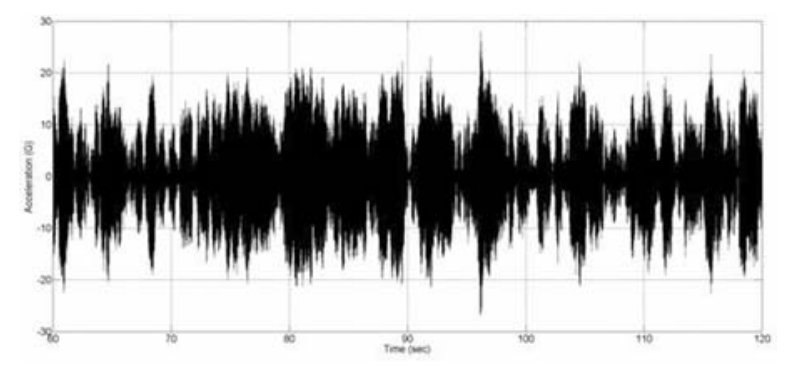

Figure 47. Random vibrations.

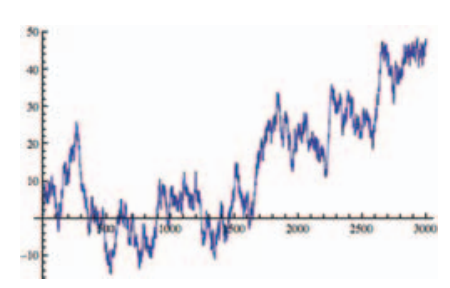

(A) $1 \mathrm{D}$

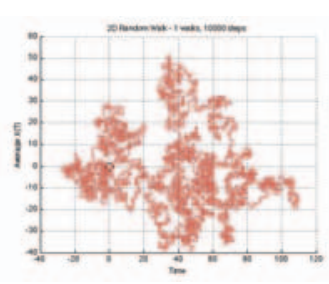

(в) $2 \mathrm{D}$

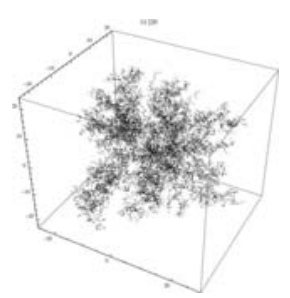

(c) $3 \mathrm{D}$

FigURE 48. Simulated Random Walks in Dimensions 1, 2 and 3.

\subsection{Motion of Matter}

We observe motions of soil and rocks: the soil shifts and the rocks fall. Moreover, there are avalanches, tectonic motions, earthquakes and explosions of volcanoes. We observe flowing of water: rivers, streams, tides and rain overflows. The air is moved by winds, which bring changes of temperature and humidity.

The rocks thrown in the air follow the ballistic trajectories. The comets follow the parabolic trajectories, and planets of the Solar system have elliptical orbits described by Kepler laws. The cosmic rays can penetrate through large objects. That's why the cosmic rays have been used to detect an unclaimed cargo 


\section{RASTISLAV TELGÁRSKY}

in a covered unopened truck. Similar devices just use X-rays. The alpha particles result from a radioactive decay, for example, Uranium 235, which is found in the nature. The electrons are present in lightning and other electric currents. In direct current the electrons move from one location to another through a wire, but in an alternating current the electrons move back and forth according to a sinusoidal rhythm. The speed of the electrical field in a wire is close to the speed of light in vacuum, but the speeds of electrons in wires are on the order of millimeters per hour (Wikipedia: Speed of electricity). The photons are particles constituting the sunlight and any electromagnetic wave. The photon has no mass, no charge, and its energy is $E=h \nu$, where $h$ is the Planck constant and $\nu$ is the frequency.

\subsection{Motion of Living Organisms}

Birds fly, walk or jump; bugs walk or jump; frogs hop and swim; fish swim; wolves walk and run; etc. So, animals can walk, run, jump, crawl, swim or fly. Plants can rotate leaves to get the suitable portion of sunlight. The plant called Venus Flytrap can catch insect and also supplement its nutrition with photosynthesis. Similarly, the sea slug called Elysia Chlorotica can eat plants but it also has chlorophyll for photosynthesis. In life-cycles of individual plants, sea creatures, insects, etc. the motion is the way to gather food for survival, that is, the growth and the reproduction. The common sayings are: Life is motion. Motion is life.

Nicola Tesla invented and constructed first radio-controlled electric submarine, and in 1898 received U.S. patent for his "Teleautomaton boat". He presented it to military representatives, but they did not show interest in utilization of his invention. Today, however, remote control submarines are used for deep sea research, military reconnaissance, and small smart submarines are sold as toys, which can be ordered via Internet.

The name of robot was introduced by Karek Čapek in his science fiction play R.U.R. published in Czech in 1920. The machines which build today's cars are also called robots, as well as are many other machines which perform desired physical tasks with sensors and intelligent control software.

However, robots can also imitate bugs, spiders, birds, etc. For example, a tarantula (Figure 49A) is imitated by a hexapod robot called Hermes (Figure 49B).

We always admire the beauty and technique of bird's flying. Figure 50 compares Magpie to the British-French airliner Concorde.

From large airplanes carrying people and cargo the attention of civil and military industry includes small flying units, called drones, which are preprogrammed or remote controlled. 


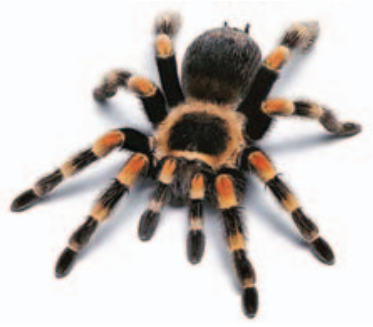

(A) Tarantula

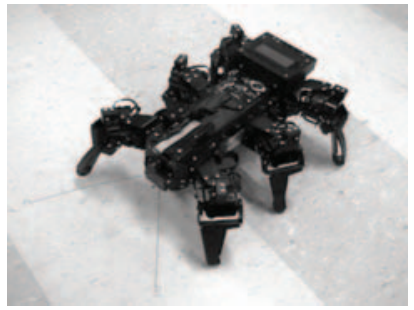

(в) Hexapod

FiguRE 49. Tarantula spider and Hexapod robot.

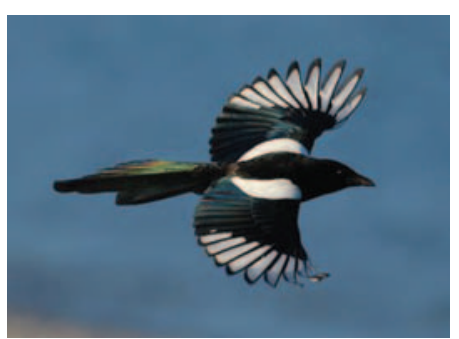

(A) Magpie

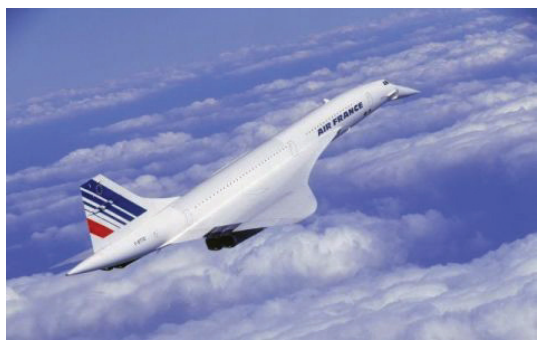

(в) Concorde

Figure 50. Magpie bird and Concorde airplane.

From propellers and jet engines used in airplanes and drones, the attention is also paid to small wing-flapping drones, called Micro Unmanned Airborne Vehicles. Figure 51 compares Twelve-spotted skimmer dragonfly to a wing-flapping drone.

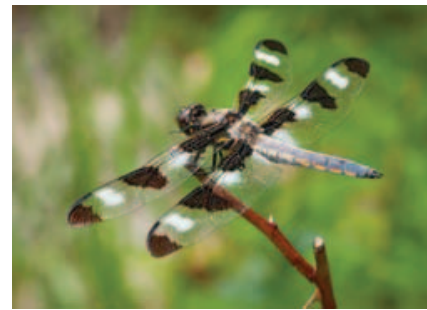

(A) Dragonfly

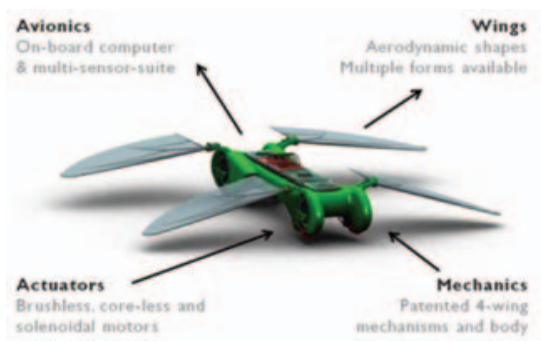

(в) Wing-flapping drone

Figure 51. Dragonfly and wing-flapping drone. 


\section{RASTISLAV TELGÁRSKY}

\subsection{Sounds and Vibrations in Nature}

Animals produce sounds: birds sing, wolves howl, and chicken, ducks, and whales also make their characteristic sounds. The winds generate sounds with trees, rocks and water waves. The lightning is accompanied by the sound of thunder. The earthquakes are seldom heard, but rather felt as vibrations or moving ground under the feet; the sounds are generated by the destruction of houses, roads, bridges, etc.

\subsection{Periodic Motion and Waves}

We hear the sound, or acoustic wave, which propagates through the air and also through the water. Sonar, passive or active, uses acoustic waves to detect shapes and create maps under water (Wikipedia: Sonar). Ultrasound is generated and heard by bats, and allows them to navigate and hunt at night. Ultrasound echo is used by sonograms for a limited imaging of internal organs in human body (Wikipedia: Medical ultrasonography). Infrasound, or subsonic sound, is generated by volcanic activities, earthquakes, and also by the deformations of the Earth crust by the Moon (the effect is similar to the tide). Water surface waves have low frequencies, but they end up in a clash, which sounds like a noise having high audible frequencies in the spectrum.

The visible light comes from the Sun, or from the Moon, which is the reflected sunlight, or from auroras, fires, bioluminiscence, etc. The infrared light has frequency below dark red and it feels on skin like invisible warm rays. The Sun and the fires emit the infrared light. There are infrared LED's and infrared sensors, which are used for communication and control, for example, in TV controllers. The ultraviolet light (UV) comes from the Sun, but it is partially blocked by the ozone layer in the upper atmosphere. The UV light is seen by some insects, and it is used in many technical and medical applications. The $X$ rays come from cosmic space (including the Sun), so we can create X-ray (false color) photographs of the Sun and faraway stars. The macromolecular X-ray (MX) crystallography is crucial to many areas of research, particularly in identifying the atomic structure of new materials. We use radiotelescopes to create images from radio waves that come from the cosmic space. Since the energy of radio waves is very small, we connect radiotelescopes into large arrays, like the Very Large Array Radio Telescope facility near Socorro, New Mexico, U.S.A.

\subsection{Theory of Everything and Big Bang}

The base assumption is that our world is composed of strings - vibrating entities (Figure 52). These strings roll, rotate, twist, vibrate, and tweak. They should ultimately result in the familiar configurations of the observable matter. However, this is the main goal: to connect the string theory to the physical measurements. The supersymmetric string theory is known as the superstring theory (Wikipedia: Superstring theory). 


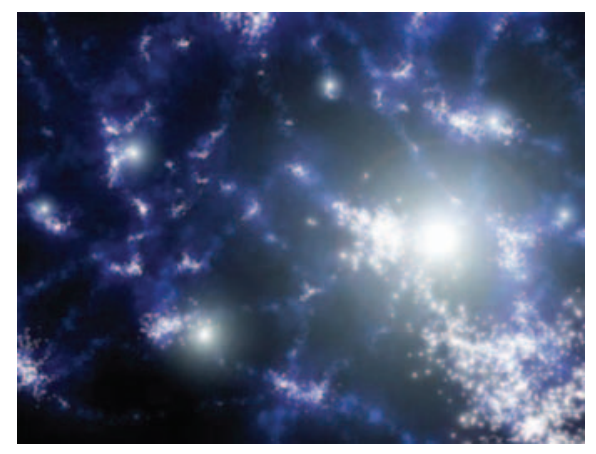

Figure 52. Microscopic physical processes involving strings.

The Big Bang Theory extrapolates the results of our astronomical observations into the very past of the universe. According to these observations, all stars are moving apart from each other, and therefore there must be a location (a point or not) in the universe from where it all started to expand (Figure 53). But this extrapolation has a little problem well expressed by Terry Pratchett: In the beginning there was nothing, which exploded. The image in Figure 53 is

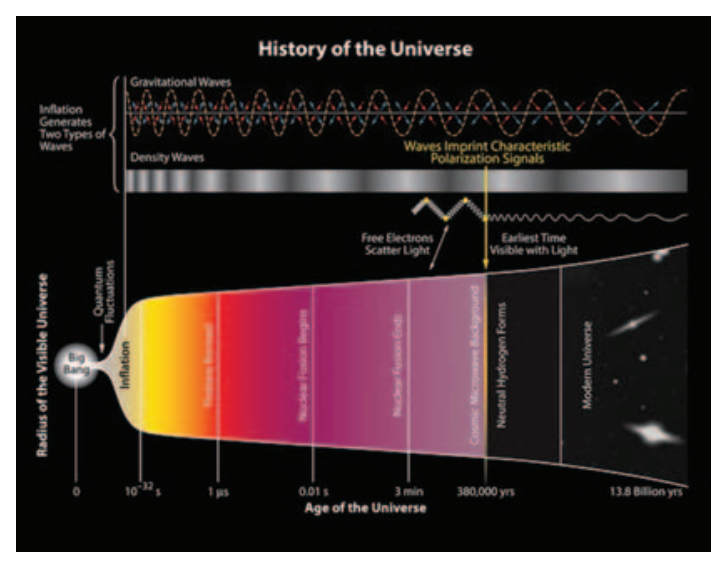

Figure 53. History of the universe: Big Bang.

from Wikipedia's article: Chronology of the Universe. There is nice discussion of these problems in Max Tegmark [22]. The probabilistic nature (or probabilistic interpretation) of everything real leads to the concept of multiverses.

\subsection{Time Measures}

Time has duration, structure, and intensity. We talk about time intervals during which some events happen. The diagram of events within a time interval 


\section{RASTISLAV TELGÁRSKY}

defines the time structure. The number of events in time interval defines the time intensity. Time is a comparison of two sequential events - processes. There are slower and faster processes. In particular, the biological time is the time duration of life of a living organism (from the birth to the death). The time units range from split-seconds to light years. For example, the artificially created particle $\mathrm{Y}(4260)$ exists only $1 \times 10^{-23}$ seconds. The age of the universe is estimated to $13.798 \pm 0.037 \times 10^{9}$ years (Wikipedia: Age of the universe).

Time (or process) has past, present and future. There is no past without a memory and ability to compare what is now to what was then. Similarly, the future time requires a brain, so that current actions are (sequentially) coordinated toward the goal that should be achieved in future. For the reference to past events and planning future events we use clocks, calendars and planners. The astronomical time is measured relative to stars. The sidereal time is used in telescopes for tracking of the preset star. According to relativistic transformation of time, the local time of an object depends on its velocity relative to the origin of the coordinate system. The effect depends on the magnitude of the velocity.

\subsection{Time Devices}

They range from very simple to very sophisticated in order to achieve the desired precision. Time devices are used for sequencing of the events which should occur in specific time, moment or interval. So, they are necessary for planning and prediction of future actions and events. There is no absolute reference for time, and copying the time value from a designated device is voluntary or mandatory.

The most simple clock is the sand clock (hourglass) used for boiling eggs or soaking the tea leaves. The solar clock (sundial) is a daily clock with accuracy of an hour or less, depending on its size. The sundial requires the sunlight, which should not be too much dispersed by clouds. The mechanical clock, with a pendulum or a wind-up spring, can keep the continuous time, and its accuracy is one minute or less. The electronic clocks also show the continuous time, but their accuracy is one second or less. These clocks usually have more functions than just showing the current time; they may include the timer and the stopwatch. They can also show the date: day of the week, the day, the month, and the year.

The ability to sequence quick and short actions (interventions) and many of them is seen in the high frequency trading of stocks at the U.S. stock market. Clearly, slower frequency traders (dealers) are at a substantial disadvantage when compared to high frequency traders.

The need of central reference for time in the U.S. lead to the creation of the atomic reference clock used by the U.S. Government to adjust all other clocks in the U.S.A. (Wikipedia: Atomic clock). Other countries or their groups also 
have reference clocks to consolidate all local times around them. The international transport and communication mostly refer to the Greenwich Mean Time (GMT) maintained by the United Kingdom.

\subsection{Time Discrepancies}

The Julian year is defined as 365.25 days. The year requires 1-day compensation every 4 years (it is the leap year) and also every 400 years. The Revised Julian year is 365.242222 years. In this calendar 218 out of 900 years are leap years. The lunar phase is 29.53 days, and constitutes an uneven input into lunarbased calendars, like Hebraic and Islamic. The female menstrual cycle, commonly compared to the duration of the lunar phase, does not have a fixed duration. It is ranging from 21 to 35 days, and the designated average length is 28 days, which is $(21+35) / 2$.

Each week has 7 days, but 7 does not divide the number of days in a year. The 7-day week was used in 6th century BC by ancient Babylonian and Chaldean religions, as well as Judaism, where it is based on the Creation narrative in the Bible (Wikipedia: Week). Other traditions in other times used weeks made with number of days different from 7 , and also weeks with variable duration. The weeks are usually imposed by governments over the people for alternating cycles of work days and rest days (or holidays). The duration of week as 7 days does not relate to any process or rhythm in the nature. From all weeks of different lengths occurring in history of humanity, the 7-day week is the most spread out today.

The Mean Solar Day is $86,400.0025$ SI seconds, where SI denotes the International System of Units, in which the second is defined via the speed of light (Wikipedia: SI base unit). The Stellar Day is 86,164.098903691 seconds of the Mean Solar Time.

The sunspot cycles (protuberances) have an average duration of about 11 years. Cicadas (critters) hatch after 13 years underground, while Magicicada septendecim come out after 17 years.

The calendars in antiquity differed from region to region, and it is quite difficult to translate the dates of past events. There are still many calendars in use, and they went through adjustments in course of history. Western calendar is the Gregorian calendar (Christian calendar), and it is the most accepted calendar in countries and international relations. This calendar does not have the year 0 , and has two parts: B.C. and A.D. (Wikipedia: Gregorian calendar). According to comparative historical studies of calendars, Jesus Christ was born few years earlier than in the year 1 AD. Assyrian, Byzantine, Buddhist, Hebrew, Iranian and Islamic calendars are also based on religious events. China uses Western calendar and the traditional Chinese calendar (Han calendar). Iran uses 3 calendars: Iranian (Persian), Islamic and Western. Israel uses two calendars: the Hebrew 


\section{RASTISLAV TELGÁRSKY}

calendar and the Western calendar. India has about 30 calendars, depending on religion and national tradition of the particular population and geographic area. Each calendar always depended on the knowledge of astronomy, religious events and country's historical events. The radioactive carbon dating is helpful in determination of age of archaeological and paleontological artifacts, however, its accuracy and applicability is limited. Each planet of the Solar System has its own planetary year and planetary day.

\section{Energy and Forces}

\subsection{Energy Sources in Nature}

The Sun provides light and heat, which are essential for maintaining the life on the Earth. The Sun can power the solar cells (photovoltaic cells) which produce the electricity. The Sun gives a free supply of energy for the agriculture, and influences the weather patterns, such as the winds. The winds can turn wind turbines to create the electricity. The geothermal water and steam have various uses, but they also can power the generators of electricity. The streams, rivers, sea waves and tides can also power the generators of electricity. Finally, burning the fossil fuels such as the coal, raw oil, and natural gas, is today the major source of usable energy, whether for heating and cooling of the houses, and powering the vehicles: cars, trucks, trains, ships, airplanes, etc. The fossil fuels are also burned to power the generators of electricity.

\subsection{Forces of Nature}

The first force is the gravitation causing the free fall, and roots of the plants growing in the direction of the force. This downward growth of roots is called the positive geotropism. The upward growth of plant shoots is an instance of the negative geotropism. The standard gravity (gravitational acceleration) is defined as $9.80665 \mathrm{~m} / \mathrm{s}^{2}$, but more precise calculations require the latitude, the longitude and the elevation of the location (Wikipedia: Standard Gravity).

The strong winds, tornadoes (Figure 54) and hurricanes have irregular occurrence and are hard to predict. Their effects on residential areas, agriculture and industrial installations are totally destructive.

The floods come after heavy and/or long rains. The droughts usually stretch to whole agricultural seasons. The droughts can be followed by fires (Figure 55). The forest fires are ignited by lightnings, power lines, careless tourists, etc.

The earthquakes have destructive powers measured in various scales. One of them is the Richter scale (Figure 56A), which is a logarithmic scale, and is used to express the total amount of energy released by an earthquake. Its values typically fall between 1 and 10. On March 28, 2005, near Northern Sumatra, 


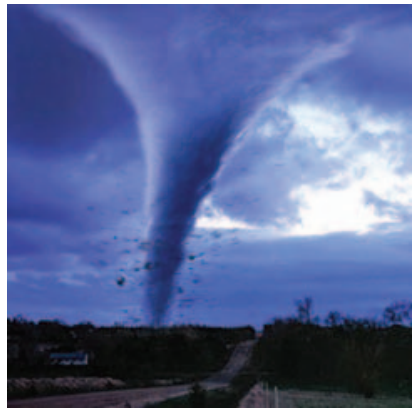

(A) Destructive Tornado

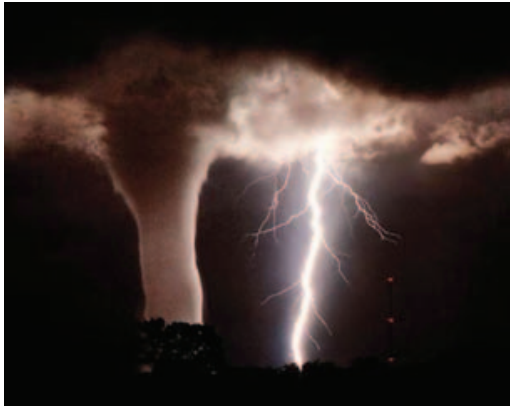

(в) Tornado and Lightning

Figure 54. Tornadoes.

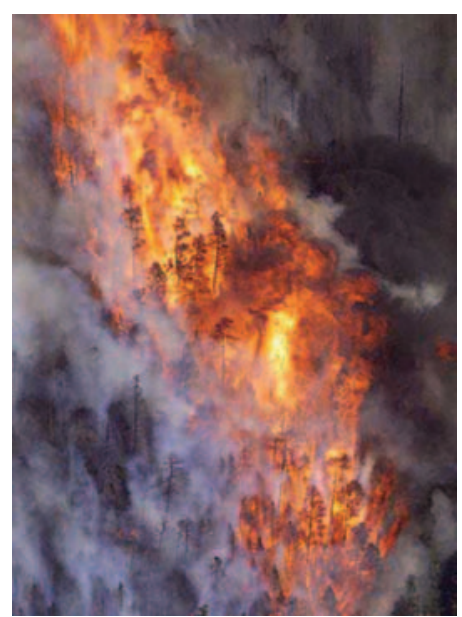

(A) Forest fire

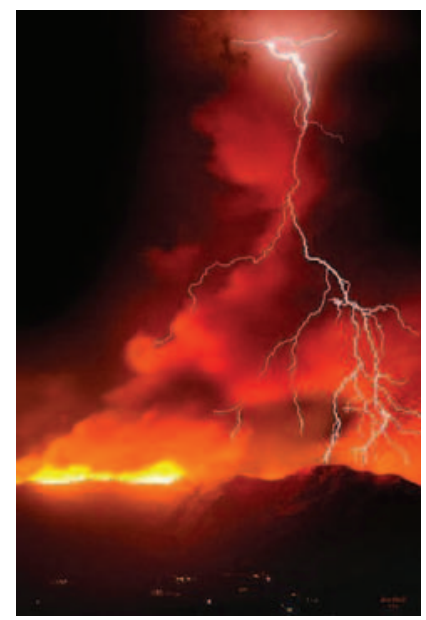

(в) Fire and storm

Figure 55. Forest fires.

Indonesia, there was an 8.7 magnitude earthquake (Figure $56 \mathrm{~B}$ ), which came only three months after the devastating magnitude 9.0 earthquake of December 26, 2004 which occurred in the same region. The seismic signatures of underground nuclear explosions and earthquakes are typical and clearly distinguished from each other (Figure 57).

There are many small meteors striking the Earth every day, and most of them burn in the Earth atmosphere, which acts like a protective shield. Larger meteors strike the Earth very rarely. The Baringer Meteorite Crater near Winslow, 


\begin{tabular}{|c|l|}
\hline Value & Rating Explanation \\
\hline 10 & Extraordinary \\
\hline 9 & Outstanding \\
\hline 8 & Far-reaching \\
\hline 7 & High Quality \\
\hline 6 & Noteworthy \\
\hline $\mathbf{5}$ & Intermediate \\
\hline 4 & Sensible/Good \\
\hline 3 & Minor/Average \\
\hline 2 & Low/Below Average \\
\hline 1 & Insignificant/Poor \\
\hline
\end{tabular}

(A) Richter scale

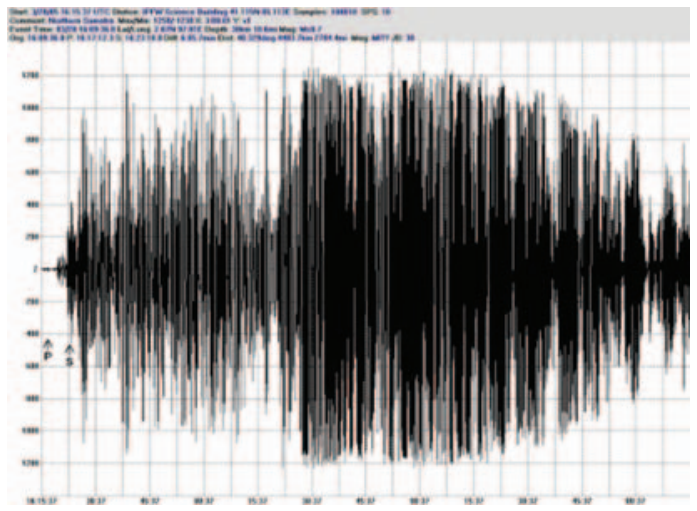

(в) Seismograph of earthquake

Figure 56. Richter scale and seismograph of a N. Sumatra earthquake.

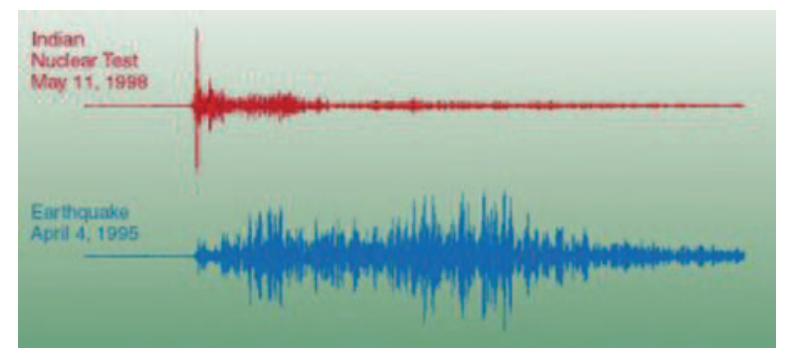

Figure 57. Seismographs of a nuclear test and an earthquake.

Arizona (Figure 58), is nearly one mile across, 2.4 miles in circumference and more than 550 feet deep.

\subsection{Electricity}

The electricity, the field and the current, is produced in nature by the electric eels (Figure 59) and by the lightnings (Figure 60). The electric eel can also sense electric fields, in particular, those produced by other electric eels. The electric eel uses these fields to electrocute (shock) its prey, and weak fields to interact with other electric eels. The electric eel can grow to 8.2 feet (2.5 meters) in length and discharge more than 600 volts of electricity. Getting shocked by an eel can cause respiratory paralysis and cardiac failure. 


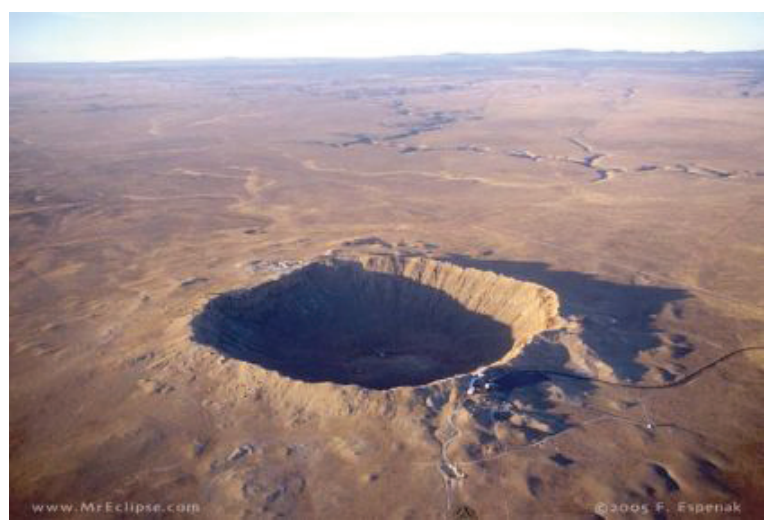

Figure 58. Arizona Meteor Crater.

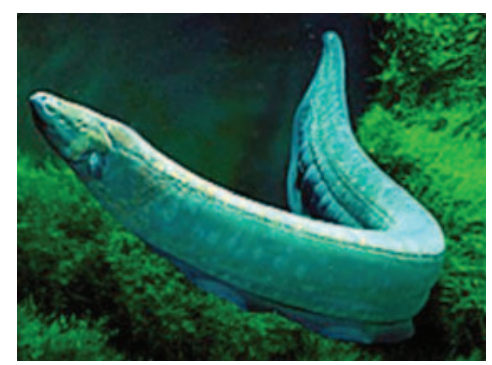

(A) Electric Eel

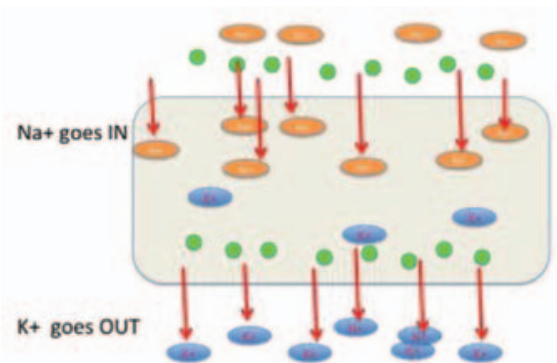

(в) Charge Modeling

Figure 59. Electric Eel - Electrophorus Electricus.

The electric fields are created between clouds when they are charged in the opposite, or between clouds and ground. They charges result in short circuits called lightnings, which can ignite forest fires (Figure 60 B), destroy buildings, and hurt or kill people. The people who survived a stroke by lightning created a community. Some of the members meet every year. The patterns left by lightning on human body are called Lichtenberg figures (Figure 61A). These figures are similar to photographs of electrical discharges created in laboratories (Figure 61B). Small lightnings (or, large sparks) are made in laboratories using the Van de Graaff generators (Wikipedia: Van de Graaff generator).

A special kind of lightning is the ball lightning (Figure 62A), which may appear after a storm. It is very rare, not yet fully understood, and we have not been able to create it in a laboratory. A weak static electricity (electric field) can be easily produced by combing a dry hair (Figure 62 B). 


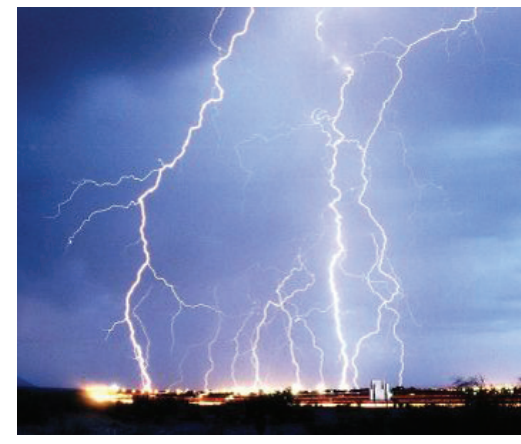

(A) Multiple Lightning

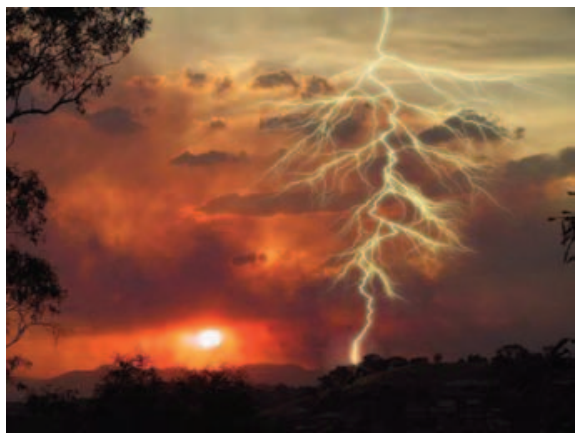

(в) Lightning Fire Starter

Figure 60. Lightnings.

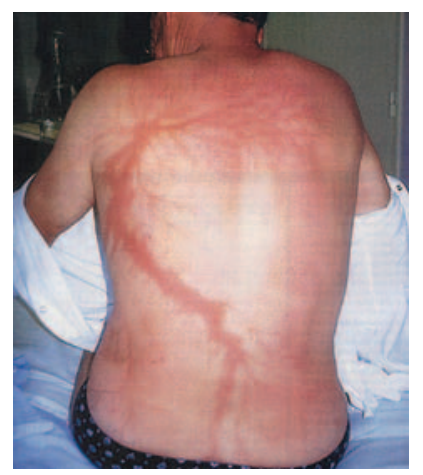

(A) Lichtenberg Figures

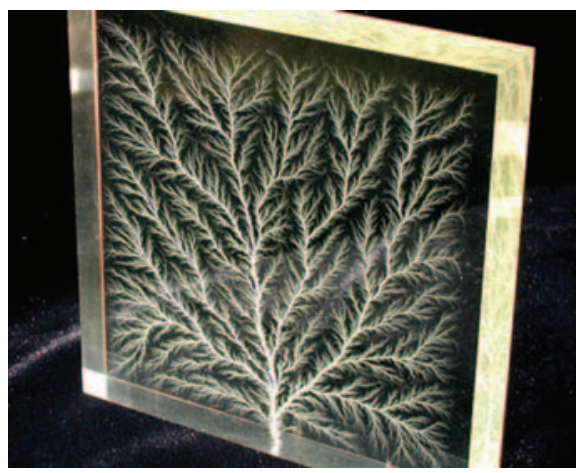

(в) Electrical Discharge

Figure 61. Patterns of Electrical Discharges.

The effect on a leaf or another non-conductive object exposed to a suitable level of static electricity can be photographed in a dark room. This imaging technique is known as the Kirlian photography, or aura imaging (Figure 63A). The Kirlian photographs are mysteriously beautiful, but the technique requires more rational exploration (Wikipedia: Kirlian Photography).

The imaging which also uses the electrostatic fields had been developed for black-and-white and color printing. The electrophotography is commonly known as the laser printing and is used in plain paper faxes, printers and copiers. The laser technology uses a photoconductor drum, electrostatic charges, toner and fusion to transfer the image to a material. For example, HP LaserJet Pro 100 color MFP-M175nw office printer uses the laser beam and the electric field 


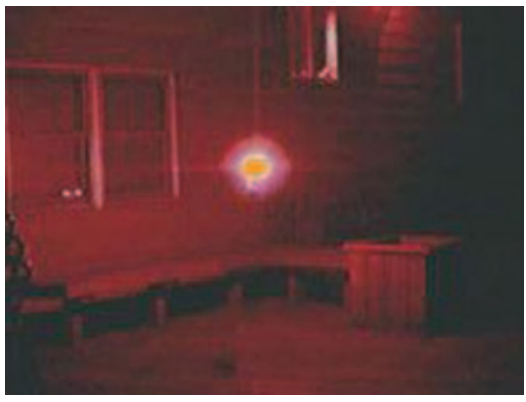

(A) Ball Lightning

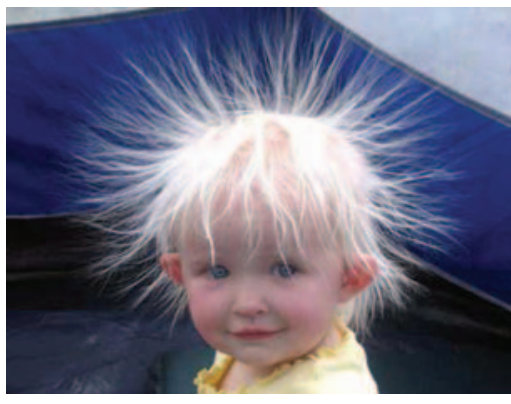

(в) Static Electricity

Figure 62. Ball lighting and static electricity.

(Figure 63B). This technology is complex, but mature, and laser with electric fields perform the printing with amazingly fine resolutions.

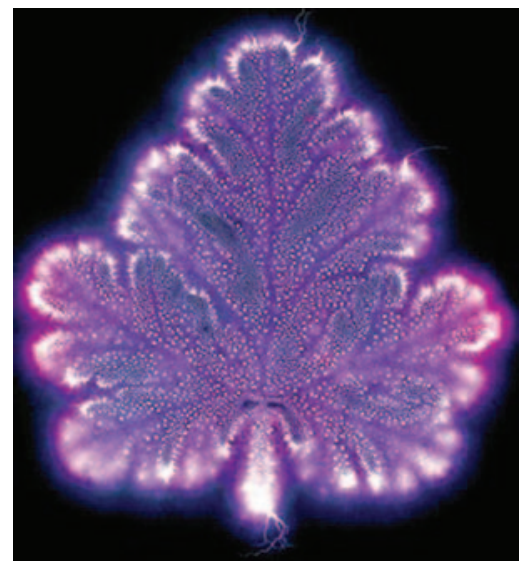

(A) Kirlian photography

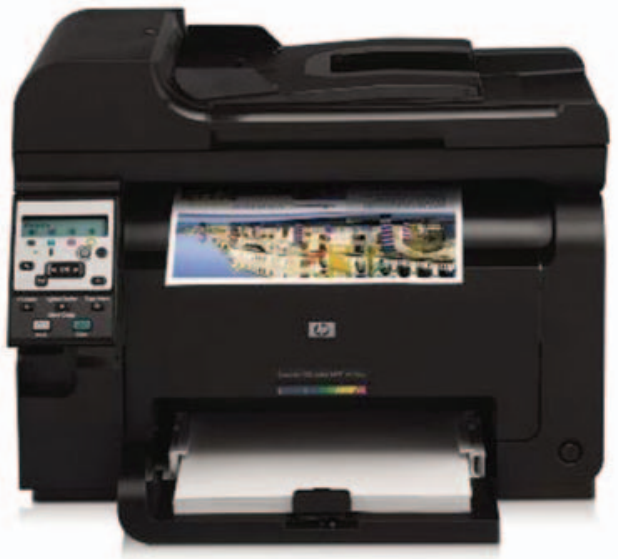

(в) HP LaserJet printer

FiguRE 63. Imaging using electrical fields.

The electricity became in last two centuries as important for factories, households, etc. as was the water in ancient times (and still is). The electricity is first generated by another source of energy (water, wind, coal, gas, nuclear, photovoltaic), and then it is transmitted and distributed to other locations, where it is used in appliances or to charge batteries of other appliances. 


\section{RASTISLAV TELGÁRSKY}

\subsection{Magnetism}

The magnetic field of the Earth has two poles, the north magnetic pole and the south magnetic pole. The field stretches far from the surface of the Earth and repels (deflects) the solar wind consisting of high energy particles emitted by the Sun (Figure 64). During the Sun protuberances the magnetic field of the Earth is

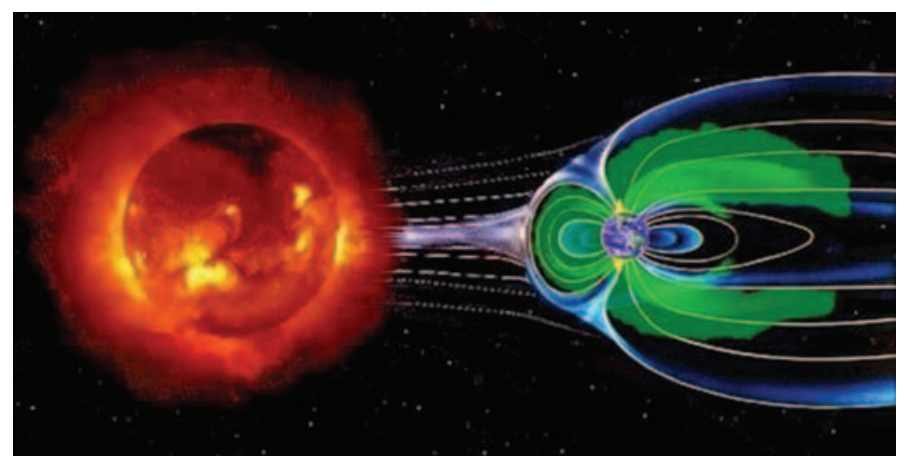

Figure 64. Magnetic field of the earth.

not strong enough to repel all particles, so we are getting disruptions of electronic communication systems. The magnetic field of the Earth also protects us from losing the atmosphere, which would be pushed away by the solar wind. The Earth magnetic field is created by periodic flows inside the Earth core. The inner core of the Earth is solid, but the outer core is liquid (Wikipedia: Structure of the Earth).

The Earth magnetic field was discovered via the mineral lodestone (loadstone, magnetite), which has a natural magnetic field and, when suspended, rotates itself along the Earth magnetic field. Only some metals have magnetic properties, for example iron, cobalt and nickel. Among rare metals it is neodymium, which is a component in many commercial products, such as headphones, speakers, etc. The compass, which is a magnetized steel arrow moving freely on a needle point, was inspired by the usage of lodestone (Wikipedia: Compass). The compass has been helping to navigate travelers during long travels, but now we have the Global Positioning System (GPS), which is more precise, and also available in smart phones. The magnetic poles of the Earth differ from the geographic poles, which are centers of the Earth rotation. The South Atlantic Anomaly (Wikipedia: South Atlantic Anomaly) is an area where the Earth's inner Van Allen radiation belt comes closest to the Earth's surface dipping down to an altitude of $200 \mathrm{~km}$ (124 mi). NASA has reported that modern laptops have crashed when space shuttle flights passed through the anomaly. 


\subsection{Weather Patterns}

The weather patterns are of great human concern since very ancient times, because especially agriculture depends on the Sun and the rain. First important pattern comes from the Earth rotation, which results in the alternations of the day and the night. During the course of the day the sunlight spectrum changes, in particular, the amounts of infrared and ultraviolet radiations change too. The light intensity can be measured by photovoltaic cells, which are also used to convert the light to the electric current. Clouds (Figure 65) are created by condensation of humidity up in the air, where the temperature is lower than in the lower elevations. The density of clouds is mathematically modeled similarly to the smokes using 3D probability density distributions.

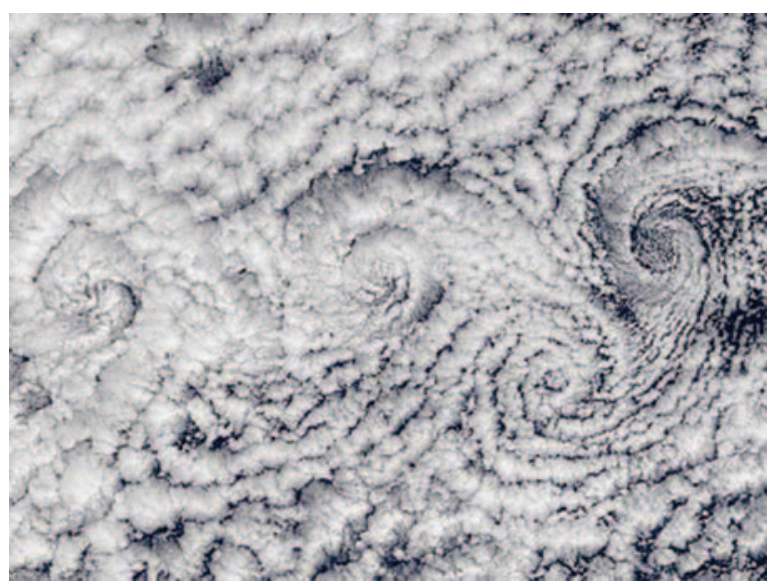

(A) Von Karman spiral clouds

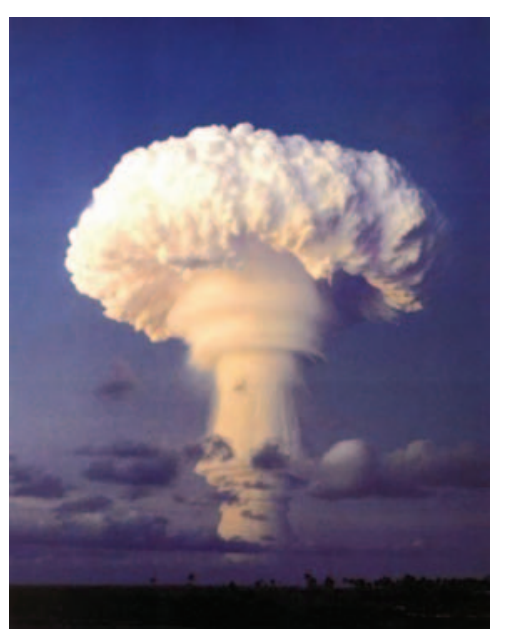

(в) Nuclear mushroom cloud

Figure 65. Clouds.

The rain is one of the least predictable element of the weather. If there is not enough rain, we must build irrigation canals and/or pipes to water the fields by flooding, sprinkling, or dripping. The humidity comes from earlier rains or lakes or seas, and it is necessary for creation of new rains. The forests and mountains help to create clouds, and consequently, rains. The air temperature typically goes up until a middle of the day, and goes down toward the evening. The variation of temperature is larger for Spring and Fall, then for Summer and Winter. The wind brings the changes of weather from lakes, mountains, oceans, as well as from deserts. The wind velocity is a compensation for the difference in temperatures of remote locations. Rapid winds create storms. The storms without water are known as sand or dust storms. 
Some extremely patient photographers are able to catch the following phenomenon: at the end of sunset, when the Sun just disappears behind the horizon, the sunlight produces a green flash at the last seen Sun location (Figure 66).

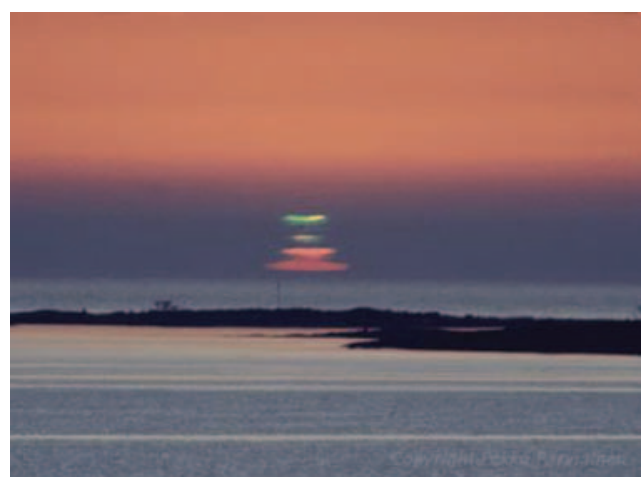

Figure 66. Green flash during a moment of sunset.

Another interesting natural light displays in the sky are the auroras (Figure 67), also called northern lights, which consist of continuous and fluidly changing color light patterns in the air. The aurora is caused by the ionization of air particles from the collision between the solar wind and the Earth magnetosphere.

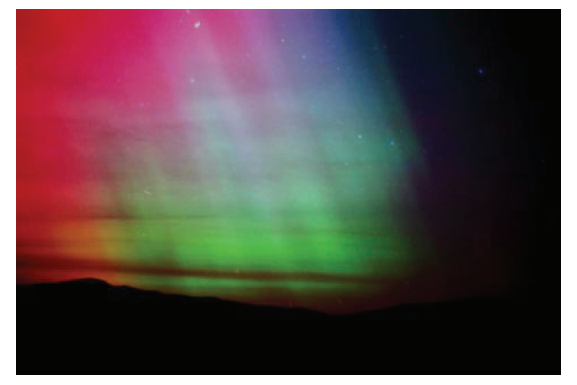

(A) Aurora

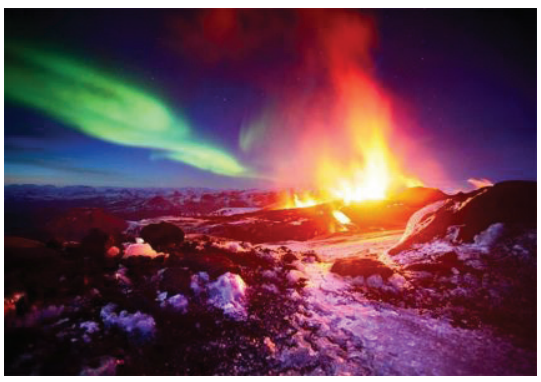

(в) Aurora and Volcano

Figure 67. Auroras.

Modeling and forecast of weather patterns requires the fastest supercomputers, which must collect data from many locations. The weather prediction is very important for air travel, agriculture, open-air social and sport events, etc. 


\section{Life on Earth}

\subsection{Life Forms and Organisms}

All living creatures strive for survival, and interact with other creatures and environment. There are many cases of interdependence of species, including symbiosis and parasitism. It turns out that a human body consists of 1 to $2.6 \mathrm{~kg}$ of bacteria, which are necessary for the human body metabolism, especially for the digestion of food. Moreover, the number of bacteria is larger than the number of cells in the human body, but the bacteria are much smaller than the human cells. However, not all bacteria are useful. Some of them carry or cause diseases, as do also the viruses. The structures of human lungs and kidneys are very complex tree-like structures (Figure 68). The blood circulation system brings oxygen

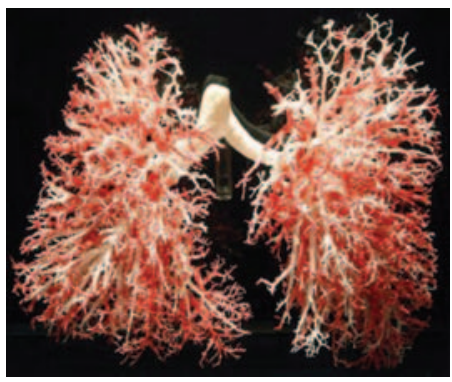

(A) Human lungs

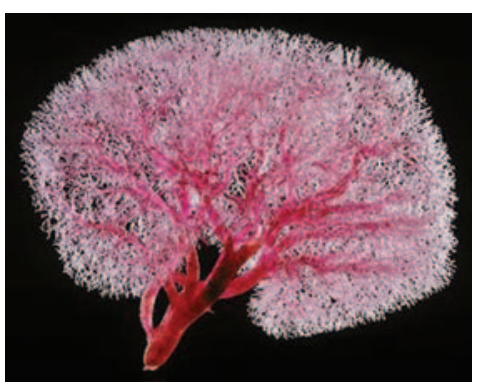

(в) Human kidney

Figure 68. Lungs and kidneys are tree-like structures.

and nutrients to body tissues, and removes carbon dioxide and other "burnouts" from the system. The bones and muscles support the posture and mobility functions. The neurons process the impulses from sensors and send control impulses to muscles, and/or to other organs. The five senses of mammals provide complex information about the environment.

The artificial muscles perform linear motion, and have been developed for prosthetic and industrial applications. They are based on various principles: hydraulic, pneumatic, piezoelectric, ultrasound, magnetic levitation, etc.

The tissue $3 D$ printing of human body organs started with ink jet printers, when the ink was replaced by a liquid life tissue. The tissue printers create parts of human body, which are used for reconstruction after an accident or a disease.

The $3 \mathrm{D}$ printing is also used to produce industrial parts. It is a rapidly developing and promising technology. Similarly to 2D copy machines (laser copiers), the object to be copied is first scanned with a laser beam from all directions. Then the surface of the object is reconstructed by computer algorithms. Finally, 


\section{RASTISLAV TELGÁRSKY}

it is $3 \mathrm{D}$ printed with special materials, which are liquid like an ink. The tiny liquid drop quickly solidifies when it lands on the created object.

\subsection{Structures in Nature}

There are many 1D, 2D and 3D structures in the nature such as tessellations, partitions, decompositions, repeating patterns on strips, etc. Honeycombs (Figure 69) are hexagonal structures built by honeybees from bees wax. The perfectness of honeycombs and bee honey are awesome.

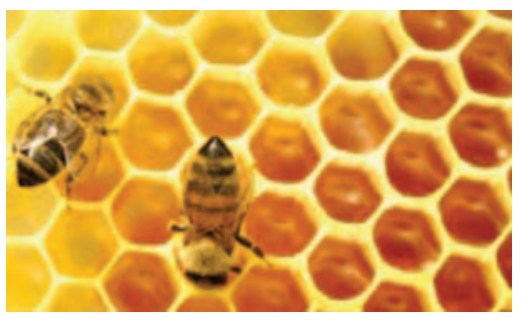

(A) Bees in beehive

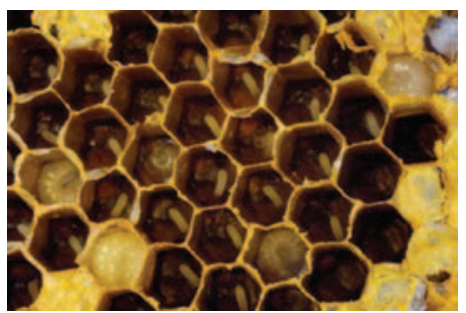

(B) Honeycombs

Figure 69. Bees and honeycombs.

The gallium nitrite (GaN) growing on sapphire (Figure 70A) also has a hexagonal structure, although with small random variations shown in 20,000x magnification. The graphene (Figure [70 B) consists of a hexagonal sheet of carbon atoms.

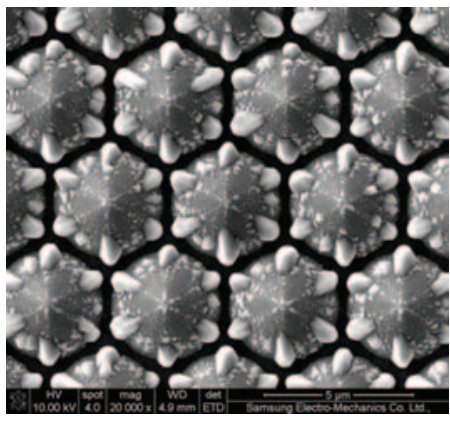

(A) GaN on sapphire

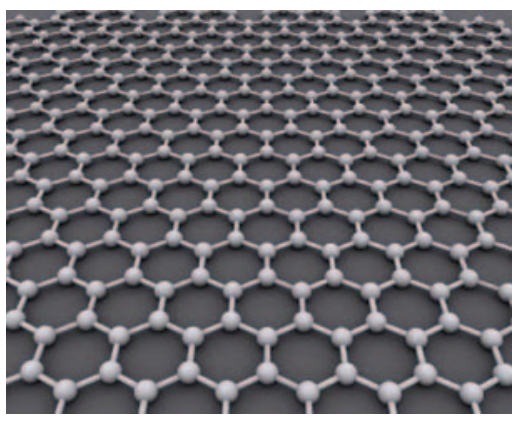

(в) Graphene model

Figure 70. Hexagonal engineering structures.

The skins of reptiles, compound eyes of flies, and human lung alveoli form hexagonal nets. The Sunbeam snake has a very clear hexagonal skin pattern 
(Figure [71). The human muscle cells join in close-packed hexagonal pattern to act in concert in the striped muscle.

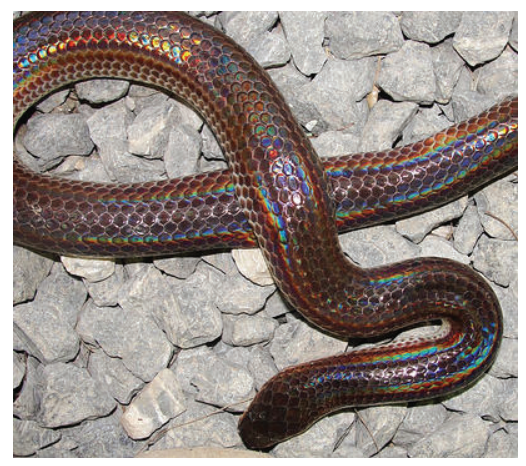

Figure 71. Hexagonal skin pattern of Sunbeam snake.

Tessellations with random variations are found in mud cracks (Figure [72). When the rain water evaporates, the surface contracts and creates breaks forming the edges of the tessellation.

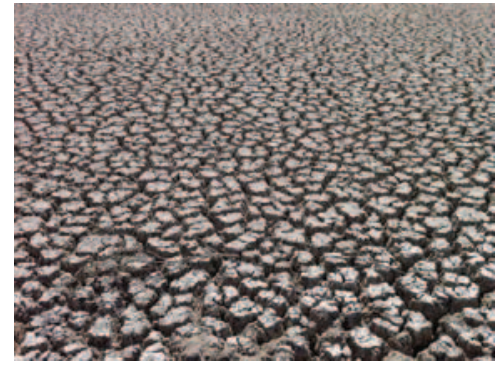

(A) Mud Cracks A

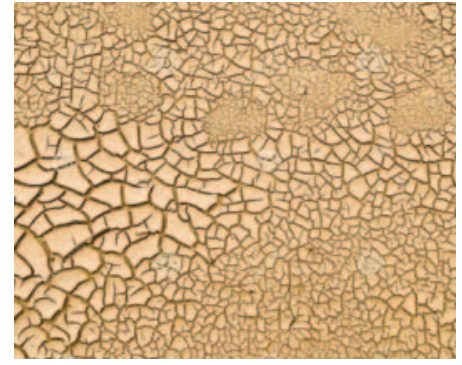

(B) Mud Cracks B

FiguRe 72. Mud Cracks.

Wind creates regular patterns on sand, for example, at White Sands National Monument, New Mexico, U.S.A. (Figure $73 \mathrm{~A}$ ).

Lichen is a composite organism showing beautiful tessellations (Figure 73B). It usually grows on trees, rocks or boulders (Wikipedia: Lichen).

The animal skin, feathers and body cover patterns have enormous variety. We selected just two examples. The male peacocks attract the mates with the extended and repeating patterns in their plumage (Figure 74A). Pangolin is a mammal with a body armor made of large, hardened, overlapping plate-like scales 


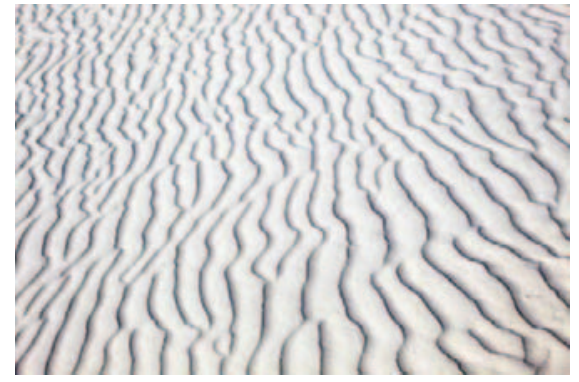

(A) Sand patterns

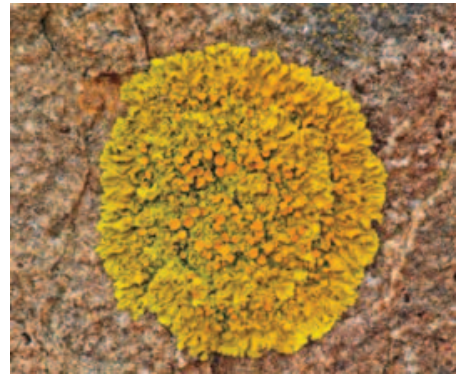

(в) Lichen

Figure 73. Sand patterns and Lichen colony.

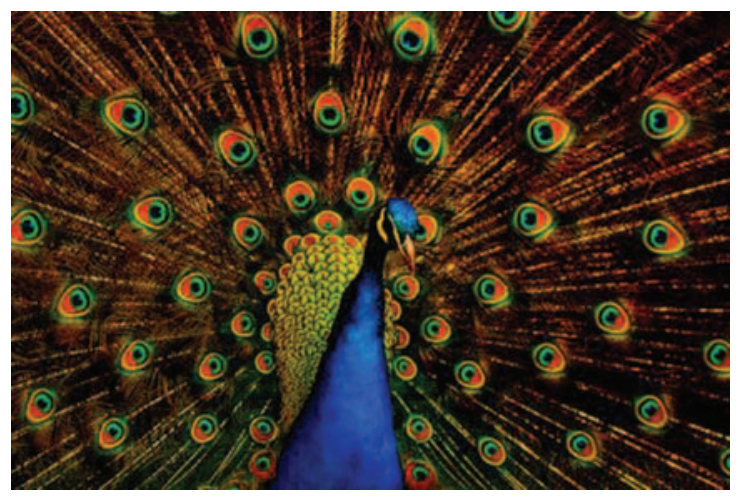

(A) Peacock feathers

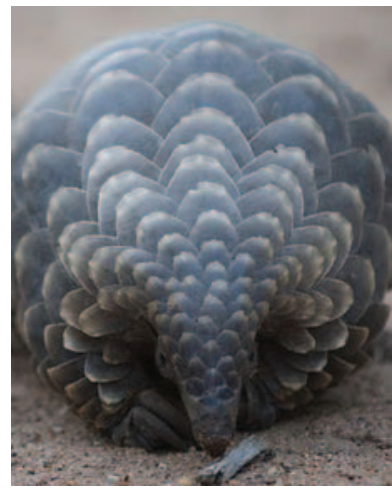

(в) Pangolin scales

Figure 74. Patterns on peacock and pangolin.

(Figure $74 \mathrm{~B}$ ). The scales are protecting it from predators. Pangolin is an endangered species.

There is a huge variety of corals. Figure [75] contains just three samples. The pollution and global warming destroys coral reefs at many locations.

Siphonophore is related to the jellyfish and corals (Figure 76). It is a continuous chain of specialized polyps - the individual animals that grow from one another in an organized colony. Some polyps in the colony are devoted to feeding, some are armed with stinging cells to snag fish or invertebrates, and others are devoted to locomotion, propelling the whole group with a continuous pumping motion, while some polyps exist only to reproduce.

There are cases when people invented technical devices, and only later discovered them in the nature. One of these is the flagellum motor (described earlier), 


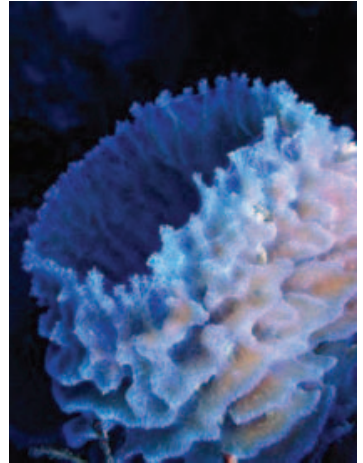

(A) Blue Coral

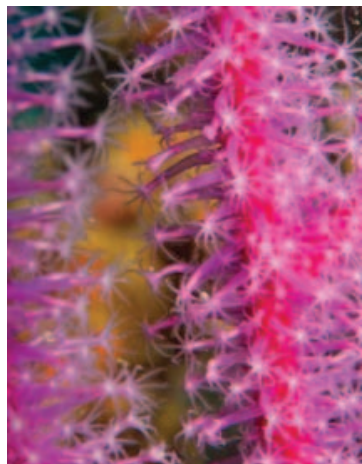

(в) Purple Coral

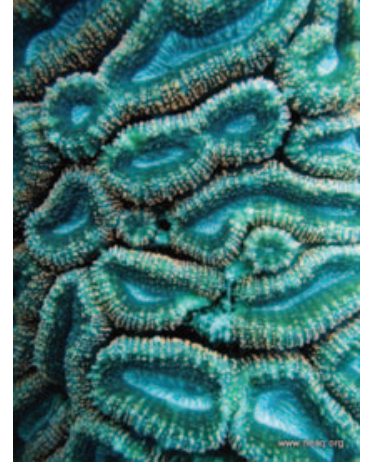

(c) Green Coral

Figure 75. Corals.

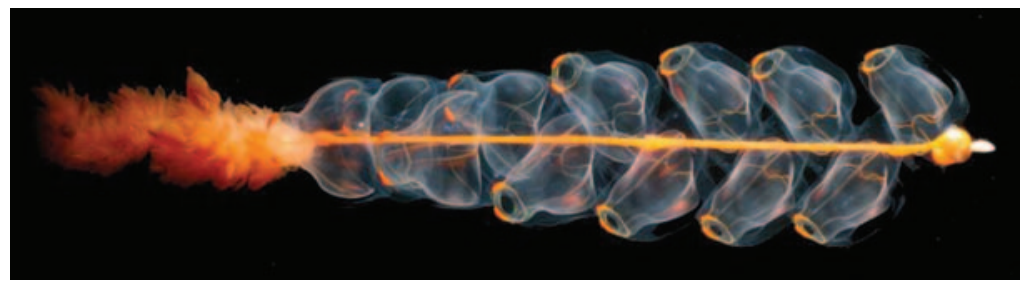

Figure 76. Siphonophore.

and another is the biological gear found in planthopper insect Issus (Figure 77). The primary role of the gears is to ensure that the hind legs move synchronously within microseconds of each other.

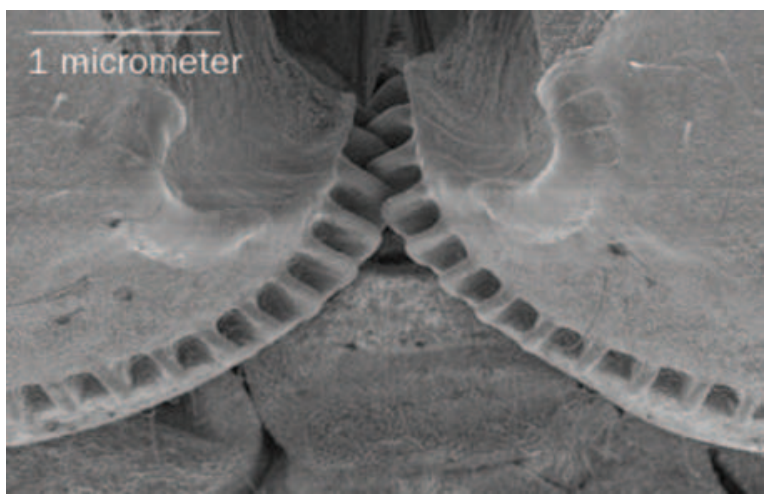

Figure 77. Biological gears of planthopper insect Issus. 


\section{RASTISLAV TELGÁRSKY}

Bamboo is an incredible green plant (Figure 78A ). It is as strong as steel, more sturdy than concrete, and grows to timber size in a year. Drawing inspiration from the structure of bones and bamboo, researchers have found that by gradually changing the internal structure of metals they can make stronger, tougher materials that can be customized for a wide variety of applications - from body armor to automobile parts. The gradual interface of the large and small grains (Figure [78B) makes the overall material stronger and more ductile, which is a combination of characteristics that is unattainable in conventional materials.

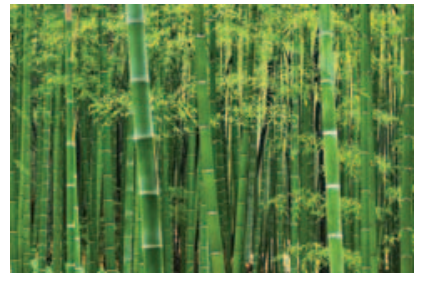

(A) Bamboo plants

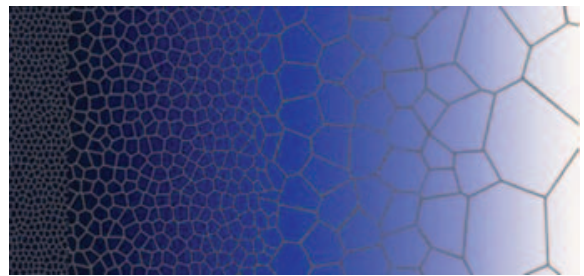

(в) Gradient structure

Figure 78. Bamboo plants and gradient structure.

\subsection{Changes and Evolution}

The life on Earth goes through perpetual cycles of changes broken only by death of individuals and species. The individual life cycle is: the birth, the growth, the sustain, the decline, and the death. Almost all patterns in currently living individuals are inherited from their parents. The changes in the individuals are slow, and some of them are not inherited. The difficulty with the theory of evolution of species is that the vast majority of living organisms do not leave shells, bones, or another firm structure to be investigated thousands and millions of years later. Consequently, we have extremely incomplete and very biased samples of the past life on Earth. It has not been definitely determined whether the life on the Earth was created during unusual electrochemicalthermal reactions on Earth, or it was brought, say, by meteors, from other planets or from other stellar systems (Wikipedia: Panspermia).

Richard Dawkins ( [7, p. 75) explains that Darwinism in not a theory of random chance. It is a theory of random mutation plus non-random cumulative natural selection. And, on page 139: Darwin famously used the eye to introduce his discussion on 'Organs of extreme perfection and complication'. Dawkins' Chapter 5 is entirely about structures of eyes in various living creatures; he compares the structures and a possible development of levels of complexity.

John Maynard Smith [13] initiated mathematical modeling of evolutionary processes via evolutionary games. Later he focused his attention to evolutionary 
genetics [14]. The evolutionary games became and are a very popular subject for mathematical modeling (Nowak [15]).

\subsection{Life Cycles and Reproduction}

The life cycle of a single organism has impact on the genetic information passed to its descendants, because of its exposure and adaptation to fast and slow changes of the environment. These changes can be short term or long term. The life cycles can be simple or complex. For example, the plants grow flowers, the flowers gets pollinated, grow seeds, the seeds get to a different location, where they touch the soil, start sprouting, and the new plants grow from the sprouts. The insects go may go through different phases and forms. For example, the monarch butterfly lies fertilized eggs, from which develop caterpillars, which grow and at maturity they create pupae. Inside pupa everything dissolves, then reorganizes with certain control centers, and a butterfly is created, which breaks the pupa, gradually opens the wings, and then flies without learning to fly. It is unfortunate, that mathematicians prefer to study stochastic processes rather than these interesting and complex natural processes.

It is the reproduction of organisms which may pass the individual adaptation changes to the offsprings. The reproduction can be sexual and asexual. One form of asexual reproduction is parthenogenesis, in which a female gives birth without conception. Parthenogenesis may exist along the sexual reproduction and enables the continuation of life when a male is not available. It was detected in Bonnethead sharks, Komodo dragons, rock lizards, boa constrictors, mice, aphids, etc. Other forms of parthenogenesis occur when two egg cells fuse after meiosis. The cell fusion is rather rare in the nature. Snails, earthworms and many sea creatures are hermaphrodites. Their sexual act results in mutual fertilization. The reproduction extends the life of an individual organism by creating similar organisms which start new life cycles.

\subsection{Heredity and DNA}

The natural selection is widely accepted (Wikipedia: Natural selection). The discovery of the double helix in DNA structure pointed to the parts of cells which carry the crucial genetic information (Figure 79). The DNA (Figure 80A A) is composed of 64 six-part codons, or, genetic words. The $R N A$ (Figure $80 \mathrm{~B}$ ) has 7-part codons (Wikipedia: Genetic code). The allele (allelomorph) carries the combination of male and female alleles. The mutations are errors in DNA replications, but the error rates are usually very low: 1 error in every 10-100 million bases. Gregory Chaitin ( [5], p. 66) writes: So I think of the DNA as a computer program for calculating the organism. Viruses have a very small program, single-celled organisms have a larger program, and multi-celled organisms need an even larger program. 


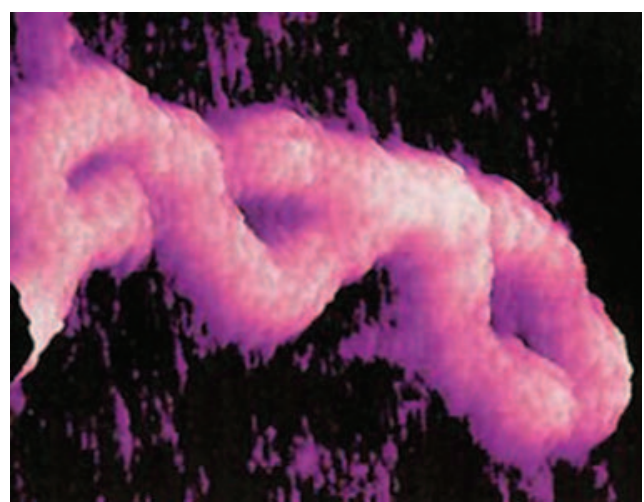

Figure 79. DNA magnified 850,000x in scanning electron microscope.

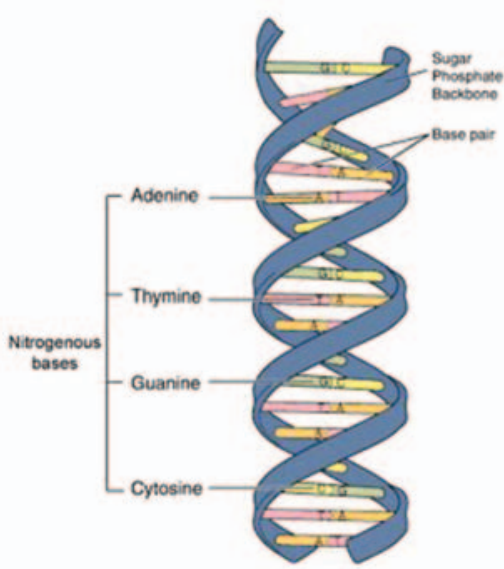

(A) DNA structure

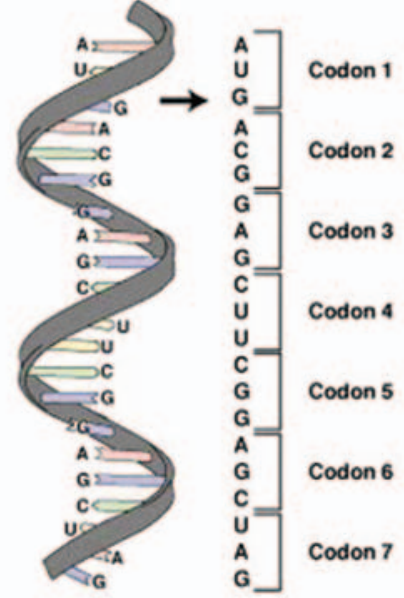

(в) RNA structure

Figure 80. DNA and RNA structures.

\subsection{Population Dynamics}

Keeping records on population growth was done in ancient countries including Mesopotamia (Wikipedia: Mesopotamia) and Egyptian kingdoms (Wikipedia: Ancient Egypt). The purpose was to match the agricultural yield to the changing population size. Malthusian population theory is characterized by the statement that the production of the food is getting behind the increasing population. Thus, in consequence, the insufficient production of food limits the population growth. 
Pierre-François Verhulst introduced the logistic equation (Figure 81) for the population growth in which the initial exponential growth is followed by a sustain, and then by a saturation (all continuously). The simplest form of the logistic curve is

$$
\frac{d N}{d t}=\frac{r N(K-N)}{K}
$$

where $\mathrm{r}$ is the rate of maximum population growth and $\mathrm{K}$ is the carrying capacity, i.e., the maximum sustainable population.

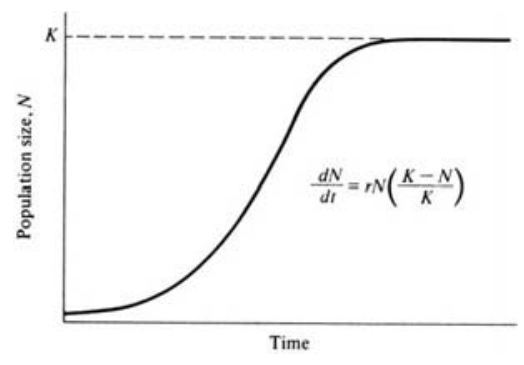

Figure 81. Logistic equation.

Vilfredo Pareto observed that the distribution of wealth in several Italian cities follows a power law (Figure 82). The probability density function (histogram) of Pareto distribution (Wikipedia: Pareto distribution) is

$$
f(x)= \begin{cases}\frac{\alpha x_{m}^{\alpha}}{x^{\alpha+1}} & \text { if } x \geq x_{m} \\ 0 & \text { if } x<x_{m}\end{cases}
$$

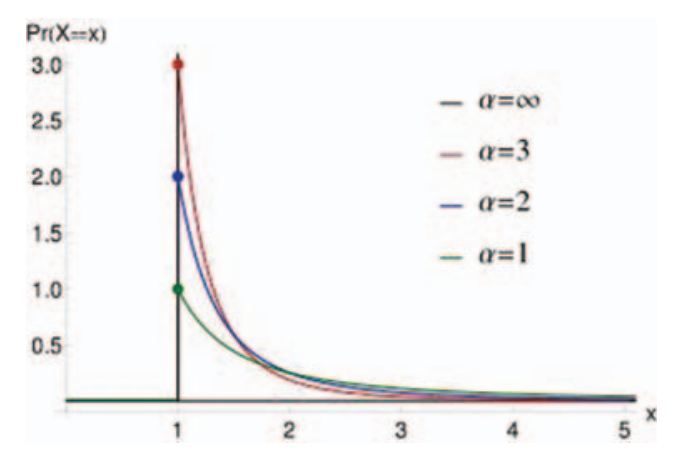

Figure 82. Probability density functions of Pareto distributions. 
Pareto also formulated the principle known as the Pareto 80/20 Principle: 20 percent of the people own 80 percent of the wealth (Wikipedia: Pareto principle). This principle applies to surprisingly many situations, but it is not a law of the universe, such as are, for example, the Newton laws in classical physics.

The Pareto distribution may show up in contemporary income distributions, but the social engineering, which helps the most poor, changes the decreasing function into one having the maximum somewhere in the interval of the middle class incomes (Figure 83). Zipf's law is similar to Pareto distribution (Wikipedia:

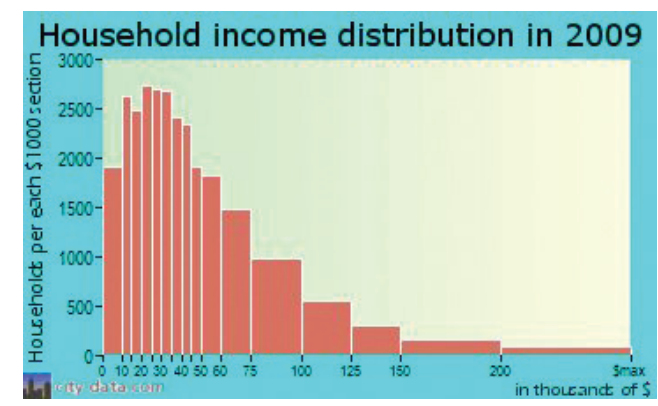

Figure 83. Income distribution in Albuquerque, NM, 2009.

Zipf's law). Another path from the Pareto discovery is the relative species abundance studied in macroecology (Wikipedia: Relative species abundance).

\section{Eyes and Imaging}

Note: An early version of this section was published in [24].

\subsection{Eyes}

Eyes enable the perception of surrounding world without electrical, mechanical or chemical contact. The number of eyes ranges from zero to several thousands. Eyes have different configurations, complexity, and neural processing.

Earthworms have no eyes, but they do possess light sensitive organs - the receptor cells. The cyclops, also called waterflies, have only one eye. Fish, birds, mammals, and many other species have two eyes. Each eye has lens with variable focusing, retina and many neural connections to the brain. Some of these species have eyes on sides of the head so that they get large spherical angle of vision, while others have both eyes in front of the face to provide the stereo vision with field depth, and good estimation of sizes and distances. Notostracans Triops (tadpole shrimps) have 3 eyes: 2 compound eyes plus the larval nauplius eye. 
Honey bees and bumble bees have 5 eyes: 2 compound eyes, each composed of 4500 "little eyes" called ommatidia (Wikipedia: Ommatidium), and 3 simple eyes, called ocelli (Wikipedia: Simple eye in invertebrates) on top of the head (Figure 84A). Honey bees can see in ultraviolet light. Their vision is trichromatic like ours, but their visible spectrum is shifted toward the ultraviolet (westmtnapiary.com/Bees_and_color.html).

The sand spider Sicarius Hahni has 6 eyes. The jumping spiders, and many other spiders, have 8 eyes. The eye locations have various configurations, but typically 4 eyes are on the face and form very sharp images, while the other 4 eyes are mostly motion detectors. Figure $84 \mathrm{~B}$ shows the eye arrangement of the Hogna Wolf spider, where all 8 eyes are visible.

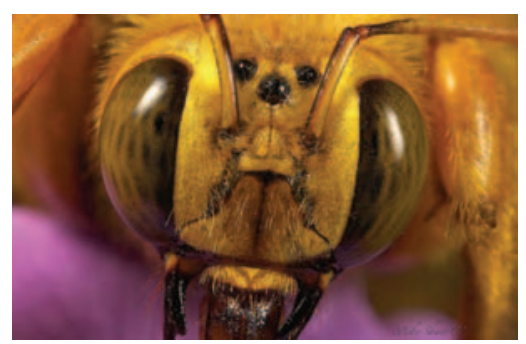

(A) Male Carpenter Bee

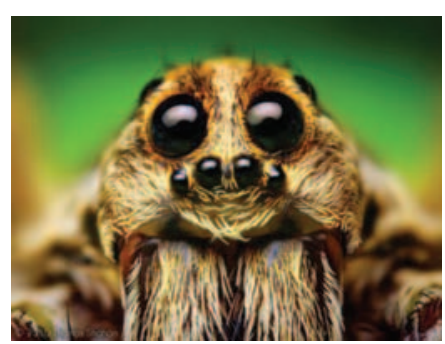

(в) Hogna Wolf Spider

Figure 84. Eye arrangements.

The starfish has 5, 21 or 40 arms (legs), and has an eye at the end of each arm (Figure 85A). Each eye is sensitive to light, but does not form an image.

Box jellyfish (Figure 85B) have of 24 eyes giving them a 360-degree field of vision (Wikipedia: box jellyfish). The jellyfish's eyes are arranged in four sets of six. Each set roughly corresponds to a 'side' of the animal's bell or main body. Each group of eyes are composed of two complex eyes, sometimes referred to as 'smart eyes' and four light sensitive pits. Their 'smart eyes' each have lenses, retinas and corneas, not unlike our own. However, the box jellyfish is one of the most deadly creatures to exist in our seas and oceans.

A single scallop (Figure 86A) can possess over a hundred eyes! The eyes are located strategically along the scallop opening, and no other configuration of eyes would give so useful image. Each eye (Figure $86 \mathrm{~B}$ ) is about a millimeter in diameter, and has a lens and a retina which is attached to a branch of the optic nerve.

The giant clam of the South Pacific, Tridachna gigas, has over 1000 eyes, but these eyes,unlike the scallop's eyes, are relatively simple photoreceptors.

The housefly, Musca domestica, has two compound eyes (Figure 87A), called ommatidia, capable of tracking movements up to five times faster than our own 


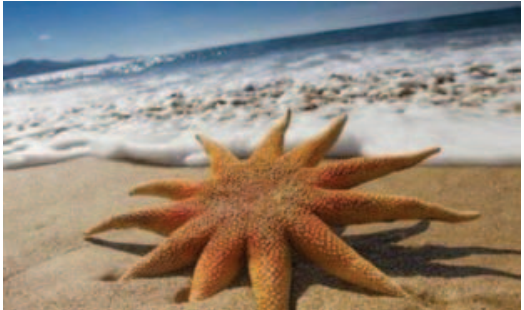

(A) Starfish with 11 eyes

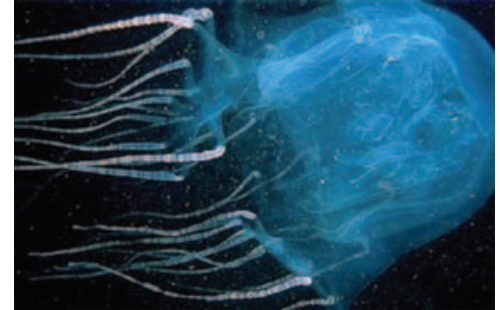

(в) Jellyfish with 24 eyes

FiguRE 85. Starfish and jellyfish.

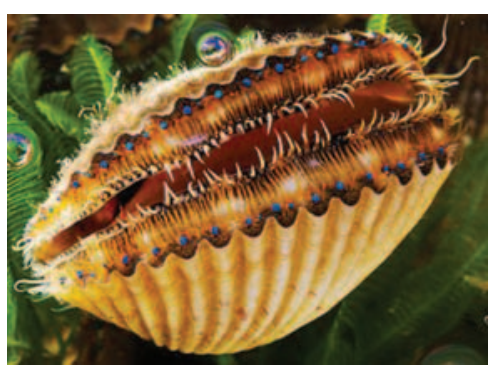

(A) Full view of a scallop

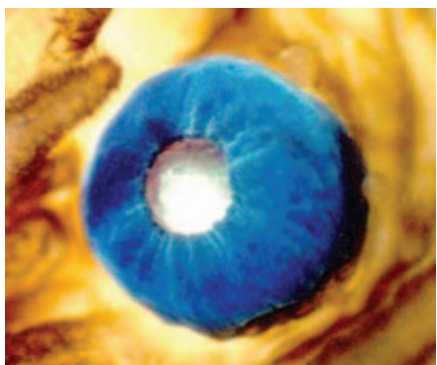

(в) Single blue eye

Figure 86. Scallop with hundreds of eyes.

eyes! Figure $87 \mathrm{~B}$ shows the compound eyes of a dragonfly (Common Darter). The fruit flies have very small compound apposition eyes that require neural processing. They can sense rapid motion approaching 200 cycles per second. A considerable image processing is confined to a very small space.

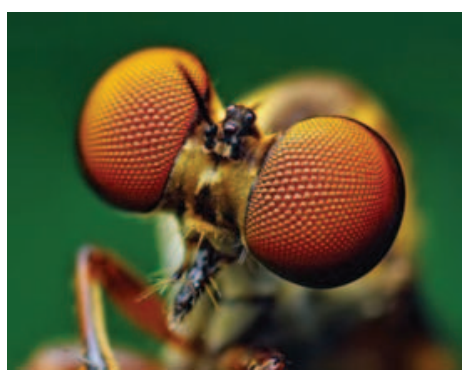

(A) Robber fly

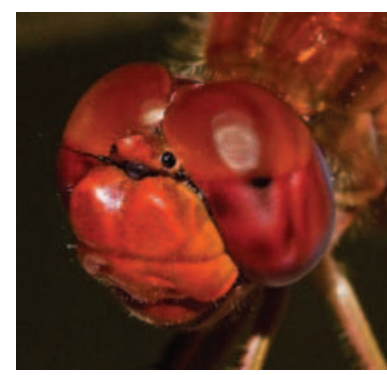

(в) Dragonfly

Figure 87. Compound eyes of flies. 


\section{MATHEMATICS AND ENGINEERING INNOVATION INSPIRED BY NATURE}

The compound eyes of insects are faster than eyes with lens and retina. U.S. Navy is studying fly compound eyes to help develop guidance systems for weapons, and more compact optical sensors (Figure 88). Hopefully, the intelligent vision processing will provide new technology for robotics, and other industrial or military applications. The cameras with compound lenses (Figure 88 A) imitate the compound eyes of insects. The 100 megapixel camera (Figure 88 B) is capable of producing images with $10,240 \times 10,240$ pixels.

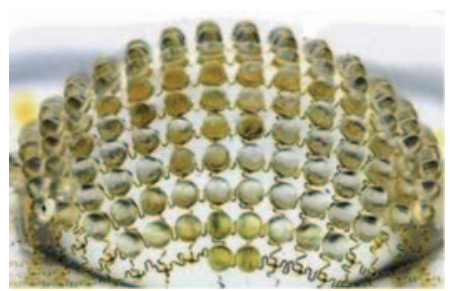

(A) Compound lenses

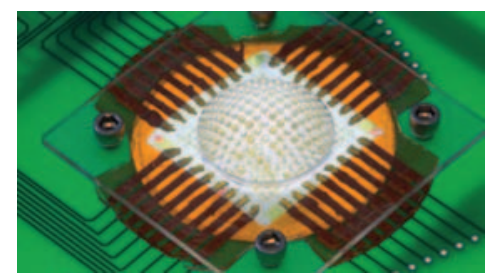

(в) Wide-angle lenses

Figure 88. Cameras inspired by compound eyes of bugs.

The fish called Stoplight Loosejaw (Malacosteus niger) has two bioluminescence spots, one emitting a low frequency red light, and the other bright green or yellow light (Figure 89). The illumination of its surrounding with the red light allows it to see around but be invisible, because other creatures cannot detect this light. When close to a prey, the fish lights up the bright bioluminescence

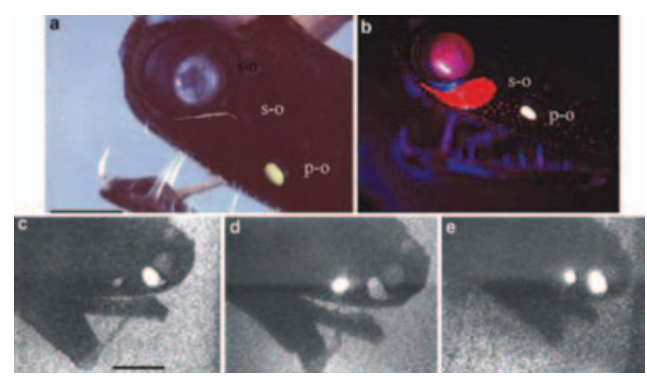

Figure 89. Stoplight Loosejaw uses bioluminescence from 2 spots.

spot to see the details before catching the prey. Another feature is the loose jaw, that is, the low jaw without the bottom allowing fast closing the mouth with sharp teeth. 


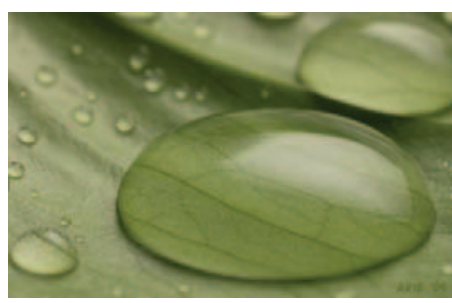

Figure 90. Water drops on a leaf.

\subsection{Optics}

A drop of water on a leaf works like a natural magnifying lens, but it has a considerable distortion (Figure 90).

The lenses cut precisely from a glass have more desirable properties. The purpose of lenses is the magnification of images of objects, with an exception of a door viewer, which minifies the images, and provides a much wider angle of view.

The microscope was invented by Antonie van Leeuwenhoek (Figure 91A), who immediately discovered a gallery of small living organisms. The single lens was later replaced by an array of lenses. An Olympus objective for a microscope is shown in Figure 91B for a comparison.

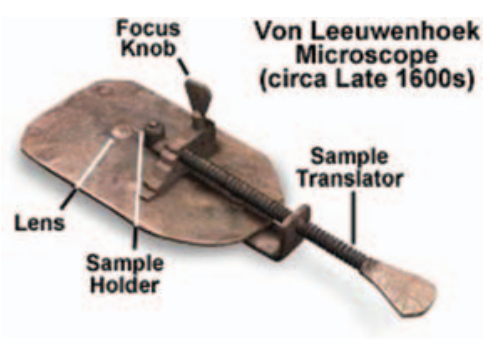

(A) Leeuwenhoek device

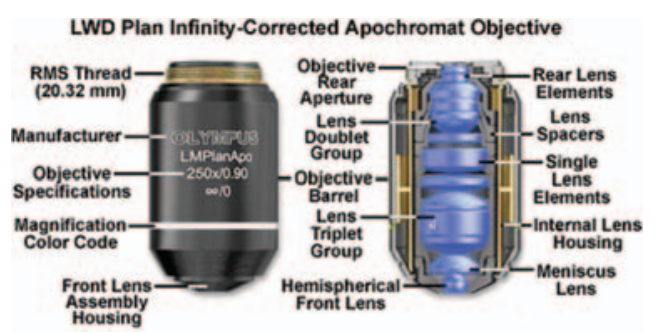

(в) Olympus objective

Figure 91. Comparison of microscope's lenses.

The research in chemistry, geology, biology and medicine is unthinkable without microscopes. Figure 92 shows a modern microscope connected to a sensitive digital camera and a large digital monitor.

Another breakthrough in science was the invention of telescope by Hans Lipperhey, a German spectacle maker, who combined curved lenses to magnify objects by up to 3 times. He received the patent in 1608. Galileo Galilei heard news of the telescope, and constructed his own version of it without ever seeing 


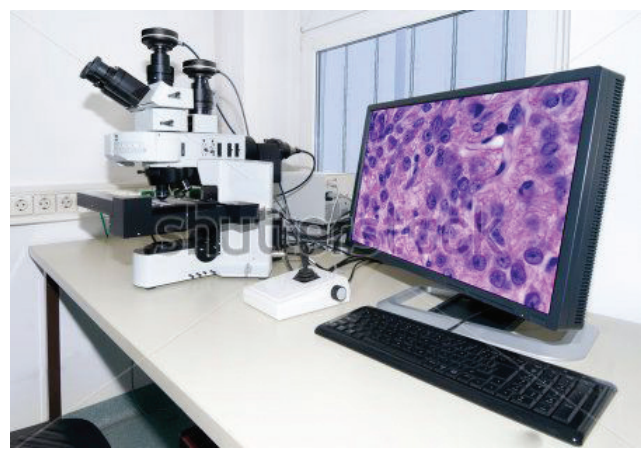

FigURE 92. Modern microscope with camera and monitor.

one. Instead of the initial 3 power magnification, he crafted a series of lenses that in combination allowed him to magnify things by 8, 20 and eventually 30 times (Figure 93). He soon discovered the rings of Saturn.

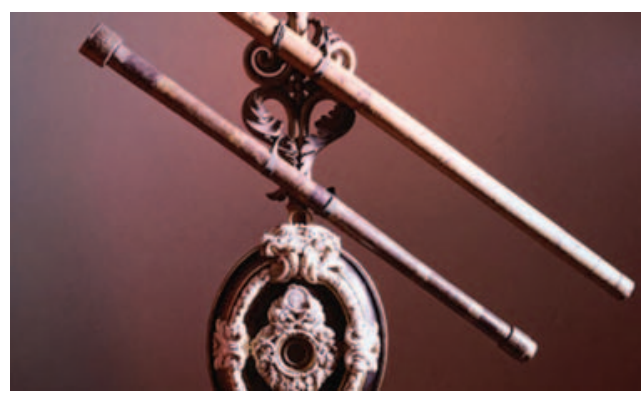

Figure 93. Galileo's telescope.

Another improvement of image quality is achieved by placing telescopes on tops of high mountains, or to the orbit of the Earth, like the Hubble Space Telescope (Figure 94A), or to the orbit of the Sun, or even farther in cosmic space. However, for many astronomy hobbyists and enthusiasts, the Meade telescope ETX70A with 882 tripod and software (Figure 94B) is of very high quality, and even it has the star/planet tracking system, called sidereal time. So, a large number of people have astronomical observatories in back yard or front yard of their houses, or they take trips out of town where the air is cleaner for the exploration of the night sky.

From telescopes for visible lights the development went to infrared, ultraviolet, $\mathrm{X}$-ray and radio waves telescopes. The infrared light better penetrates the Earth atmosphere than the visible light, but still, the Earth atmosphere acts like liquid lenses and distorts and washes the images from space. Therefore a technique was 


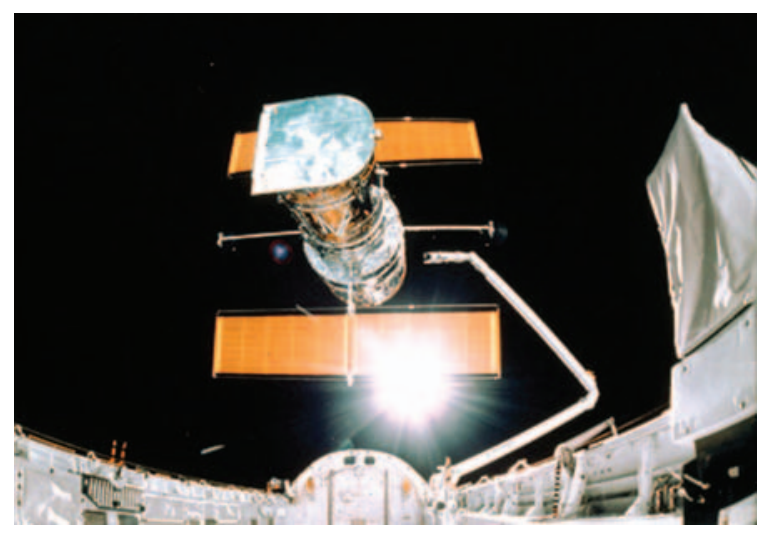

(A) Hubble Space Telescope

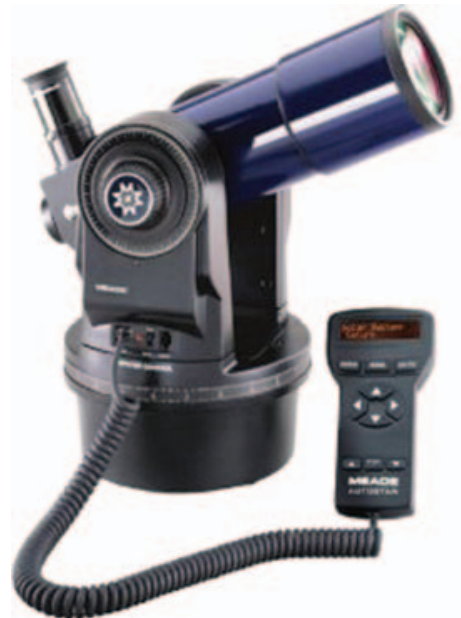

(B) Meade Telescope

Figure 94. Large and small telescopes.

developed to detect and correct the shifts of phases in image elements, where a flexible mirror is warped by electro-mechanical devices called actuators. This is called the Adaptive Optics System (Figure 95. Wikipedia: Adaptive optics). The result of the phase correction is seen in the infrared image of Neptune

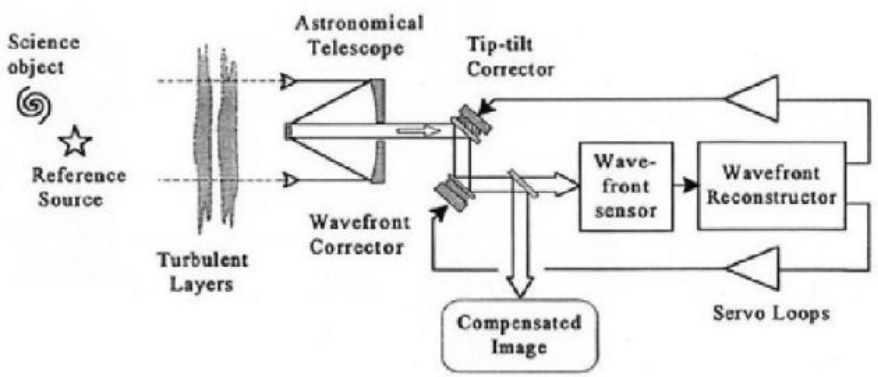

Figure 95. Astronomical Adaptive Optics System.

(Figure 96).

\subsection{Imaging}

The imaging requires a substantial electronic processing of light or invisible electromagnetic signals. The energy of electromagnetic waves coming from the space, except from the Sun, is very small. So, large arrays of telescopes or radiotelescopes are built and connected, so that computer algorithms can construct the 

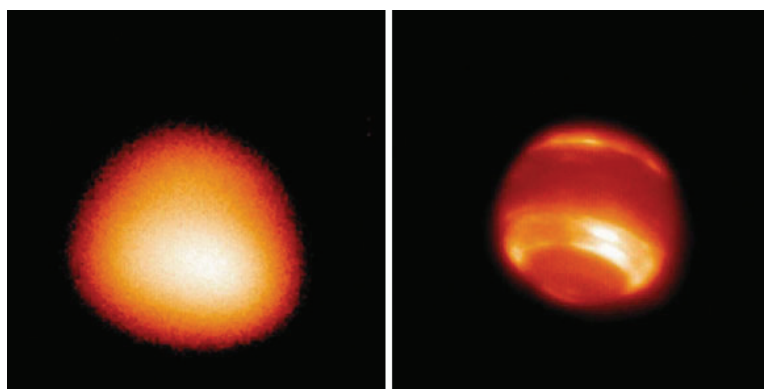

Figure 96. Infrared image of Neptune - without and with AO.

compound image. With larger energy per received bandwidth, the algorithms can even calculate the spectra of incoming light or radio waves. The analysis of these spectra allows for remote chemical analysis of the sources. In particular, there is a fascinating possibility of discovering a life on an Earth-like planet to a Sun-like star somewhere far from our solar system, or at least, to detect the physical and chemical conditions that may support the life forms.

In much lower frequencies, which propagate through the air, bats (Figure 97A) generate the ultrasound and reconstruct the range-Doppler images from its reflections. This well supplements their vision, and enables them to navigate and catch insects at night (Figure 97B).

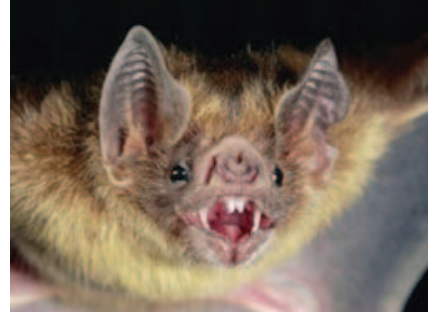

(A) Vampire bat

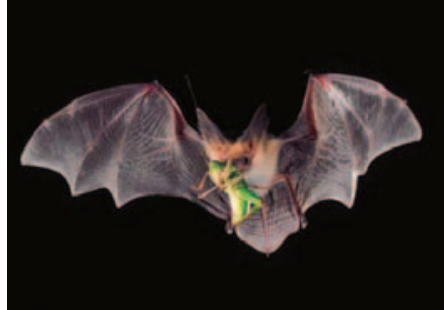

(в) Bat eating an insect

Figure 97. Bats.

The ultrasound imaging systems used in the medical diagnostic devices (Wikipedia: Medical ultrasonography) are very sophisticated extensions of bat's image processing, although the principle is the same: the ultrasound pulses are sent, reflected, received, and processed into images. The system consists of a cylindrical hand-held scanning device containing the ultrasound transmitter and receiver, which is connected to the computer processing unit with a real-time 


\section{RASTISLAV TELGÁRSKY}

display and a real-time recording system. The most important uses of the ultrasound medical system are the diagnoses of the heart (Figure 984), and monitoring the baby and the expecting mother health during the pregnancy (Figure $98 \mathrm{~B}$ ). However, it is also used in diagnostics of kidneys, bladder, gallbladder, thyroid, and other organs. There is a hand-held version of the entire image processing unit, which is not much larger than a smart phone (Figure 98C).

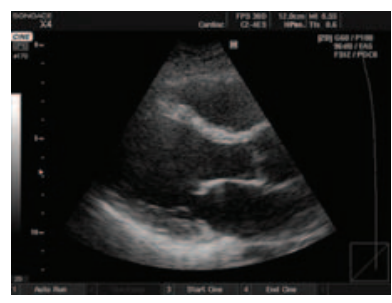

(A) Heart Valves

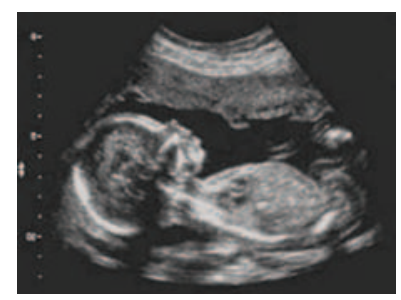

(B) Pregnancy

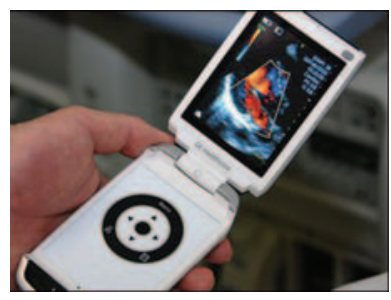

(c) Hand-held device

Figure 98. Medical ultrasonography.

The radar imaging system works similarly like the bat's ultrasound system, however, the radar can scan (sweep) a large area (a spatial angle), and thus it can construct the image of a very large scene. The invention of device called laser, which produces a narrow beam of visible or infrared light pulses, enabled the construction of an imaging system called ladar. Ladar uses the short-time Fourier transform, also called the time-frequency transform, to process the reflected pulses into the range-Doppler image, which is a $2 \mathrm{D}$ phase space, where the horizontal coordinate is the radial distance and the vertical coordinate is the radial velocity of the illuminated object. The standard optical image of a satellite is in Figure 99A, and the corresponding range-Doppler image is in Figure 99B.

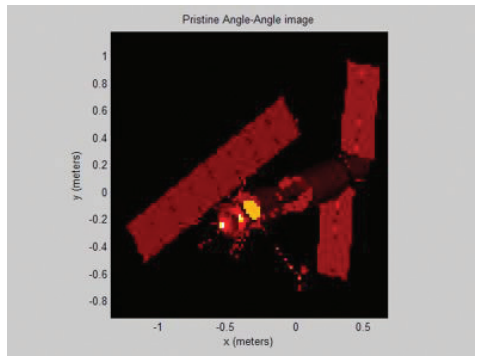

(A) Angle-Angle Image

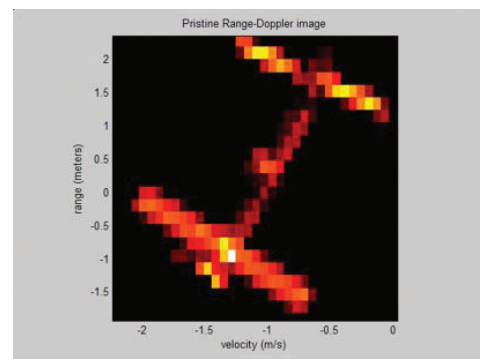

(в) Range-Doppler Image

Figure 99. Images of a Satellite. 
Stereo vision allows for depth perception and estimation of distances. However, the laser illumination of target provides an active and more precise estimation of the distance. The computer vision algorithms take a lot from eyes and compound eyes for processing the digital images. Panoramic images are created by stitching together shifted images to cover a larger view angle. The integration of images from multiple cameras is used in airplane cockpits. The planned Amazon's smartphone should have the total of 6 cameras, where 4 cameras will sense the hand gestures without the user touching the screen. Robots with vision sensors can perform complex functions such as a product assembly or reaching hard places. Hemispherical vision systems had been developed for monitoring and management of airports/airfields. This technology can be replaced by the multiple cameras modeling the compound eye of a honey bee. Multi-spectral vision systems put into one display the patches of images and pseudocolor images from different wavelengths, for example, from infrared or other invisible wavelengths.

The mantis shrimp in Figure 100 (Wikipedia: Mantis shrimp) has one of the most elaborate visual systems ever discovered in animal kingdom. Each of two eyes carry 16 photoreceptor pigments which allow to perceive both polarized light and multispectral images. Moreover, each eye possesses trinocular vision and depth perception.

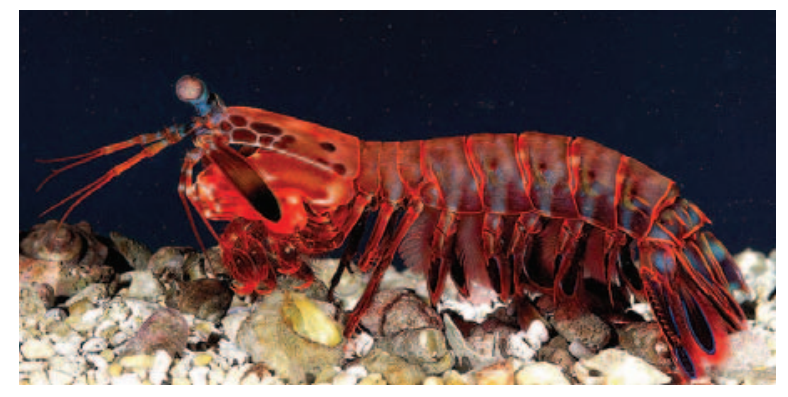

Figure 100. Mantis Shrimp, Odontodactylus Scyllarus.

Hyperspectral vision system is similar to the Mantis Shrimp visual system. The system splits the visible spectrum into disjoint bands, say, 224 bands (aviris.jpl.nasa.gov), and calculates the pixel intensities for each band. The resulting vector-valued image is also a stack of 224 images, or, one 3D image, called datacube (Figure 101A). Each of 224 bands has a specific sensitivity to the chemical structures of regions in the field of view. Note that there are 


\section{RASTISLAV TELGÁRSKY}

two layers in the datacube without data. These are caused by atmospheric absorption bands, specifically, $\mathrm{H}_{2} \mathrm{O}$ at 1.5 and 2.0 microns. Many useful properties can be detected when looking at forests, fields, marshes, valleys, etc. (Figure 101B). The hyperspectral vision system is important for registration of data used in Geographic Information Systems (GIS).

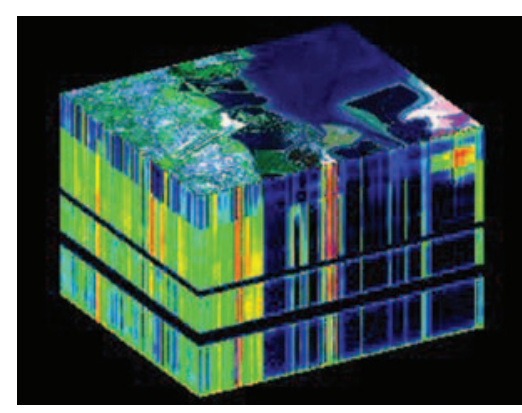

(A) HS Datacube

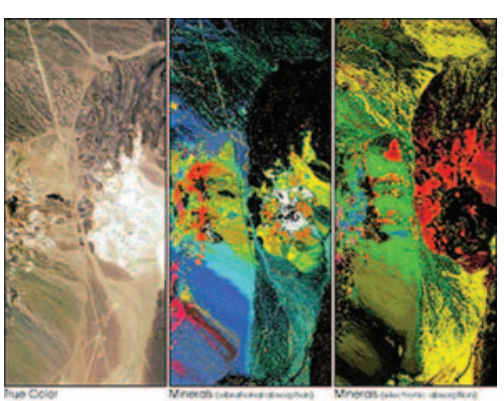

(в) Aviris Minerals

Figure 101. Remote Sensing Images.

\subsection{Camouflage}

The camouflage used by insects, sea creatures and other species appears to protect them from predators, and shows that their evolution and brain are surprisingly advanced. The camouflage consists in mimicking the background, and this function is either permanent or adaptive. A moth or a beetle have very similar patterns to tree barks, where they rest (Figure 102). The Leaf Insect resembles the leaves in its forest environment (Figure 103A). Similarly, the Leafy Sea Dragon has shapes almost identical to plants in its sea environment (Figure $103 \mathrm{~B})$.

The adaptive camouflage depends on living environment. A fish can create a cover-up by mimicking the color patterns of an octopus (Figure104). The brain of this fish performs very complex image processing algorithms to change colors of its skin according to what it saw before assuming the camouflaged position.

This fish behavior inspires some researchers to work on invisibility devices. First is the kind of cloth, which becomes invisible, when the surface, turned to the observer, maps the background behind the person wearing the cloth. To the observer it looks like there is nobody there because the seen background is not interrupted by the spot occupied by the person. Except the invisibility of objects in visible light, there are also studied surfaces and materials making objects invisible to radars, such as stealth planes, stealth helicopters and stealth drones. 


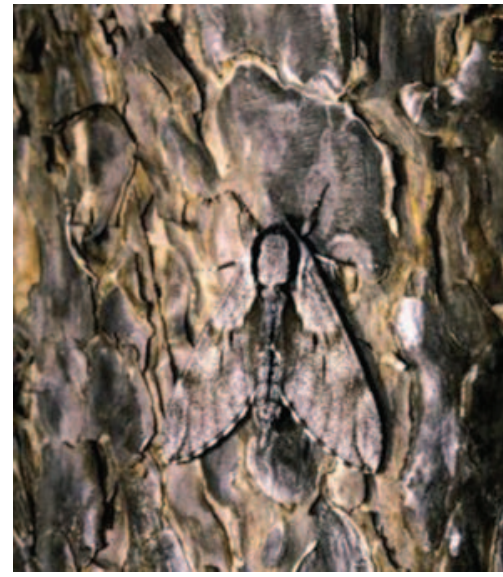

(A) Pine Hawk Moth

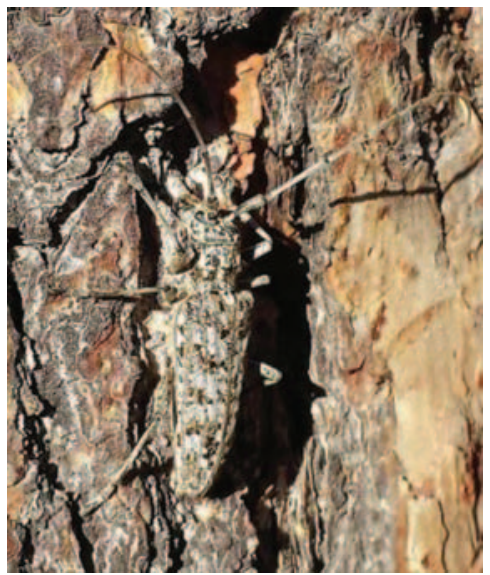

(B) Monochamus Notatus

FiguRE 102. Moth and beetle camouflaged on tree bark.

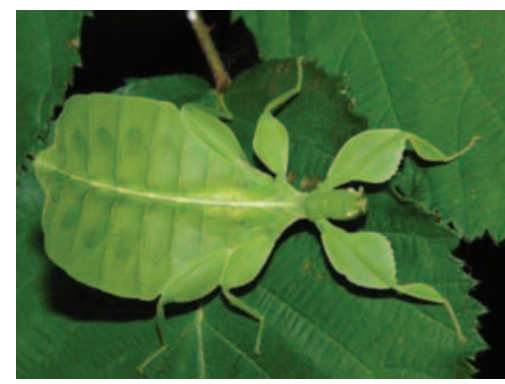

(A) Leaf insect

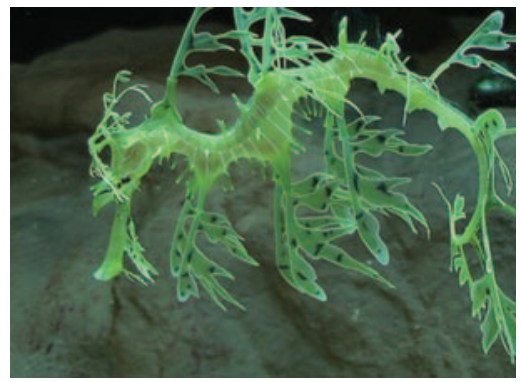

(B) Leafy sea dragon

Figure 103. Insect and sea dragon look like leaves.

\subsection{Spectra and Fourier Transform}

The rainbows appear in nature frequently after rains (Figure 105A). Rainbows are also created by water drops at waterfalls. In high resolution spectra of the sunlight we can identify thousands of dark absorption lines, also called Frauenhofer lines (Figure 105B). The intensities of components in sunlight spectrum are not the same (Figure 106A). The sunlight spectrum is only a narrow interval (bandwidth) of the electromagnetic spectrum detected in the nature (Figure 106B).

The rainbows inspired a lot of kinds of spectra in sciences. The spectral studies, or, spectral analysis, in mathematics, physics, astrophysics and chemistry 


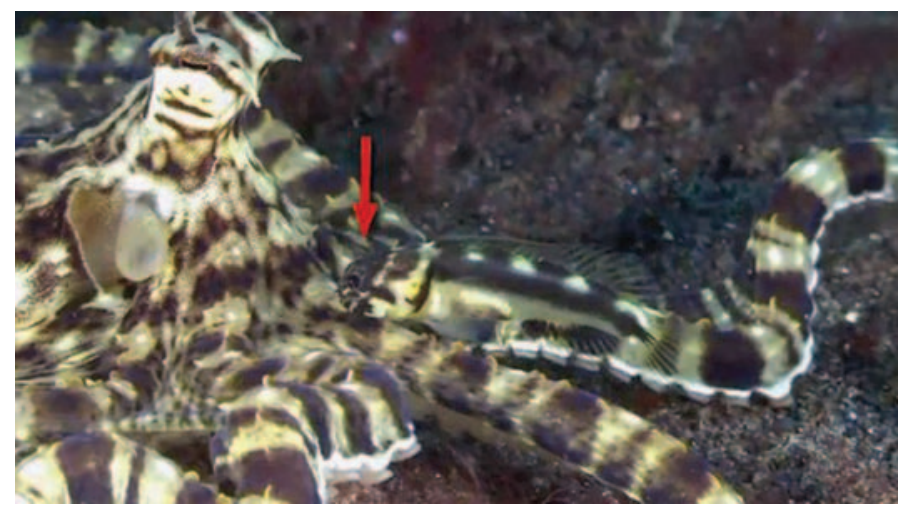

Figure 104. Fish and octopus.

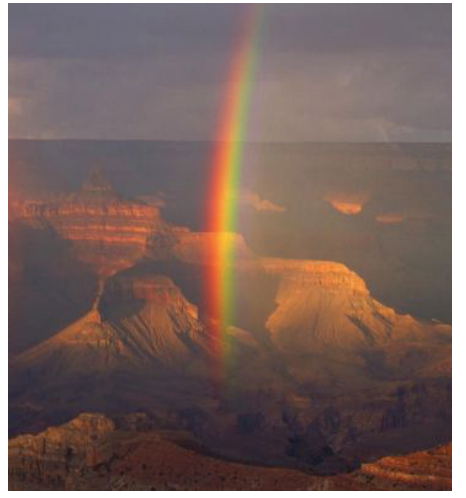

(A) Rainbow

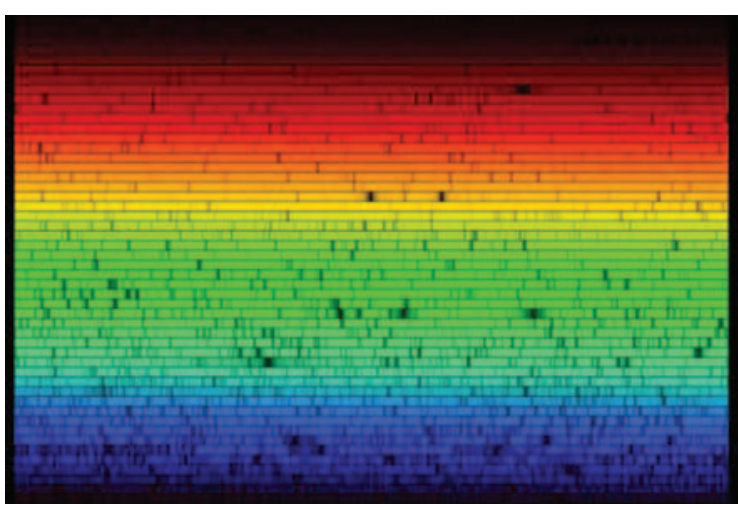

(в) Sun's Visible Spectrum

Figure 105. Rainbow and Sun's Visible Spectrum.

have the fundamental importance. The decomposition of sunlight into monochromatic components lead Joseph Fourier to construction of spectra for some classes of integrable functions. Now, we use Fourier transforms which are real or complex, discrete or continuous, finite or infinite, and many others. The signal processing also uses the Short-Time Fourier transform (STFT), also called the Time-Frequency Transform. The introduction of wavelets was a radical departure from the periodic sine and cosine functions as the base functions. However, the popular transforms such as the cosine transform and Hadamard Transform use the periodic components. 


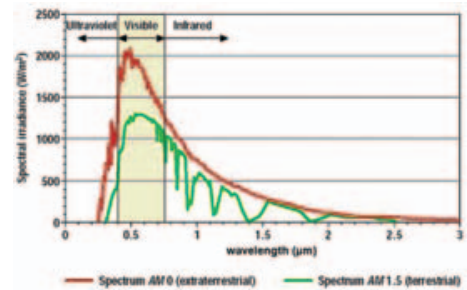

(A) Sunlight Spectrum

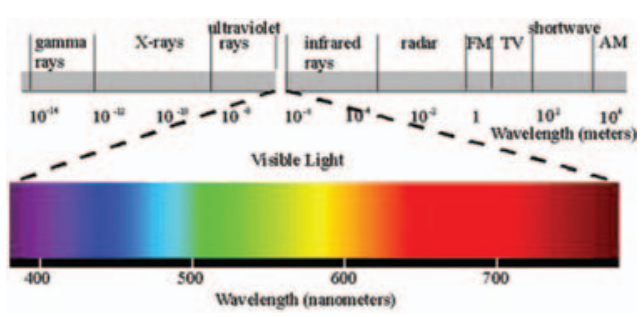

(в) EM Spectrum

Figure 106. Sunlight and Electromagnetic Spectra.

Using prisms in dark room led to the discovery of infrared and ultraviolet components of the sunlight. Each of these invisible components of the sunlight are divided into 3 bandwidths: A, B and C (Wikipedia: Sunlight).

The $X$-rays (Wikipedia: X-ray) and gamma rays (Wikipedia: gamma ray) are electromagnetic waves (photons) distinguished by these names because of the source of origin. X-rays (gamma rays) carry much larger energy than the visible light, and they penetrate the solid matter. Since X-rays show optical and spectral properties similar to light, they enable the study of the structure of matter (to see inside). X-rays coming from the Sun and stars witness the structures and events out there in vast outside space.

\section{Processes}

\subsection{Events in Nature}

Some events are unique in the sense that they happen only once in the life of the universe. For example, the birth of a particular human being is a unique event. If we declare all events in the universe to be unique, then we will have to name, describe and compare them, because the inventory listing, the comparison, and the classification are the basic methods of science and human understanding of nature. But, we do not have the ability to make a catalog of all events and their properties. Therefore, the collection of known unique events is very limited: we cannot know everything. We may see stars every night without an identification which stars we see and which we do not. But we can identify some planets and some stars depending on our knowledge of the night sky at our geographic location and time of the year.

Some events are rare, for example, a very large meteor striking the Earth surface (Figure 58). Some events are infrequent, for example, the eclipses of the Moon or the Sun. Some events are frequent, for example, the new day following 


\section{RASTISLAV TELGÁRSKY}

a night. Some events are continuous or nearly continuous, for example, the flow of a river or the movement of ocean waves. Some events are seasonal, that is, they occur over and over, for example, spring following winter. The tides and migrations of birds are also seasonal events. The periodic events have similar but different meaning from seasonal events. The mathematical models of events must reflect these differences between events.

\subsection{Causality}

The relationship between events, where one event is a cause the other, called the effect, was studied very early in human history. The study of causes and effects was useful in ancient medicine on Indian subcontinent known as Ayurveda (life knowledge, science of life). Various texts were written between 6 th century B.C. and 5th century A.D. (Wikipedia: Ayurveda). The Buddhist writings have Sutra of Cause and Effect from 8th century Japan (Figure 107).

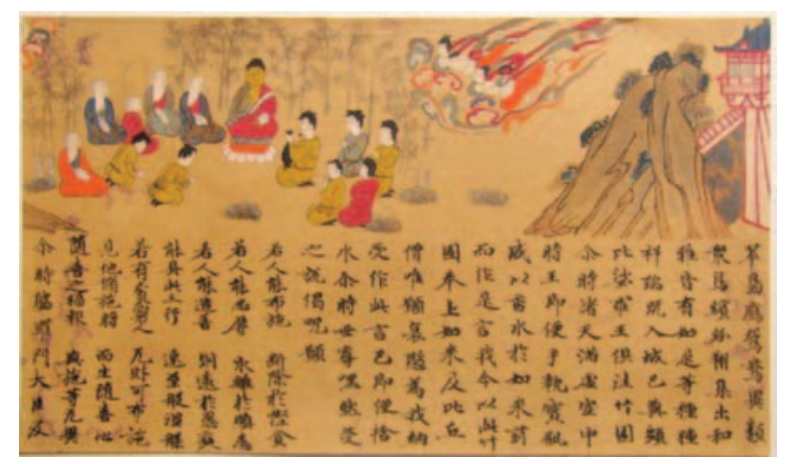

Figure 107. Sutra of Cause and Effect.

The sequence (chain) of events connected by the causality (causation) relation can lead to explanation of unusual facts. Some events are caused by short term and recent events, and others by long term events, i.e., the events that happened over a longer period of time. The effect of accumulation of causes is an effect of long term causes. It requires a guided study to construct the fishbone diagram of causes preceding an effect (Figure 108). A reversed fishbone diagram can be constructed for consequences of a cause or a group of causes. Other situations require to construct causal loops (Figure 109), where certain events re-occur regularly (periodically). The dynamics of the causal loop is usually powered by the Reinforcing feedback (R), and the Balancing feedback (B).

While the intention of the causality studies is to describe deterministic processes and situations (this is obvious in processes described by ordinary and partial differential equations), it turns out in many cases the desired effects do not occur always. Thus the main tools in causality studies are the probability 


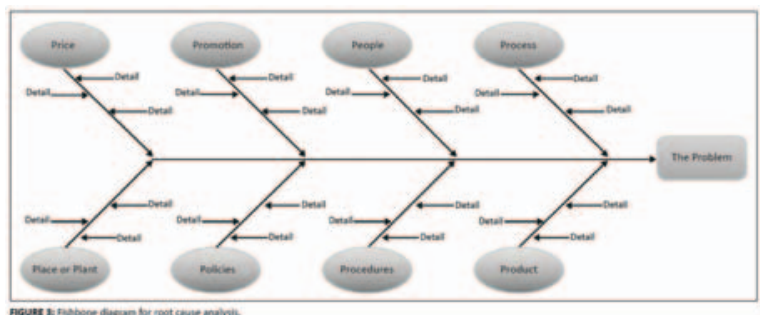

Figure 108. Fishbone diagram for causes and effects.

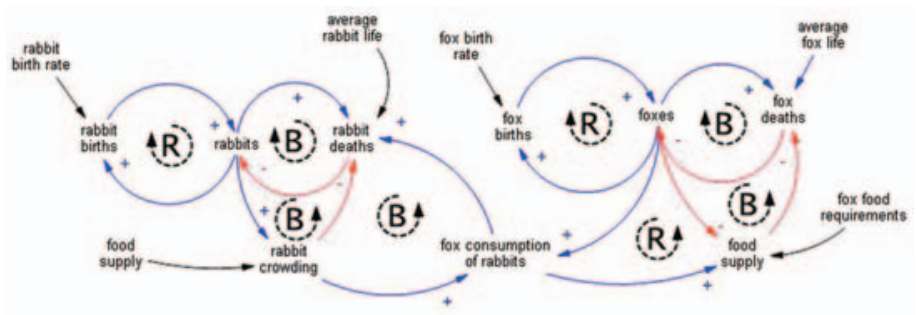

Figure 109. Causal loop for a prey-predator model.

theory and mathematical statistics (Judea Pearl [16]). The relationship between the causation and the correlation is not straightforward. The important point is, that if $\mathrm{A}$ is a cause of $\mathrm{B}$, then if $\mathrm{A}$ does not happen, then $\mathrm{B}$ should not happen either. So, the causality is typically about 4 events: A, B, A', and B' (Figure 110).

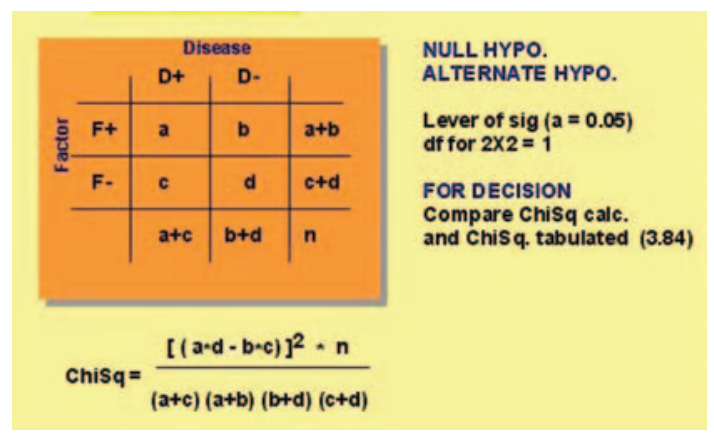

Figure 110. Statistical association table.

There two ways how to look at cause-effect relationship. If an event B happened, we are looking for the cause A of B. If an event A happened, we are looking 


\section{RASTISLAV TELGÁRSKY}

for the effect B of A. This observation had been the starting point of the Bayes Rule for two events (Wikipedia: Bayes' rule).

Typically, we consider the cause of a disease, the disease, the treatment of the disease, and the effect of the treatment of the disease. Therefore the model of this situation contains at least 4 consecutive events.

The mathematical statistics techniques for causality studies and modeling involve the conditional probabilities, the Bayes rules, and overall, the Bayesian networks.

The notion of Granger causality deals with the case when one time series is affecting another one.

The standard dilemma (paradigm) in causality analysis occurs when the hypothesis (suspicion) is that an event $\mathrm{X}$ is the cause of the event Y. However, in a deeper analysis, usually supported by more experiments, it turns out that there is an event $\mathrm{Z}$ which causes both $\mathrm{X}$ and $\mathrm{Y}$, where $\mathrm{Y}$ has some time delay relative to $\mathrm{X}$. This event $\mathrm{Z}$ is called a confounding event, or confounding factor, or a lurking variable.

Classical physics and chemistry are based mostly on deterministic causality; they do not need as much of the probabilistic causality as do the medicine, pharmacology, psychology, social and political sciences.

The applications of causality are also in Computational Intelligence and $\mathrm{Ma}$ chine Learning.

\subsection{Randomness and Chaos}

We can easily create an event for which nobody can predict the outcome. So, let's take a near perfect die and roll it. All we can tell is that the result will be one the numbers $1,2,3,4,5$, or 6 . Here is only 6 possible outcomes, but the particular outcome is unknown prior to the event. When we try to determine location and speed of a particular water molecule in a glass filled with water, then the number of outcomes is enormously large. First problem is how we mark the molecule to distinguish it from other molecules? And, how we predict a rain (event, location, intensity, and duration) with an imperfect and incomplete information about the weather parameters? We call some events random not because they are free from laws of causality, but because we are unable to predict their outcomes. In another words, we are unable to make a $100 \%$ accurate prediction of the outcome. Why? It is because there are myriads of conditions (circumstances) to take into account for the attempted prediction.

While the known causal dependence of events implies a partial predictability, the independent events have no common denominator to be used for predictability. The space-time cone delimited by the speed of light shows that some events must be independent. 
Randomness suggests the presence of a non-order or a non-coherence in a sequence of symbols or steps, such that there is no intelligible pattern or combination. Gregory Chaitin ( [5], p. 168) writes: I learned that when things are very small the physical world behaves in a completely crazy way. In fact, the things are random - intrinsically unpredictable.

Randomness and computational complexity are central themes of Calude et al. [3]. The randomness is considered in the realm of numbers, bringing to discussions the algorithmic random numbers, recursive incompressability, recursive unpredictability, and compressibility of information. The fundamental notion is the program-size complexity introduced independently by Gregory Chaitin, Andrey Kolmogorov and Ray Solomonoff.

In determinism every event must happen with probability 1 or 0 , while in random world we must accept intermediate probabilities. Sometimes it is hard to accept that something works, but not always. We expect to get the paycheck every month. The pill of aspirin should always relieve the symptoms of rheumatoid arthritis (Wikipedia: Aspirin). However, products from the manufacturing industry have been assigned general probabilities of structural or functional efficiencies as well as failures. A product may stop working after the expiration of the warranty.

In many processes we must deal with the mixture of a deterministic component and a stochastic component. One example of a mixture is the recording of a human voice in the presence of the background noise. There are several variants of the Wold Decomposition Theorem (Wikipedia: Wold's theorem), and each of them represents a mathematical vision of the world as composed of deterministic and random (ephemere) events. Unfortunately, in many particular situations we have no way to check whether the assumptions for the theorem are fulfilled or not.

Many mathematicians are studying regularities in chaos, which might be fascinating, but the main issue for the applications of mathematics stays always the same: the degree of predictability of the process.

\subsection{Statistical Decisions}

The decisions under incomplete information but with some knowledge of probability distributions fall into the category of statistical decisions. The simplest decisions are binary, yes or no, and are determined by a one key event, which either occurs or not. This event can be defined by a random variable and a threshold, where we compare the value of the random variable to the threshold. Instead of one variable we can have a time series or a process, and we might need to select a time instance when the value is greater than threshold or the opposite. We can make decisions based on confidence intervals, hypotheses testing, Bayesian nets, 
etc. The goodness-of-fit measures of decision rules (decision trees) include duration, cost, gain, and various statistical tests.

\section{Cooperation and Conflicts}

\subsection{Coexistence}

The feeding pattern in the nature is a partial ordering, where the organism at each level eats the entities at the lower levels, for example, wolves eat rabbits, rabbits eat grass, and grass uses nutrients in the soil. Some species do not affect others, for example, birds population does not affect the deer population. However, new studies indicate that trees in forests have a symbiosis with several organisms to enable the creation of proper nutrients in the soil.

For people, the peaceful coexistence on the Earth is important, but often violated in various parts of the world. The rule Live, and let others live! seems to work only when there are enough resources for everybody.

But, there are always some people or groups of people which want to have more than other people have: quality food, nice place to live (apartment, house or residence), quality health care, quality transport, and overall comfortable life. With the increasing world population there is a perpetual fight for an access, resources, better opportunities, etc. Every large city grows so much, that there is not enough water for it, even if it is situated just by a river or a lake. Unemployment, people taking jobs without benefits, people taking part-time jobs instead of full-time, and highly qualified people taking low qualified jobs are symptoms of societies with too many unsolved problems.

\subsection{Communication}

The communication in nature is necessary for life in groups, colonies and communities. Elephants live in groups, wolves live and hunt in packs, monkeys live in groups, and birds have flocks. The bees and ants live in large colonies, which would not function without a communication. The communication occurs between individuals of the same species, where it is used as a sign of warning (threat), the defense of the territory, looking for a mate, etc. It is also common between different species, for example, between people and domesticated animals. The communication between people is usually a mixture of two extremes: cooperation and competition. Another mixture of two extremes is made of acceptance and rejection.

\subsection{Conflicts, Control and Domination}

Each living organism strives for the survival as an individual and as its species. (This sounds like a definition of the living organism.) The survival depends 


\section{MATHEMATICS AND ENGINEERING INNOVATION INSPIRED BY NATURE}

on finding food, processing it, expelling the unusable components, and the reproduction. Moreover, it depends on avoidance of hostile environments. The most common survival strategy is that one organism eats another one in order to survive. The striving for survival leads to competition for getting the resources, but sometimes to cooperation, or, sometimes to a balanced mixture of those two called coopetition. Symbiosis and parasitism are biological forms of coopetition. Symbiosis is more fair than parasitism. The parasite can take control over the host organism, and use it as a resource for its own feeding and/or reproduction.

The survival seems to be good enough for all species except humans. Humans want to control the resources, the access, and the distribution; moreover, they want to have more than they need. This control demonstrates the human need for domination over the lives of other humans.

The coopetitive pairs among lower animals are the host and the parasite, among the higher animals are the predator and the prey, while in human society the relationship becomes the master and the slave. Whether a particular society is considered to be civilized or not, there exist threats, bribes and deceptions. So, the human society lives in inequality and hierarchy. There are conflicts between those who want to get to the higher levels of the social pyramid. Street protests and wars are examples of extreme conflict-resolution tools, where some people participating in those resolutions must pay which their lives. An American saying for the loss of a person's life due to unlucky circumstances is being removed from the genetic pool.

An individual biological life, as we know from experience, always begins and always ends. So, the survival of the descendants is a way of an extension of the individual life. However, 99.9 percent of all species that have existed on the Earth are extinct (Wikipedia: Extinction). So, how long it takes for the nature to create by evolution twice more new species from the species existing now?

\subsection{Game Theory and Economy}

The game theory originated from playfulness of people, from parlor games, and as well as from the intention to solve the conflict situations or to predict their outcome. Hunting and fighting battles are also game situations. According to an old division, there are of three kinds of games: the combinatorial games, the games of chance, and the strategic games. A typical mathematical model for games assumes: intelligence, rational behavior, fair communication, and perfect memory of players (Wikipedia: Game theory).

Unfortunately for the mathematical modeling, none of these three assumptions is ever fulfilled! Why? People forget the necessary circumstances of the game, they may disrespect or disregard the game rules, they forget or do not want to communicate, and they get into the battle blindly, that is, without evaluating their chances of gains or losses, or even without recognizing the best and 


\section{RASTISLAV TELGÁRSKY}

worst scenarios. These departures from rationality and agreements lead to the "extended" games which include: threats, bribes, spying, lying, stealing, inside trading, revenges, and many other kinds of unfair and deceptive strategies.

In many cases the change of game rules becomes the desire and strategy of the strong player, so that instead of the original game, the players must play the new game, which is beneficial for the strong player.

In classical game theory literature there are studied games against nature, where the nature neither wins nor loses, because its resources are infinite, that is, enormously abundant. Of course, now we are aware that the Earth resources are limited, and each move by a human player against the nature decreases its resources, and usually, it also has some side effects.

The gambling with money, property or people's lives does not produce any goods, so the game theory should be focused on the economy of production and distribution of goods rather than to gambling strategies. The basic events in economy are the exchange of values represented by products or services, where money is an intermediate.

A positive side of the game theory development is the revival of the concept of coopetition, which is a mixture of cooperation and competition (Yami et al. 26]). Neither cooperative nor non-cooperative games are fully adequate to describe the human behavior and enterprises. The models of coopetition should effect the standard areas of economy such as management of resources, production, distributions, prices and planning.

\subsection{Threat of Disasters}

Harvard University biologist E. O. Wilson estimates that 30,000 species per year (or, three species per hour) are being driven to extinction. The lack of safe drinking water is felt at many regions of the world. The rationing of the water and the restrictions of its use are only the short term solutions. The availability of gasoline, natural gas and electricity are also problems without immediate solution. The world travels create favorable conditions for occurrence of epidemics. The food manufactured in large quantities at few locations and shipped all over the world also creates potentials for widespread of epidemics.

Global warming (Figure 111A) and increased contents of $\mathrm{CO}_{2}$ in the atmosphere (Figure 111B) is the cause of worsening the conditions for life on the Earth (Wikipedia: Global warming).

The world population projections for the year 2100 (Figure 112) use different assumptions on regional expansions, and availability of resources.

The usage of artificial fertilizers containing traces of heavy metals has a negative effect on human health. The food containers made of plastic and aluminum have potential of food contamination and long term effects on diseases such as allergies, cancers, and birth defects. The genetically modified food narrows the 


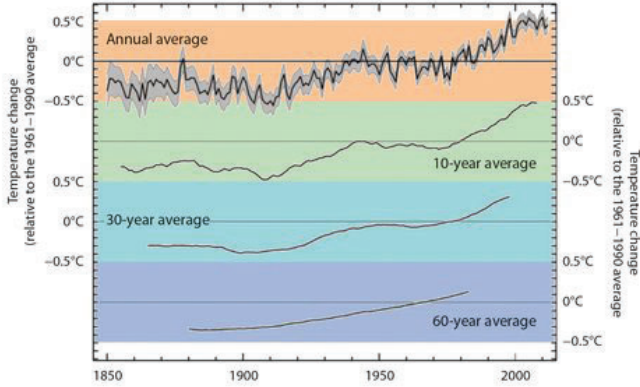

(A) Global Warming

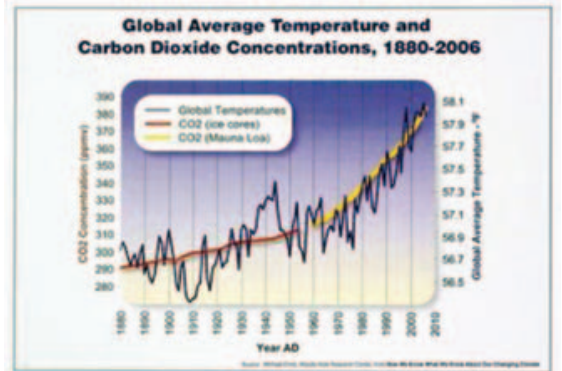

(B) $\mathrm{CO}_{2}$ vs Temperature

Figure 111. Global Warming and $\mathrm{CO}_{2}$.

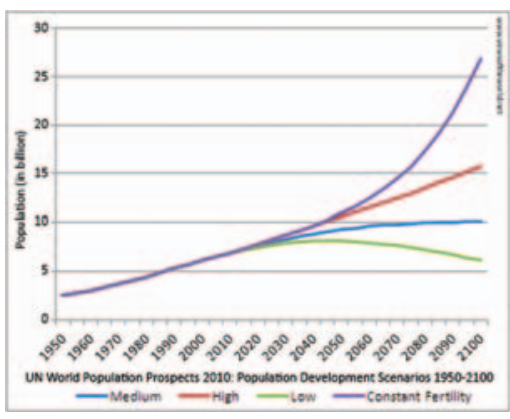

(A) Prediction from 2011

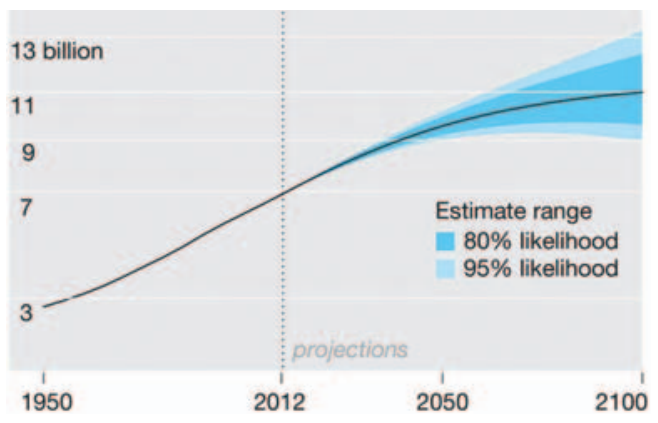

(B) Prediction from 2012

Figure 112. United Nations predictions of world population increase.

genetic pool of available food, thus it is asking for troubles in long term consequences. The growing difference between poor and rich increases harsh competition between those who have something and those who don't have enough. There are local and larger-scale wars, which are based on disrespect to other cultures and traditions and desires to acquire their natural resources. Finally, this list is closed by reference to earthquakes, volcanic eruptions, hurricanes, tornadoes, and ecological catastrophes caused by oil spills.

Gordon Woo [25] approaches the natural catastrophes from mathematician's perspectives. He writes on page 2: Natural perils will never cease to pose a hazard to the human environment, and mathematicians should always play a key part in helping to understand their causes, warn of their occurrence, forecast their behavior, and mitigate their effects. A more recent book, also with references for each chapter, is by Khlebopros, Okhonin and Fet [10]. 


\section{RASTISLAV TELGÁRSKY}

\section{Conclusions}

The needs of computers increased during the World War II, when several computers were built using electronic circuits with electron tubes. The building of large computers had the profound impact on mathematics. The new branches of mathematics were created: the computer science and informatics. On the other hand, computers became the physical (material, machine) implementations of mathematical processes such as algorithms and proofs. This connection between mathematical ideas and machine implementations also caused the growing divergence between mathematics and natural sciences. Mathematical concepts of infinity, infinitesimal, and infinite divisibility do not have corresponding material equivalents in atoms and subatomic particles. But, on the positive side, there is the rise of Computational Sciences within Mathematics, Physics (especially Mechanics and Optics), Chemistry, Biology, Genomics, Intelligence, Cardiology, Psychology, Topology, Game Theory, and more. Similarly, there is a rise of Algorithm Sciences: Game Theory, Graph Theory, etc. Some natural sciences develop their own branches of statistics: Physics (Mechanics, Optics, etc.), Quantum Mechanics, Psychology, Sociology, etc. There are also demands to develop new methods and robust mathematical models for actuarial sciences, demographic databases, financial engineering, economy, and as well as for the management of natural and intellectual resources.

\section{REFERENCES}

[1] ADAM, J. A.: Mathematics in Nature: Modeling Patterns in the Natural World. Princeton University Press, Princeton, NJ, 2006.

[2] BARROW, J. D.: The Artful Universe. Clarendon Press, Oxford, 1995.

[3] Randomness and Complexity, from Leibniz to Chaitin (C. S. Calude, ed.), World Scientific, Hackensack, NJ, 2007.

[4] CALUDE, C. S.-GRUSKA, J.: Quantum informatics and the relations between informatics, physics and mathematics: a dialogue, Centre for Discrete Mathematics and Theoretical Computer Science, CDMTCS-306, April 2007.

[5] CHAitin, G. J.: Meta MATH! The Quest for Omega. Vintage Books, New York, 2005.

[6] COLES, P.: From Cosmos to Chaos. The Science of Unpredictability. Oxford University Press, Oxford, 2006.

[7] DAWKINS, R.: Climbing Mount Improbable. W. W. Norton and Company, New York, London, 1996.

[8] HENDERSON, H.: Mathematics: Powerful Patterns into Nature and Society. Chelsea House, New York, 2007. 


\section{MATHEMATICS AND ENGINEERING INNOVATION INSPIRED BY NATURE}

[9] HUNTER, G.-KOWALSKI, M.-MANI, R.-WADLINGER, R. L. P.-ENGLER, F.-RICHARDSON, T.: Photon diameter measurements, Fund. Theories Phys. 126 (2002), $157-166$.

[10] KHLEBopros, R. G.-OKHONIN, V. A.-FET, A. I.: Catastrophes in Nature and Society. Mathematical Modeling of Complex Systems. World Scientific, Hackensack, NJ, 2007.

[11] LIVIO, M.: Is God a Mathematician? Simon \& Schuster, New York, NY, 2009.

[12] MANKIEWICZ, R.: The Story of Mathematics. Princeton University Press, Prineceton, NJ, 2001.

[13] SMITH, M. J.: Evolution and the Theory of Games. Cambridge University Press, Cambridge, 1982 .

[14] SMITH, M. J.: Evolutionary Genetics (2nd ed.). Oxford University Press, Oxford, 1998.

[15] NOWAK, M. A.: Evolutionary Dynamics. Exploring the Equations of Life. The Belknap Press of Harvard University Press, Cambridge, MA, 2006.

[16] PEARL, J.: Causality: Models, Reasoning and Interface (2nd ed.). Cambridge University Press, Cambridge, 2009.

[17] PICKOVER, C. A.: A Passion for Mathematics. Numbers, Puzzles, Madness, Religion, and the Quest for Reality., J. Wiley \& Sons, Hoboken, NJ, 2005.

[18] PICKOVER, C. A.: The Math Book; From Pythagoras to the 57th Dimension, 250 Milestones in the History of Mathematics. Sterling, New York, 2009.

[19] SCHNEIDER, M. S.: A Beginner's Guide to Constructing the Universe. The mathematical archetypes of nature, art, and science. A voyage from 1 to 10. HarperPerrenial, New York, NY, 1995.

[20] SIEGFRIED, T.: A beautiful Math; John Nash, Game Theory and the Modern Quest for a Code of Nature, Joseph Henry Press, Washington, DC, 2006.

[21] TAYLOR, J. C.: Hidden Unity in Nature's Laws. Cambridge University Press, Cambridge, 2003.

[22] TEGMARK, M.: Our Mathematical Universe: My Quest for the Ultimate Nature of Reality. Knopf, New York, 2014.

[23] TELGÁRSKY, R.: Mathematics without Infinity, in: Matematyka w przyrodzie i sztuce, Vol. 3 (A. Płocki, ed.), Zeszyty Nauk. PWSZ, Nowy Sącz, Poland, 2013, pp. 223-252.

[24] TELGÁRSKY, R.: Eyes, optics and imaging: mathematics and engineering innovations inspired by nature, in: 21st Czech-Polish-Slovak Mathematical Conference, Karpacz, Poland, 2014, Scientific Issues, Jan Długosz University, 2014, Mathematics Vol. 19, pp. 101-114.

[25] WOO, G.: The mathematics of natural catastrophes. Imperial College Press, London, 1999.

[26] Coopetition: Winning Strategies for the 21st Century (S. Yami, S. Castaldo, G. B. Dagnino, F. LeRoy, eds.), Edward Elgar Publishing, Northampton, MA, USA, 2010.

[27] YANSON, A. I.-RUBIO-BOLlingER, G.-VAN DEN BROM, H. E.-AGRAÏT, N.-VAN RUITENBEEK, J. M.: Formation and manipulation of a metallic wire of single gold atoms, Nature 395 (1998), 783-785.

[28] YOON, S.-H.-PARK, S.: A mechanical analysis of woodpecker drumming and its application to shock-absorbing systems, Bioinsp. Biomim. 6 (2011), 1-12. 


\section{RASTISLAV TELGÁRSKY}

\section{Figure Credits}

Figure 1A: sacredsquare.wordpress.com/2013/04/18/the-big-ching-all-64-hexagrams-of-thei-ching-in-chakra-colors-i-ching-and-chakra-art/

Figure 1B: www.ichingmeditations.com/2010/03/27/circular-chart-of-i-ching-hexagrams

Figure 2] : www.72namesofgod.net; guideangel.com; www.guiculture.com/fs11sanshi6.htm

Figure 3 : awamtv.com/islamic/99-names-of-allah-asma-ul-husna-99-names-of-allah/; alislamstuff.blogspot.com/2013/09/99-names-of-allah-with-urdu-translation.html

Figure 4 : astronomyonline.org/Science/QuantumPhysics.asp; lpc1.clpccd.cc.ca.us/lpc/harpell/physics8a/lectures/philosophy_units.htm

Figure 5A: divisbyzero.com/2011/04/26/what-do-you-want-on-your-tombstone

Figure [5B: www.chemistryland.com/CHM130S/02-MMM/Measure/Measuring.htm

Figure 6] : phys.org/news/2012-01-leonardo-da-vinci-tree.html

Figure 7 : math.stackexchange.com/questions/490344/interesting-math-facts-thatare-visually-attractive

Figure 8] : www.studyblue.com/notes/note/n/flash-cards-from-book-on-neurmuscularphysiology/deck/5263161

Figure 9]: www.willamette.edu/ gorr/classes/cs449/brain.html

Figure 9B: www.pinterest.com/maryscaletta/productivity-mind-mapping/; www.pinterest.com/pin/320740804684106003/

Figure 10A: www.2aida.net/aida/research2.htm

Figure 10B: www.cslu.ogi.edu/tutordemos/nnet_recog/recog.html

Figure 11A: www.wavemetrics.com/products/igorpro/imageprocessing/imageanalysis/ imagesnake.htm

Figure 11B: bigwww.epfl.ch/teaching/projects/abstracts/romain/

Figure 12A: de.wikipedia.org/wiki/Dorylus

Figure 12B: theantroom.blogspot.com/2006/11/ant-death-spiral.html

Figure 13A: www.roysfarm.com/bee-colony/

Figure 13B: en.wikipedia.org/wiki/Swarm_behaviour

Figure 13C: www.evols.org/; www.evols.org/uploads/images/photos/ school\%20of\%20fish.eps

Figure 14A: www.piquenewsmagazine.com/whistler/sea-to-sky-corridor-avalanche-dangerrating-creeping-up/Content?oid $=2446179$

Figure 14B: www.nbcnews.com/storyline/deadly-mudslide/ mudslide-wipes-away-landscape-leaving-only-memories-n62801

Figure 15A: www.brera.mi.astro.it/ carpino/ricognizione/schede/N0416/scheda.html

Figure [15B: www.laserfocusworld.com/articles/2011/06 avalanche-photodiodes-geiger-mode-apds-get-more-channels.html

Figure 16]A: en.wikipedia.org/wiki/Geiger\%E2\%80\%93M\%C3\%BCller_tube

Figure 16B: www.lasercomponents.com/us/news single-photon-counting-a-comparison-between-two-types-of-technology-1

Figure 17A: www.muhlenkamp.com/investment/principles/bailouts_your_dollars the_whole_credit_mess

Figure [17B: www.nytimes.com/2008/11/20/business/economy/20markets.html?_r $=0$

Figure 18A: rkm.com.au/VIRUS/HIV

Figure 18B: www.euroalgerie.org/2014/08/27/ebola-le-mensonge-generalise

Figure 19A: www.publicdomainpictures.net/view-image.php?image $=22545$

Figure 19B: www.flickriver.com/places/Australia/Queensland/Tuan+Forest/search/; www.flickr.com/photos/teejaybee/4884440719/; 


\section{MATHEMATICS AND ENGINEERING INNOVATION INSPIRED BY NATURE}

theconversation.com/do-you-see-what-i-see-rural-reactions-to-changing-land-use$-11445$

Figure 20A: www.dreamstime.com/royalty-free-stock-images-tree-stump-background-image1829839

Figure 20B: www.universe-galaxies-stars.com/n-archive_368.html

Figure 21]A: jeanraffa.wordpress.com/2014/03/18/the-souls-never-ending-journey/

Figure 21B: oneclimbs.com/2011/02/21/two-the-exploration-of-archety pal-symbols-series /

Figure 22] : www.deniswarren.com/en/?page_id $=980$

Figure 23] : www.pinterest.com/pin/340162578078229155/

Figure 24A: pamphotography.wordpress.com/2011/08/06/the-golden-ratio-phi-and-photography

Figure 24B: www.mnn.com/earth-matters/climate-weather/blogs/finding-the-fibonacci-sequence-in-hurricane-sandy; www.gawaher.com/topic/740239-golden-ratio-in-nature-quran-and-position-of-the-kaba

Figure 25A: goldcoastpermaculture.org.au/native-bee-workshop/

Figure 25B: www.wired.com/2010/09/fractal-patterns-in-nature/?viewall=true

Figure 26] : enrichla.org/fibonacci-flowers/

Figure 27A: mynatureplace.org/mathematics-and-nature.html

Figure 27B: www .askipedia.com/6-fascinating-appearances-of-the-fibonacci-numbers-in-nature

Figure 28.A: Photograph by the author

Figure 28B: christinecagle.wordpress.com/2011/07/

Figure 29 : ankakedisi.com/kitaplardan/richard-a-dunlap-altin-oran-ve-fibonacci-sayilari/; arxiv.org/ftp/arxiv/papers/1301/1301.6606.pdf

Figure 30A: apolyton.net/attachment.php?attachmentid $=158589 \& \mathrm{~d}=1228063287$

Figure [30B: kelasarithmancy.blogspot.com/2010/10/golden-ratio.html

Figure 31A: nosauvelta.blogspot.com/2013/02/the-fibonacci-numbers-and-golden-ratio.html\#axzz3DKdFir7E

Figure 31B: jwilson.coe.uga.edu/EMAT6680/Simmons/Essay1/ 6690ProjectFibonacciF.htm

Figure 32A: scienzadellanima.myblog.it/2014/08/12/scienza-sezione-aurea-2/; www.answers.com/Q/What_is_the_historical_significance_of_the_golden_ratio; www.answers.com/Q/Are_Ratio_o_parts_of_a_mixture_are_exact; www.answers.com/Q/What_does_- Fibonacci_and ${ }_{-}$the _oolden_ratio_have_in _common;

www.esopedia.info/images/thumb/d/db/Goldener_Schnitt_Blattstand.png/

Figure 32B: www.solaripedia.com/13/404/6185/phyllotaxis_example_from_above.html Figure 33: www.mymilez.com/chocolate-hills-bohol-philippines/

Figure 34A: www.sci.ccny.cuny.edu/ mcesaire/glacier.html

Figure 34B: www.angelfire.com/hero/gerald_koh_s9029362a/v_shaped.htm

Figure 35A: en.wikipedia.org/wiki/Meander

Figure 35B: commons.wikimedia.org/wiki/File:Lena_River_Delta_-_Landsat_2000.eps

Figure 36A: geology.isu.edu/wapi/Geo_Pgt/Mod09_Mars/Earth- $\bar{M} \overline{a r s}$ _Drainage channels.htm

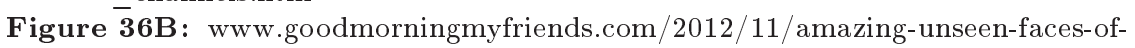
earth.html

Figure 37A: www.pxleyes.com/blog/2011/08/the-beauty-of-the-fern-presented-in-50quality-photos/

Figure 37B: www.wired.com/2010/09/fractal-patterns-in-nature/\#slideid-592160 


\section{RASTISLAV TELGÁRSKY}

Figure 381A: personal.denison.edu/ bressoud/cs110-f10/lab09/lab09.htm

Figure 38B: sprott.physics.wisc.edu/pickover/menger.eps; www.ics.uci.edu/ eppstein/junkyard/sierpinski.html

Figure 39: warosu.org/diy/thread/656207; www.xena.ad/lcf/mars2010/fractale/fractale.htm

Figure 40A: www.its.caltech.edu/ atomic/snowcrystals/class/class.htm

Figure 40B: benrushpta.org/2013/12/01/kindergarten-snowflake-social/

Figure 40C: www.its.caltech.edu/ atomic/snowcrystals/photos/photos.htm

Figure 41A: rebloggy.com/post/succulent-crassula-buddha-s-temple-crassula/33374300873

Figure 41B: www.psdgraphics.com/psd-icons/fruit-illustrations-lemon-and-orange-icons/

Figure 41C: giardinaggio.efiori.com/Cactacee-e-Succulente-Ec75/A-F-S89Pg1/

Echinocactus-SP123.html

Figure 42A: thiswoo.wordpress.com/2009/07/09/downsizing-right-down/

Figure 42B: mannaismayaadventure.com $/ 2012 / 06 / \mathrm{page} / 4 /$

Figure 42C: nualgiaquarium.com/nano-silica-diatoms/

Figure 43 : people.rit.edu/andpph/text-digital-stroboscopy.html

Figure 44A: iopscience.iop.org/1748-3190/6/1/016003

Figure 44B: scitation.aip.org/content/aip/journal/adva/2/4/10.1063/1.4770305

Figure 45: commons.wikimedia.org/wiki/File:Human_spermatozoa.png

Figure 46] : www.creationscience.com/onlinebook/LifeS ciences46.html

Figure 47: www.vibrationresearch.com/articles/sine_or_random_2004.html

Figure 48A: mathematica.stackexchange.com/questions $/ \overline{2} 4187 /$ help-with-1-dimensional-random-walk

Figure 48B: people.sc.fsu.edu/ jburkardt $/ \mathrm{m}_{-}$src $/ \mathrm{random}$ _walk_2d_simulation/random _ walk_2d_simulation.html

Figure 48] $\overline{\text { : }}$ mathematica.stackexchange.com/questions/41693/how-to-generate-this-fractal-like-3d-distribution-of-points-in-mma-7-0

Figure 49A: seocekret.ru/indeksaciya-stranicy/; www.thesun.co.uk/sol/homepage/news/4854862/warning-after-asbestos-covered-tarantula-gets-free.html

Figure 49B: www.cc.gatech.edu/ai/robot-lab/facilities.html; www.cc.gatech.edu/ai/robot-lab/images/hermes.eps

Figure [51A: www.birdseyesandbutterflies.com/twelve-spotted-skimmer-dragonfly/

Figure [51B: www.gizmag.com/techject-dragonfly-microuav/24900/

Figure [52] : www.pbs.org/wgbh/nova/physics/theory-of-everything.html

Figure [53 : en.wikipedia.org/wiki/Chronology_of_the_universe; catholiccitizenamerica.blogspot.com $/ 201 \overline{4} / 03 /$ gravity-waves-finding-ripples-from-big.html

Figure 54A: science.howstuffworks.com/nature/natural-disasters/eye-of-tornado.htm

Figure [54B: www.freestockphotos.biz/stockphoto/331; scijinks.jpl.nasa.gov/tornado/ Figure [55A] www.sere.org/pages/wildfire.html; www.hphanson.com/fiction/ environment/SERE/wildfire.shtml

Figure 55B: www.dailydigitalphoto.com $/$ cgi-bin $/$ potd $/$ potd.pl?day $=28 \& m o n t h=1$ \&year $=2011$; www.pinterest.com/pin/152629874846900573/

Figure [56]A: mishunderstanding.wordpress.com/2011/01/23/what-is-the-richter-scale/

Figure [56B: www.geosci.ipfw.edu/observe/earthquake/sumatra/seismograph.gif

Figure 57] : pesn.com/2011/09/18/9501916_Evidence_Denver_and_DC_Quakes Caused_by_Nukes/

Figure [58: www.mreclipse.com/Observatory/Crater/Crater.html 


\section{MATHEMATICS AND ENGINEERING INNOVATION INSPIRED BY NATURE}

Figure [59A: wildlifeanimalz.blogspot.com/2012/01/electric-eel-info-and-photos.html

Figure 59B: pages.vassar.edu/magnes/advanced-electromagnetism-phys-341/ daniel-pearlman/

Figure 60AA: en.wikipedia.org/wiki/Lightning_injuries

Figure 60B: freeenergynews.com/Tangent/Wyoming_fire-starter.htm

Figure 61A: www.miqel.com/fractals_math_patterns/visual-math-natural-fractals.html

Figure 61B: www.miqel.com/fractals_math_patterns/visual-math-natural-fractals.html

Figure 62A: greencomet.org/2012/10/23/ball-lightning-part-three/

Figure 62B: joyerickson.wordpress.com/2012/08/05/pull-up-something-cool/

Figure 63A: www.pantarei2004.it/aura_reiki.htm

Figure 63B: www.pcmag.com/article2 $/ \overline{0}, 2817,2392766,00$.asp

Figure 64: solar.gmu.edu/teaching/2012_CSI662/class_notes.html

Figure 65]A: www.jessicacrabtree.com/journal1/2010/09/patterns-in-nature-fractals

Figure 65B: www.pinterest.com/pin/68328119321219646/; www.ebay.com/itm/Atomic-Bomb-Test-Nuclear-Mushroom-Cloud-11-x-14-PhotoPicture-Poster-mc1-/261004920876

Figure 66: apod.nasa.gov/apod/ap021110.html

Figure 67A: www.astrosurf.com/luxorion/aurore11.htm; www.astrosurf.com/luxorion /Images/aurora-060400-ianlaw-ray.eps; rasathane.ankara.edu.tr/files/2013/02/auroralar.pdf

Figure 67B: twitter.com/NationalGeograC/status/493000281446420480

Figure 68A: paddys-wagon.blogspot.com/2012/05/hopping-on-off-around-dublin.html

Figure 68B: www.pinterest.com/ranmanj/resin-blood-networks/; www.sciencephoto.com/media/310509/view

Figure 69A: www.talismancoins.com/servlet/Detail?no $=2272$

Figure 69B: malini-math.blogspot.com/2010/08/maths-and-nature.html; mathsomu.blogspot.com/2012/10/maths-in-nature.html; urbanshakedowns.wordpress.com/2011/03/27/the-shape-of-nature/

Figure 70A: www.flickr.com/photos/fei_company/4799452124/

Figure 70B: en.wikipedia.org/wiki/Graphene

Figure 71] : www.thailandsnakes.com/non-venomous/sunbeam-snakesnon-venomous-no-danger/

Figure 72A: www.dolphindude.com/2011_06_01_archive.html

Figure 72B: www.dreamstime.com/stock-photos-mud-cracks-image 14509043

Figure [73A: www.ilyke.net/porcelain-desert/49194/?pid=19

Figure 73B: hikinginmainewithkelley.blogspot.com/2011/11/111411-ship-harborwonderland-area.html

Figure 14A: www.wired.com/2010/09/fractal-patterns-in-nature/\#slideid-592151

Figure 174B: rebloggy.com/post/animals-nature-wildlife-south-africa-originalendangered-mammals-zoology-pangoli/64659463418

Figure [75]A: deliciousdimension.tumblr.com/post/88337444941/coral-by-side78http-flic-kr-p-bl8x $1 \mathrm{~h}$; www.flickr.com/photos/side78/7062963613/in/photostream/

Figure 75B: omsriganesh.tumblr.com/post/96914819267/our-amazing-worldpurple-whip-coral-amazing

Figure 75C: explorers.neaq.org/2010/01/saudi-arabia-science-at-sea.php

Figure [76 : www.clipzine.me/u/clip/67009617757651615591; www.pinterest.com/pin/25543922858552315/; www.medioambiente.org/2012/10/marrus-orthocanna-una-de-las-formas-de.html

Figure 77] : www.evolutionnews.org/2013/09/mechanical_gear076801.html 


\section{RASTISLAV TELGÁRSKY}

Figure 78]A: www.organicauthority.com/delicious-beauty/bamboo-natural-beauty-secrets.html

Figure 78B: www.laboratoryequipment.com/news $/ 2014 / 07 /$ researchers-create-tougher-metal-materials

Figure 79: science.kqed.org/quest/2008/04/14/hug-a-helix-celebrate-dna-day-april-25th/

Figure 80A: www.deoxyribosenucleicacid.com/dna/what-does-dna-mean/

Figure 80B: www.tech24hours.com/2011/07/rewriting-code-of-life-as-simple-as.html

Figure 81: www.zo.utexas.edu/courses/Thoc/PopGrowth.html

Figure 82 : en.wikipedia.org/wiki/Pareto_distribution

Figure 83: www.city-data.com/city/Albuquerque-New-Mexico.html

Figure 84A: www.flickr.com/photos/75899207@N00/3520921034/

Figure 84B: thomasshahan.com/\#photos

Figure 85A: impressivemagazine.com/2012/06/11/striking-colors-starfish/

Figure 85B: yellowmagpie.com/box-jellyfish-about/

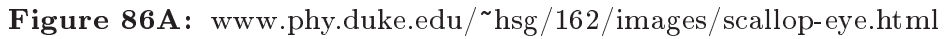

Figure 86B: www.phy.duke.edu/ hsg/162/images/scallop-eye.html

Figure 87A: commons.wikimedia.org/wiki/File:Eyes_of_a_Holcocephala_fusca_Robber Fly.eps

Figure [77B: bestphotos2share.blogspot.com/2011/12/incredible-eye-macros.html

Figure 89] : en.wikipedia.org/wiki/Stoplight_loosejaw

Figure [0]: www.duiops.net/seresvivos/galeria_plantas_14.html; www.duiops.net/seresvivos/galeria/plantasflores/Leaf\%20with\%20water.eps

Figure 91A: micro.magnet.fsu.edu/primer/anatomy/introduction.html; www.olympusmicro.com/primer/anatomy/introduction.html

Figure 91B: www.olympusmicro.com/primer/anatomy/objectives.html

Figure 92 : www.finnpathologists.co.uk/about.html; www.biomedcode.com/gr/en/ /content/preclinical-efficacy-platforms; www.shutterstock.com/pic-109591796/stock-photo-modern-microscope-equipped-with-digital-camera-computer-and-monitor.html?src=0-BWEn5fgM468CdffcY7Yg$-1-20$

Figure 93: www.theguardian.com/science/blog/2009/aug/25/galileo-telescope-anniversary

Figure 95: astro.berkeley.edu/ jrg/chabot/Slide11.EPS

Figure 96 : spinoff.nasa.gov/spinoff2003/hm_9.html

Figure 94A: culturepology.wordpress.com/category/the-universe/; www.graymanwrites.com/blog/two-space-anniversaries-first-china-and-hubble-reaches-orbit

Figure 94B: www.amazon.com/Meade-ETX70AT-Telescope-Tripod-Software/dp/ B00005ATSR

Figure 97]A: animals.nationalgeographic.com/animals/mammals/common-vampire-bat/

Figure 97B: insectbio.blogs.rice.edu/; charles-harvey.co.uk/batting-away-pesticide-use/

Figure 98A: www.medison.ru/uzi/eho405.htm

Figure 98B: community.babycenter.com/post/a36383725/level_2 _ultrasound

Figure 98C: www.legitreviews.com/a-hand-held-ultrasound-scanner-fit-for-dr-mccoy 7429

Figure [99]A: Matlab data archive of the author

Figure 99B: created in Matlab by the author

Figure 88A : nanohub.org $/$ resources $/ 19612 /$ watch resid $=19613$; pmanewsline.com/2013/05/02/camera-captures-bugs-eye-like-image/ \#.VBnQPfldWqg 


\section{MATHEMATICS AND ENGINEERING INNOVATION INSPIRED BY NATURE}

Figure 88B: ibnlive.in.com/news/chinese-institute-develops-100megapixel-camera/ 405546-11.html;

engineering.illinois.edu/news/article/2013-04-29-bugs-view-inspires-new-digital-cameras-unique-imaging-capabilities

Figure 101A: aviris.jpl.nasa.gov/data/image_cube.html; www.sarracenia.com/astronomy/remotesensing/primer0350.html

Figure 101B: ces.iisc.ernet.in/hpg/envis/Remote/introfile27.htm

Figure 100: en.wikipedia.org/wiki/Mantis_shrimp

Figure 102A: insects.about.com/od/photography/ig/Sphinx-Moths/Pine-Hawk-Moth.htm

Figure 102B: bugguide.net/node/view/814232/bgimage

Figure 103A: planetapex.blogspot.com/2013/05/leaf-insect-amazing-walking-leaf.html; www.animalsinhands.com/zoo-animals/; litsciox.wordpress.com/2014/04/

22/exhibition-and-public-talk-on-natural-mimicry-at-oxford-natural-history-museum-april-may-2014

Figure 103B: flickriver.com/photos/tags/taxonomy\%3Aorder\%3Dsyngnathidae/ interesting

Figure 104: cestovanie.aktuality.sk/clanok/5773/novy-objav-podmorskeho-zivota-ryba-maskujuca-sa-na-chobotnicu

Figure 105A: www.flickr.com/photos/30615498@N05/2870303606/

Figure 105B: wps.prenhall.com/esm_chaisson_BG4/10/2718/695956.cw/index.html

Figure 106A: www.volker-quaschning.de/articles/fundamentals1/index_e.php

Figure 106B: www.schome.ac.uk/wiki/Proposal

Figure 107: en.wikipedia.org/wiki/Causality

Figure 108: www.phcfm.org/index.php/phcfm/article/view/598/860

Figure 109 : www.systemswiki.org/index.php?title=Prey/Predator_Model

Figure 110 : compepid.tuskegee.edu/syllabi/microbiology/epidemiology/epifull/ 7_epi._cha7-mehtods-92.htm

Figure 111A: www.washingtonpost.com/blogs/capital-weather-gang/wp/2014/02/28/ confronting-the-exploitation-of-extreme-weather-events-in-global-warming-reporting/

Figure 111B: oceanworld.tamu.edu/resources/oceanography-book/co2 problem.htm

Figure 112A : www.viewsoftheworld.net $/ ? p=1889$

Figure 112B: news.nationalgeographic.com/news/2014/09/140918-populationglobal-united-nations-2100-boom-africa/

Received June 17, 2014

Department of Mathematics

Central New Mexico Community College

525 Buena Vista Drive

Albuquerque, NM 87106

U.S.A.

E-maill:rtelgarsky@cnm.edu

rastislav@telgarsky.com 